\title{
Hypervelocity stars in the Gaia era
}

\section{Revisiting the most extreme stars from the MMT HVS survey}

\author{
S. Kreuzer, A. Irrgang, and U. Heber
}

\begin{abstract}
Dr. Karl Remeis-Observatory \& ECAP, Astronomical Institute, Friedrich-Alexander University Erlangen-Nuremberg (FAU), Sternwartstr. 7, 96049 Bamberg, Germany

e-mail: simon.kreuzer@fau.de
\end{abstract}

Received / Accepted

\begin{abstract}
The hypervelocity star (HVS) survey conducted at the Multiple Mirror Telescope (MMT) identified 42 B-type stars in the Galactic halo whose radial velocity in the Galactic rest-frame exceeds $+275 \mathrm{~km} \mathrm{~s}^{-1}$. In order to unravel the nature and origin of those highvelocity outliers, their complete six-dimensional phase space information is needed. To this end, we complemented positions and proper motions from the second data release of Gaia with revised radial velocities and spectrophotometric distances that are based on a reanalysis of the available MMT spectra of 40 objects using state-of-the-art model spectra and a tailored analysis strategy. The resulting position and velocity vectors for 37 stars were then used as input for a subsequent kinematic investigation to obtain as complete a picture as possible. The combination of projected rotational velocity, position in the Kiel diagram, and kinematic properties suggests that all objects in the sample except two (B576, B598) are very likely to be main sequence stars. While the available data are still not precise enough to constrain the place of origin for 19 program stars, we identified eight objects that either come from the outer rim of the Galactic disk or not from the disk at all, along with ten that presumably stem from the Galactic disk. For almost all of those 18 targets with more or less well-constrained spatial origin, the Galactic center (GC) is disqualified as a possible place of origin. The most notable exception is B576, the origin of which coincides extremely well with the GC when assuming a blue horizontal branch (BHB) nature for it. HVS 22 is by far the most extreme object in the sample. Although its origin is completely unconstrained, an ejection from the GC by the Hills mechanism is the most plausible explanation for its current Galactic rest-frame velocity of $1530_{-560}^{+690} \mathrm{~km} \mathrm{~s}^{-1}$.
\end{abstract}

Key words. stars: distances - stars: early-type - stars: fundamental parameters - stars: kinematics and dynamics

\section{Introduction}

The population of faint blue stars in the Galactic halo is dominated by white dwarf (WD), hot subdwarf, and blue horizontal branch (BHB) stars. However, now and then, some stars have turned out to be normal main sequence (MS) stars of spectral type B (Greenstein 1966; Greenstein \& Sargent 1974; Keenan \& Dufton 1983; Tobin 1987). These stars are not expected to be found in the halo because the clouds from which they formed are located in the Galactic disk rather than in the halo. Therefore, MS stars in the halo are believed to have been ejected from their place of birth in the Galactic disk and, accordingly, the term runaway stars was coined (Zwicky 1957; Blaauw 1961). The stars have to travel fast in order to reach their present-day positions in the halo within their comparatively short lifetimes. Every major survey for faint blue objects in the halo has continued to find MS B-type stars (e.g., Saffer et al. 1997; Heber et al. 1997; Lynn et al. 2004b,a). Silva \& Napiwotzki (2011) list 96 bona-fide runaway B stars located beyond $1 \mathrm{kpc}$ from the Galactic disk with ejection velocities up to $\approx 400 \mathrm{~km} \mathrm{~s}^{-1}$.

The most extreme runaway stars, the so-called hypervelocity stars (HVS, for a review see Brown 2015) were first discovered serendipitously by Brown et al. (2005), Hirsch et al. (2005) in the Sloan Digital Sky Survey (York et al. 2000), and Edelmann et al. (2005) in the Hamburg ESO survey (Wisotzki et al. 1996), traveling with speeds that exceed their local Galactic escape velocity. HVSs have also been discovered among hot subdwarf stars (e.g.,
HVS 2, which is also known as US 708, Hirsch et al. 2005; Geier et al. 2015) and WDs (Vennes et al. 2017).

These discoveries triggered a systematic search for more blue stars with high radial velocities in the Galactic halo. Since HVSs are distant objects and thus rather faint, it is not straightforward to obtain spectra with sufficient signal-to-noise ratio $(\mathrm{S} / \mathrm{N})$ to reveal their nature. The first HVS survey by Brown et al. (2006) was later extended using the $6.5 \mathrm{~m}$ Multiple Mirror Telescope (MMT) on Mount Hopkins, Arizona, yielding a moderate resolution survey that covered 12000 square degrees of the sky, the so-called MMT HVS survey (Brown et al. 2009, 2014). This survey finally led to the discovery of 21 HVSs and 16 runaway stars of late B spectral type (Brown et al. 2014). Brown et al. (2015) added five additional objects and studied the kinematics of 15 of them using proper motions measured with the Hubble Space Telescope (HST). Recent additions of four stars (Zheng et al. 2014; Huang et al. 2017; Li et al. 2018) to the list of HVSs of A and B spectral type came from the LAMOST survey (Cui et al. 2012). The latest one (S5-HVS1, Koposov et al. 2020) from the Southern Stellar Stream Spectroscopic Survey $\left(\mathrm{S}^{5}, \mathrm{Li}\right.$ et al. 2019) is also the most extreme one, because its Galactic restframe velocity of $1700 \mathrm{~km} \mathrm{~s}^{-1}$ is record-high.

A classical ejection scenario for runaway stars is the binary supernova scenario developed by Blaauw (1961) in which the secondary star of a close binary system is ejected when the core-collapse of the more massive primary unbinds the binary. 
Alternatively, close encounters between (binary) stars in dense stellar clusters or the gravitational collapse of proto-stellar clusters may lead to the ejection of stars, most likely of the lightest one involved (dynamical ejection scenario, Poveda et al. 1967). Both of these classical scenarios are, however, not capable of ejecting stars beyond $\approx 500 \mathrm{~km} \mathrm{~s}^{-1}$ at the most (e.g., Portegies Zwart 2000; Gvaramadze et al. 2009; Perets \& Šubr 2012; Tauris 2015; Oh \& Kroupa 2016), see the discussion in Irrgang et al. (2018b, 2019). Runaway stars from those two channels could reach Galactic escape velocity only if their ejection happens to occur in the direction of Galactic rotation, which would give them an additional boost.

The only mechanism that is thought to be powerful enough to eject HVSs is the slingshot mechanism proposed by Hills (1988). Via tidal interactions, a binary system may be disrupted during a close encounter with a supermassive black hole, leading to the ejection of one component with a velocity as large as $4000 \mathrm{~km} \mathrm{~s}^{-1}$. In this scenario, the place of origin must be the Galactic center (GC) as it is the only site in the Galaxy that hosts a supermassive black hole. The recent discovery of S5-HVS1 (Koposov et al. 2020), whose trajectory points to an origin in the GC, may be considered as the smoking gun for the Hills mechanism. The origin of HVSs may, however, be extragalactic as well. The Large Magellanic Cloud has been proposed as a potential source of HVSs (Boubert \& Evans 2016; Boubert et al. 2017). Indeed, the unique object HVS 3 has been suggested to originate from the Large Magellanic Cloud (Edelmann et al. 2005). This idea was supported by chemical tagging (Przybilla et al. 2008) and finally confirmed with Gaia astrometry (Irrgang et al. 2018a; Erkal et al. 2019). Another extragalactic scenario involves the disruption of dwarf galaxies by the Milky Way (Abadi et al. 2009). However, simulations by Piffl et al. (2011) rendered this possibility unlikely because the perturber needs to be unbound itself and the HVSs would travel along with the perturber.

ESA's Gaia space mission revolutionized astronomy by providing proper motions, parallaxes, and photometry of unprecedented precision for 1.3 billion objects. Its second data release (Gaia DR2, Gaia Collaboration et al. 2018) immediately triggered publications reporting spectacular discoveries, such as hypervelocity WDs as surviving companions of dynamically driven double-degenerate double-detonation Type Ia Supernovae (D6 stars, Shen et al. 2018), and partly burnt runaway stellar remnants from peculiar thermonuclear supernovae leaving the Galaxy (Raddi et al. 2019). The previously known B-type HVSs were readily studied from the new Gaia data (Irrgang et al. 2018a; Brown et al. 2018; Erkal et al. 2019). The nature of candidate HVSs of low mass was also clarified by Gaia data leading to the elimination of all but one of them (Boubert et al. 2018). On the other hand, Gaia DR2 paved the way to search for new HVSs because it also provides radial velocities of cool stars, albeit limited to relatively bright ones. New cool nearby (10$15 \mathrm{kpc}$ ) high speed stars have been reported (e.g., Bromley et al. 2018; Marchetti et al. 2019; Du et al. 2019). However, Boubert et al. (2019) pointed out that the radial velocities of a couple of those candidates may be flawed by blending with nearby stars as confirmed by independent radial-velocity measurements in one case. Additional ground-based spectroscopy is required to clarify their nature.

While proper motion measurements from Gaia are far superior to any ground-based ones, high-precision parallaxes are still limited to relatively nearby stars. To ease this problem, Bayesian statistical methods have been developed (Bailer-Jones 2015; Astraatmadja \& Bailer-Jones 2016; Bailer-Jones et al. 2018), which might be useful for distances of about $10 \mathrm{kpc}$ under the premise that an appropriate prior is available. The latter, however, is very difficult to derive in the case of ejected stars.

Because B-type HVSs are so far away, mostly beyond $30 \mathrm{kpc}$, Gaia parallaxes are too uncertain to draw firm conclusions and will remain so even at the end of the Gaia mission. Therefore, spectrophotometric distances are and will be crucial to understand the kinematics of HVSs. This requires high-quality spectra, sophisticated model atmospheres and synthetic spectra, as well as an objective analysis strategy. Over the past years, those tools have been developed (Przybilla et al. 2011; Irrgang et al. 2014). Recently, we applied them to 14 out of the 42 highest velocity stars of the MMT HVS sample (Brown et al. 2018) to derive their spectrophotometric distances (Irrgang et al. 2018b, henceforth Paper I). Combining these distances with Gaia DR2 proper motions, we studied the kinematic properties and sites of origin of those 14 stars (Irrgang et al. 2018a, henceforth Paper II). This particular subsample was chosen because HST proper motions are available that allowed a cross-check to be made, which showed that proper motions from both sources are consistent.

In this work, which we regard as Paper III in this series, we extend the spectrophotometric analysis to 40 out of the 42 highvelocity outliers of the MMT HVS sample. We did not have access to the spectra of the two missing object. Complete astrometric data is available for 37 of them, allowing us to carry out a subsequent kinematic analysis as well. In Sect. 2, we describe our model atmospheres and synthetic spectra. Section 3 illustrates how these models are used to fit the observed MMT spectra and derive atmospheric parameters as well as radial and rotational velocities. In Sect. 4, spectral energy distributions (SEDs) are constructed and spectrophotometric distances and stellar parameters are derived. Those are then used to perform the kinematic analysis presented in Sect. 5. In Sect. 6, we discuss our results. Finally, we present our conclusions and our outlook in Sect. 7.

\section{Model atmospheres and synthetic spectra}

We calculated a grid of synthetic spectra with solar chemical composition following the so-called ADS approach (Przybilla et al. 2011), which involves a sequence of the three codes ATLas 12 (Kurucz 1996), DetaIL (Giddings 1981; Butler \& Giddings 1985), and Surface (Giddings 1981; Butler \& Giddings 1985). Assuming local thermodynamic equilibrium (LTE), AtLas 12 computes the initial atmospheric structure which is then used by DeTAIL to compute population numbers for specific chemical species in non-LTE. As we did previously in Paper I, we iteratively feed back the resulting population numbers for hydrogen and helium to ATLAs12 to incorporate deviations from LTE also in the computation of the atmospheric structure. Once this iterative process has converged, a final synthetic spectrum with more sophisticated line-broadening data is calculated with Surface. The resulting grid of synthetic spectra spans a range in effective temperature $T_{\text {eff }}$ between $9000 \mathrm{~K}$ and $16000 \mathrm{~K}$ (in steps of $250 \mathrm{~K}$ ) and surface gravities $\log (g)$ between 3.0 and 4.8 (in steps of 0.2 ). Our recent improvements of all three codes, namely the implementation of the occupation probability formalism (Hummer \& Mihalas 1988) for hydrogen and ionized helium - following the description given by Hubeny et al. (1994) - as well as state-of-the-art line broadening tables for hydrogen (Tremblay $\&$ Bergeron 2009), are included as well. These changes result in a much more realistic representation for the region around the Balmer jump and are thus very important for the analysis of the available spectra, which cover exactly this region. 
The list of spectral lines included in the ADS grid is tailored to B-type stars. Going to cooler temperatures, that is, to A-type stars, a rapidly increasing number of metal lines shows up in the spectrum that is not implemented in the grid. To crosscheck whether this affects our analysis, we compared our results with those based on models computed with a combination of AtLas 12 and the LTE spectrum synthesis code Synthe (Kurucz 1993), which contains many more metal lines. The corresponding grid covers temperatures between $7200 \mathrm{~K}$ and $11000 \mathrm{~K}$ (in steps of $200 \mathrm{~K}$ ) and gravities between 3.0 and 4.6 (in steps of 0.2 ). The relatively large overlap between the two grids was chosen on purpose to enable us to analyze many stars with both sets of models in order to check whether our results are model dependent, which turned out not to be the case. In the following, we will therefore only refer to the results obtained with the ADS grid.

\section{Spectral analysis}

The basic strategy of the spectral analysis is very similar to Paper I. However, there is one significant improvement, namely that flux-calibrated instead of normalized spectra are considered here. Consequently, we also re-analyze the objects from Paper I to have a homogeneously studied sample.

\subsection{MMT survey data and relative flux calibration}

The spectra analyzed in this work were taken during the MMT HVS survey and kindly provided by Warren Brown. A prime goal of that survey was spectral classification rather than a highprecision quantitative analysis. Consequently, the average $\mathrm{S} / \mathrm{N}$ of the co-added - for some of the stars, more than one spectrum is available - spectra is only of the order of 10-30 because most of the targets are quite distant and thus very faint, even for a $6.5 \mathrm{~m}$ telescope. Table 1 lists the number of individual observations as well as the wavelength-averaged $\mathrm{S} / \mathrm{N}$ of the co-added spectra.

The low $\mathrm{S} / \mathrm{N}$ and the relatively small wavelength coverage of the MMT spectra make it crucial to use as much information as possible to determine accurate temperatures and surface gravities. Consequently and in contrast to Paper I, we fitted fluxcalibrated rather than normalized spectra to also exploit the information contained in the slope of the continuum as well as in the shape of the Balmer jump. The effective temperature mainly affects the height of the Balmer jump while the surface gravity primarily its slope. By using this approach, the derived values for $T_{\text {eff }}$ and $\log (g)$ are more accurate and less uncertain, which is important for the spectrophotometric distance estimation where both parameters contribute significantly to the error budget. Our relative flux calibration followed the typical procedure, that is, we corrected for Rayleigh scattering, aerosols (see e.g., Patat et al. 2011), telluric absorption features (Moehler et al. 2014), and then use a standard star to calibrate the flux. MMT spectra for the flux standards were taken from the same night whenever possible, otherwise from the previous or following one. The fluxcalibrated reference spectra of the standards were available in the HST CALSPEC database (Bohlin et al. 2014).

\subsection{Fit method}

The spectral analysis strategy basically followed Irrgang et al. (2014). The underlying idea was to simultaneously fit all individual spectra of a star over their entire spectral range using the concept of $\chi^{2}$ minimization. Given the limited quality of the available spectra, it was not possible to determine abundances of individual chemical elements. Therefore, a solar chemical composition was assumed and the microturbulence was kept fixed at $2 \mathrm{~km} \mathrm{~s}^{-1}$, which is characteristic of late B-type MS stars. We were thus left with four fitting parameters for the stellar spectrum: the effective temperature $T_{\text {eff }}$, the surface gravity $\log (g)$, the projected rotational velocity $v \sin (i)$, and the radial velocity $v_{\text {rad }}$. Because we dealt with flux-calibrated spectra, we also had to consider interstellar reddening. Using the extinction law by Fitzpatrick (1999), three additional parameters were introduced: a distance scaling parameter, the color excess $E(B-V)$, and the extinction coefficient $R_{V}$, which was kept fixed at its typical value for the interstellar medium, that is, $R_{V}=3.1$.

\subsection{Cross-checks against medium- and high-resolution spectra}

Medium- and high-resolution spectra with larger spectral coverage are available for a few objects of the sample. By comparing the results based on those spectra with the ones based on the MMT spectra, we are able to validate our approach. The first test case is B1085, for which two MMT spectra with exposure times of $120 \mathrm{~s}$ and $660 \mathrm{~s}$ are available. In addition, we obtained four flux-calibrated X-shooter (Vernet et al. 2011) spectra with individual exposure times of $1200 \mathrm{~s}$ in the UVB and the VIS channel, which together span a range of 3600-9400 $\AA$. The second test case is HVS 5, for which we downloaded HIRES (Vogt et al. 1994) spectra from the KOA archive, which have already been analyzed by Brown et al. (2012). We reduced the data anew, performed a continuum normalization, and co-added the blue channel of all nine exposures. The corresponding spectral fits for both targets are shown in Figs. 1 and 2 and the resulting atmospheric and derived stellar parameters are contrasted in Tables 2 and 3. The good agreement between results based on MMT spectra and medium- to high-resolution spectra of different spectral coverage is very reassuring, showing that we can derive accurate parameters from the flux-calibrated MMT spectra.

\subsection{Atmospheric and stellar parameters}

The results of the spectral analysis are summarized in Table 1 and visualized in Fig. 3. All program stars except one (B598) have surface gravities and effective temperatures that are perfectly consistent with a MS nature. The surface gravities derived here are on average lower than those reported by Brown et al. (2014), naturally solving the issue that some stars such as HVS 11, HVS 12, and HVS 19 were lying below the ZAMS, a result that was barely compatible with a MS HVS nature. The atmospheric parameters of some stars would also be consistent with BHB stars, that is, evolved stars of lower mass; see Fig. 4. An important criterion to differentiate between the two cases is stellar rotation. BHB stars tend to rotate slowly (less than a few tens of $\mathrm{km} \mathrm{s}^{-1}$, Behr 2003) while MS B-type stars typically rotate fast (hundreds of $\mathrm{km} \mathrm{s}^{-1}$ ). Indeed, most program stars rotate rapidly (see Table 1 and Fig. 5), predominantly with $v \sin (i)=50-200 \mathrm{~km} \mathrm{~s}^{-1}$. While three stars rotate even faster than $300 \mathrm{~km} \mathrm{~s}^{-1}$, only a handful of targets shows low projected rotation velocities (upper limits of $\approx 50 \mathrm{~km} \mathrm{~s}^{-1}$ ). All slowly rotating stars except B576 are located outside the region enclosed by the ZAHB and the TAHB (see Fig. 4) indicating that they do not belong to an old population of low mass BHB stars. Low $v \sin (i)$ values of MS stars could be explained by low inclinations $i$, that is, by seeing the object almost pole-on. 
Table 1. Results of the spectroscopic analysis.

\begin{tabular}{|c|c|c|c|c|c|c|c|}
\hline \multirow[t]{2}{*}{ Object } & \multirow{2}{*}{$\begin{array}{l}T_{\text {eff }} \\
(\mathrm{K})\end{array}$} & \multirow{2}{*}{$\begin{array}{r}\log (g) \\
(\mathrm{cgs})\end{array}$} & $v_{\mathrm{rad}}$ & $v \sin (i)$ & \multirow[t]{2}{*}{$\chi_{\text {red }}^{2}$} & \multirow[t]{2}{*}{$\mathrm{S} / \mathrm{N}_{\text {tot }}$} & \multirow[t]{2}{*}{$\mathrm{N}$} \\
\hline & & & \multicolumn{2}{|c|}{$\left(\mathrm{km} \mathrm{s}^{-1}\right)$} & & & \\
\hline HVS1 & 10290 & 3.49 & 832.5 & 236 & 1.31 & 24.8 & 5 \\
\hline Stat. & +30 & +0.02 & +2.7 & +9 & & & \\
\hline Sys. & $\begin{array}{r}-40 \\
+110 \\
\end{array}$ & $\begin{array}{l}-0.02 \\
+0.04\end{array}$ & $\begin{array}{l}-2.6 \\
+1.6 \\
1\end{array}$ & $\begin{array}{l}-9 \\
+4\end{array}$ & & & \\
\hline HVS4 & 13890 & 3.97 & 605.0 & 122 & 1.29 & 24.0 & 2 \\
\hline Stat. & +60 & +0.03 & +3.0 & +11 & & & \\
\hline Sys. & $\begin{array}{r}-50 \\
+140 \\
\end{array}$ & $\begin{array}{l}-0.02 \\
+0.04\end{array}$ & $\begin{array}{l}-2.9 \\
+0.6 \\
+15\end{array}$ & $\begin{array}{r}-12 \\
+2\end{array}$ & & & \\
\hline HVS5 & 12550 & $\begin{array}{l}-0.04 \\
4.09\end{array}$ & 541.5 & 123 & 1.27 & 12.2 & 1 \\
\hline Stat. & +90 & +0.04 & +5.9 & +19 & & & \\
\hline Sys. & $\begin{array}{r}-80 \\
+130\end{array}$ & $\begin{array}{l}-0.04 \\
+0.04\end{array}$ & $\begin{array}{l}-5.9 \\
+2.3 \\
\end{array}$ & $\begin{array}{r}-19 \\
+1\end{array}$ & & & \\
\hline HVS6 & $12^{-130} 390$ & $\begin{array}{l}-0.04 \\
4.30\end{array}$ & 6063 & -1 & 13 & 125 & 1 \\
\hline Stat & +80 & +0.04 & +5.3 & +23 & & 12.5 & \\
\hline Sys. & $\begin{array}{r}-80 \\
+130 \\
\end{array}$ & $\begin{array}{l}-0.04 \\
+0.04\end{array}$ & $\begin{array}{l}-5.5 \\
+3.7\end{array}$ & $\begin{array}{l}-23 \\
+9\end{array}$ & & & \\
\hline He7 & -130 & -0.04 & -2.8 & -9 & 160 & 296 & 1 \\
\hline HVS7 & 12950 & 3.96 & 521.8 & 52 & 1.60 & 29.6 & 1 \\
\hline Stat. & $\begin{array}{l}+30 \\
-30\end{array}$ & ${ }_{-0.02}^{+0.02}$ & +2.2 & +12 & & & \\
\hline Sys. & $\begin{array}{l}+130 \\
+130\end{array}$ & $\begin{array}{l}-0.02 \\
+0.04 \\
-0.04\end{array}$ & 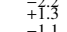 & $\begin{array}{l}-13 \\
+10 \\
+10\end{array}$ & & & \\
\hline HVS8 & 10880 & 4.06 & 498.9 & 276 & 1.42 & 25.8 & 1 \\
\hline Stat. & +50 & +0.02 & +3.3 & +12 & & & \\
\hline Sys. & $\begin{array}{l}-140 \\
+110\end{array}$ & $\begin{array}{l}-0.82 \\
+0.84 \\
-0.04\end{array}$ & $\begin{array}{l}-3: 1 \\
+1.4\end{array}$ & $\begin{array}{r}-10 \\
+7\end{array}$ & & & \\
\hline HVS9 & 10760 & 3.44 & 621.3 & 353 & 1.43 & 20.2 & 2 \\
\hline Stat. & +40 & +0.02 & +4.3 & +10 & & & \\
\hline Sys. & $\begin{array}{r}-40 \\
+110 \\
\end{array}$ & $\begin{array}{l}-0.02 \\
+0.04\end{array}$ & $\begin{array}{l}-3.99 \\
+0.5\end{array}$ & $\begin{array}{l}-10 \\
+0\end{array}$ & & & \\
\hline HVS10 & 10640 & $\begin{array}{l}-0.04 \\
3.94\end{array}$ & $\begin{array}{r}-0.5 \\
468.0\end{array}$ & 87 & 1.18 & 12.0 & 1 \\
\hline Stat & +60 & +0.03 & +4.4 & +18 & & & \\
\hline Sys. & $\begin{array}{r}-60 \\
+110\end{array}$ & $\begin{array}{l}-0.03 \\
+0.04\end{array}$ & $\begin{array}{r}-5.0 \\
+0.3 \\
\end{array}$ & $\begin{array}{l}-19 \\
+1\end{array}$ & & & \\
\hline HVS 11 & 9530 & $\begin{array}{l}-0.04 \\
412\end{array}$ & 483 & 187 & 126 & 159 & 5 \\
\hline Stat & +50 & +0.03 & $\begin{array}{r}+3.7 \\
+4.3\end{array}$ & $\begin{array}{r}101 \\
+17\end{array}$ & 1.20 & 1J.3 & $J$ \\
\hline Sys. & $\begin{array}{l}-50 \\
+100\end{array}$ & $\begin{array}{l}-0.02 \\
+0.04\end{array}$ & $\begin{array}{l}-5.1 \\
+0.5\end{array}$ & $\begin{array}{r}-9 \\
+2\end{array}$ & & & \\
\hline Dgis & -100 & -0.04 & -0.5 & 11 & 10 & 140 & \\
\hline HVST2 & 11020 & 4.08 & 545.1 & 11 & 1.19 & 14.0 & 3 \\
\hline Stat. & $\begin{array}{l}+50 \\
-50\end{array}$ & +0.03 & +3.8 & +32 & & & \\
\hline Sys. & $\begin{array}{l}-120 \\
+120\end{array}$ & $\begin{array}{l}-0.03 \\
+0.04 \\
-0.04\end{array}$ & $\begin{array}{l}-3.4 \\
+03 \\
-02\end{array}$ & $\begin{array}{l}-11 \\
+13 \\
-10\end{array}$ & & & \\
\hline HVS13 & 10810 & 3.92 & 570.8 & 187 & 1.24 & 14.7 & 3 \\
\hline Stat. & +60 & +0.03 & +5.2 & +16 & & & \\
\hline Sys. & $\begin{array}{r}760 \\
+110\end{array}$ & $\begin{array}{l}-0.03 \\
+0.04\end{array}$ & $\begin{array}{l}-4.9 \\
+1.5 \\
\end{array}$ & $\begin{aligned}-35 \\
+1 \\
+1\end{aligned}$ & & & \\
\hline HVS14 & 11420 & $\begin{array}{l}-0.04 \\
4.01\end{array}$ & 540.0 & 148 & 1.28 & 16.1 & 2 \\
\hline Stat. & +60 & +0.03 & +4.5 & +19 & & & \\
\hline Sys. & $\begin{array}{l}-60 \\
+120\end{array}$ & $\begin{array}{l}-0.02 \\
+0.04\end{array}$ & $\begin{aligned}-4.5 \\
+2.2 \\
\end{aligned}$ & $\begin{array}{l}-19 \\
+6\end{array}$ & & & \\
\hline HVS15 & $\begin{array}{r}-120 \\
-11000\end{array}$ & $\begin{array}{l}-0.04 \\
4.07\end{array}$ & 464.0 & 127 & 133 & 114 & 2 \\
\hline Stat & +50 & +0.04 & +6.2 & +27 & & & \\
\hline Sys. & $\begin{array}{l}-90 \\
+110\end{array}$ & $\begin{array}{l}-0.04 \\
+0.04\end{array}$ & $\begin{array}{l}-6.2 \\
+2.6 \\
\end{array}$ & $\begin{array}{l}-26 \\
+2\end{array}$ & & & \\
\hline HVS16 & $10-110$ & $\begin{array}{l}-0.04 \\
4.06\end{array}$ & 423.2 .3 & 165 & 121 & 133 & 2 \\
\hline Stat & $\begin{array}{r}0 \\
+60\end{array}$ & $\begin{array}{l}+0.04 \\
+0.04\end{array}$ & $\begin{array}{r}+5.3 \\
+5.3\end{array}$ & +20 & & & \\
\hline Stat. & -60 & -0.03 & -5.4 & -19 & & & \\
\hline Sys. & $\begin{array}{l}+110 \\
-110\end{array}$ & - & $\begin{array}{l}+0.4 \\
-0.3\end{array}$ & $\begin{array}{l}+0 \\
-0\end{array}$ & & & \\
\hline HVS17 & 12620 & 4.09 & 255.5 & 129 & 1.30 & 23.5 & 2 \\
\hline Stat. & +40 & +0.02 & +3.0 & +13 & & & \\
\hline Sys. & $\begin{array}{r}-40 \\
+130\end{array}$ & $\begin{array}{l}-0.02 \\
+0.04\end{array}$ & $\begin{array}{l}-3.0 \\
+1.5 \\
+\end{array}$ & $\begin{array}{l}-15 \\
+1 \\
+1\end{array}$ & & & \\
\hline HVS18 & 11600 & 3.88 & 239.4 & 132 & 1.31 & 21.6 & 4 \\
\hline Stat. & +40 & +0.02 & +3.4 & +18 & & & \\
\hline Sys. & $\begin{array}{r}-50 \\
+120\end{array}$ & $\begin{array}{l}-0.02 \\
+0.04\end{array}$ & $\begin{array}{l}-3.2 \\
+2.0 \\
\end{array}$ & $\begin{array}{l}-16 \\
+5\end{array}$ & & & \\
\hline HVS19 & $\begin{array}{r}-120 \\
11480\end{array}$ & $\begin{array}{l}-0.04 \\
4.17\end{array}$ & $\begin{array}{r}593.4 \\
\end{array}$ & 224 & 1.23 & 8.3 & 3 \\
\hline Stat & +90 & +0.04 & +9.1 & +27 & & & \\
\hline Sys. & $\begin{array}{l}-120 \\
+120\end{array}$ & $\begin{array}{l}-0.06 \\
+0.04\end{array}$ & $\begin{array}{r}-9.0 \\
+2.2 \\
\end{array}$ & $\begin{array}{r}-43 \\
+1 \\
+1\end{array}$ & & & \\
\hline & -120 & -0.04 & -0.7 & -1 & & & \\
\hline HVS20 & 10160 & 3.78 & 510.5 & 316 & 1.28 & 14.3 & 4 \\
\hline Stat. & $\begin{array}{r}+90 \\
-90\end{array}$ & +0.06 & $\begin{array}{l}+5.4 \\
-5.5\end{array}$ & +20 & & & \\
\hline Sys. & $\begin{array}{l}+110 \\
+110\end{array}$ & $\begin{array}{l}7.04 \\
+0.04\end{array}$ & $\begin{array}{l}-7.9 \\
+2.9 \\
-29\end{array}$ & $\begin{array}{l}-10 \\
+0\end{array}$ & & & \\
\hline HVS 21 & 12760 & 4.10 & 357.4 & 47 & 1.30 & 11.1 & 1 \\
\hline Stat. & +90 & +0.04 & +5.5 & +62 & & & \\
\hline Sys. & $\begin{array}{r}-130 \\
+130\end{array}$ & $\begin{array}{r}-0.04 \\
+0.04\end{array}$ & $\begin{array}{l}-2.4 \\
+2.8\end{array}$ & $\begin{array}{l}-41 \\
+50 \\
\end{array}$ & & & \\
\hline HVS 22 & 10350 & 3.94 & 596.4 & 156 & 1.21 & 9.0 & 3 \\
\hline Stat. & +100 & +0.06 & $\begin{array}{l}+7.4 \\
+7.7\end{array}$ & +32 & & & \\
\hline Sys & $\begin{array}{l}-80 \\
+110\end{array}$ & $\begin{array}{l}-0.04 \\
+0.04\end{array}$ & $\begin{array}{l}-7.7 \\
+0.5\end{array}$ & $\begin{array}{c}-31 \\
+1\end{array}$ & & & \\
\hline & -110 & -0.04 & -0.3 & -0 & & & \\
\hline
\end{tabular}

\begin{tabular}{|c|c|c|c|c|c|c|c|}
\hline \multirow[t]{2}{*}{ Object } & \multirow{2}{*}{$\begin{array}{l}T_{\text {eff }} \\
(\mathrm{K})\end{array}$} & \multirow{2}{*}{$\begin{array}{r}\log (g) \\
(\mathrm{cgs})\end{array}$} & $v_{\mathrm{rad}}$ & $v \sin (i)$ & \multirow[t]{2}{*}{$\chi_{\mathrm{red}}^{2}$} & \multirow[t]{2}{*}{$\mathrm{S} / \mathrm{N}_{\text {tot }}$} & \multirow[t]{2}{*}{$\overline{\mathrm{N}}$} \\
\hline & & & \multicolumn{2}{|c|}{$\left(\mathrm{km} \mathrm{s}^{-1}\right)$} & & & \\
\hline HVS23 & 10400 & 3.60 & 248.9 & 112 & 1.32 & 4.3 & 1 \\
\hline Stat. & +160 & +0.09 & +14.4 & +51 & & & \\
\hline Sys. & $\begin{array}{r}-230 \\
+110 \\
+\end{array}$ & $\begin{array}{l}-0.02 \\
+0.04 \\
\end{array}$ & $\begin{array}{r}-14.3 \\
+0.2\end{array}$ & $\begin{array}{r}-59 \\
+2\end{array}$ & & & \\
\hline HVS24 & 10900 & 3.95 & 496.0 & 213 & 1.24 & 16.6 & 2 \\
\hline Stat. & +60 & +0.03 & +4.2 & +17 & & & \\
\hline Sys & $\begin{array}{l}-60 \\
+110 \\
\end{array}$ & $\begin{array}{l}-0.03 \\
+0.04 \\
+0.04\end{array}$ & $\begin{array}{l}-4.4 \\
+1.5\end{array}$ & $\begin{array}{r}-19 \\
+1\end{array}$ & & & \\
\hline B095 & 9850 & $\begin{array}{l}-0.04 \\
4.17\end{array}$ & $\begin{array}{r}-1.5 \\
206.8\end{array}$ & 89 & 1.30 & 15.1 & 6 \\
\hline Stat. & +60 & +0.05 & +4.2 & +14 & & & \\
\hline Sys & $\begin{array}{l}-50 \\
+100\end{array}$ & $\begin{array}{l}-0.03 \\
+0.04 \\
+0.04\end{array}$ & $\begin{array}{l}-4.1 \\
+0.5\end{array}$ & $\begin{array}{l}-12 \\
+4 \\
\end{array}$ & & & \\
\hline B129 & 10720 & 3.046 & 351.7 & $177^{-2}$ & 1.12 & 124 & 1 \\
\hline Stat & +70 & +0.03 & +5.1 & +19 & & & \\
\hline Sys. & $\begin{array}{r}-70 \\
+110\end{array}$ & $\begin{array}{l}-0.04 \\
+0.04\end{array}$ & $\begin{array}{l}-4.3 \\
+2.5\end{array}$ & $\begin{array}{r}-20 \\
+1\end{array}$ & & & \\
\hline B143 & $\begin{array}{r}-110 \\
10910\end{array}$ & $\begin{array}{l}-0.04 \\
4.03\end{array}$ & $\begin{array}{r}-1.5 \\
217.6\end{array}$ & 269 & 130 & 157 & 1 \\
\hline stot & $\begin{array}{l}+70 \\
\end{array}$ & +0.03 & +4.8 & +21 & & & \\
\hline stat. & -50 & -0.03 & -4.8 & -18 & & & \\
\hline Sys. & $\begin{array}{l}+110 \\
-110\end{array}$ & 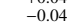 & $\begin{array}{l}+2.4 \\
-0.9\end{array}$ & $\begin{array}{l}+1 \\
-3 \\
-3\end{array}$ & & & \\
\hline B167 & 11250 & 4.20 & 297.9 & 0 & 1.19 & 19.4 & 1 \\
\hline Stat. & +40 & +0.02 & +2.6 & +34 & & & \\
\hline Sys. & $\begin{array}{l}-40 \\
+120\end{array}$ & $\begin{array}{l}-0.02 \\
+0.04 \\
\end{array}$ & $\begin{array}{l}-2.8 \\
+0.5\end{array}$ & +0 & & & \\
\hline B329 & 10800 & 3.85 & 213.7 & $\begin{array}{l}-0 \\
58\end{array}$ & 1.24 & 8.0 & 1 \\
\hline Stat. & +100 & +0.06 & +6.8 & +34 & & & \\
\hline Sys & $\begin{array}{l}-80 \\
+110\end{array}$ & $\begin{array}{l}-0.05 \\
+0.04\end{array}$ & $\begin{array}{l}-7.2 \\
+1: 4 \\
\end{array}$ & $\begin{array}{r}-48 \\
+7\end{array}$ & & & \\
\hline B434 & 10140 & 3.84 & 441.3 & 89 & 133 & 350 & 3 \\
\hline Stat & +40 & +0.02 & +1.9 & +9 & & & \\
\hline Sys. & $\begin{array}{r}-40 \\
+110\end{array}$ & $\begin{array}{l}-0.02 \\
+0.04 \\
+\end{array}$ & $\begin{array}{l}-1.9 \\
+2.2 \\
\end{array}$ & $+\frac{-8}{7}$ & & & \\
\hline B458 & $\begin{array}{l}-110 \\
9810\end{array}$ & 3.80 & 454.0 & 104 & 1.23 & 6.1 & 1 \\
\hline Stat. & +120 & +0.05 & +9.6 & +26 & & & \\
\hline Sys. & $\begin{array}{l}-100 \\
+100\end{array}$ & $\begin{array}{l}-0.05 \\
+0.04 \\
\end{array}$ & $\begin{array}{l}-8.5 \\
+1.4 \\
\end{array}$ & $\begin{array}{r}-23 \\
+2\end{array}$ & & & \\
\hline B481 & 10300 & $\begin{array}{l}-0.04 \\
3.61\end{array}$ & 133.3 & 190 & 128 & 74 & 1 \\
\hline Stat. & +120 & +0.06 & $\begin{array}{r}+8.9 \\
+8.9\end{array}$ & +24 & & & \\
\hline Sys & $\begin{array}{l}-160 \\
+110\end{array}$ & $\begin{array}{l}-0.06 \\
+0.04\end{array}$ & $\begin{array}{l}-8.3 \\
+2.1\end{array}$ & $\begin{array}{r}-30 \\
+1\end{array}$ & & & \\
\hline Dys. & & 04 & & -1 & & & \\
\hline B485 & 15710 & 3.92 & 422.7 & 81 & 1.51 & 40.1 & 1 \\
\hline Stat. & +70 & +0.02 & +1.8 & +9 & & & \\
\hline Sys. & $\begin{array}{l}-50 \\
+160 \\
\end{array}$ & $\begin{array}{l}-0.02 \\
+0.04 \\
+0.04\end{array}$ & $\begin{array}{l}-1.8 \\
+1.0\end{array}$ & $\begin{array}{r}-8 \\
+7 \\
\end{array}$ & & & \\
\hline B537 & $\begin{array}{r}-160 \\
11760\end{array}$ & 3.75 & $\begin{array}{r}-1.9 \\
150.9\end{array}$ & $\begin{array}{l}-11 \\
181\end{array}$ & 1.23 & 7.5 & 1 \\
\hline Stat. & +120 & +0.06 & +9.3 & +37 & & & \\
\hline Sys. & $\begin{array}{r}-140 \\
+120\end{array}$ & $\begin{array}{l}-0.07 \\
+0.04\end{array}$ & $\begin{array}{l}-9.2 \\
+1.7 \\
\end{array}$ & $\begin{array}{l}-29 \\
+15\end{array}$ & & & \\
\hline B572 & $\begin{array}{r}-120 \\
10920\end{array}$ & $\begin{array}{l}-0.04 \\
4.23\end{array}$ & 130.7 & -1 & 127 & 64 & 1 \\
\hline Stat & +140 & +0.06 & $\begin{array}{r}+10.7 \\
\end{array}$ & +40 & & & \\
\hline Sys & $\begin{array}{l}-140 \\
+110\end{array}$ & $\begin{array}{l}-0.06 \\
+0.04\end{array}$ & $\begin{array}{c}-12.2 \\
+2.3 \\
\end{array}$ & $\begin{array}{r}-38 \\
+1\end{array}$ & & & \\
\hline D57 & 1.00 & 370 & 216 & -1 & 133 & 279 & 1 \\
\hline D.70 & 11400 & & $\begin{array}{r}216.1 \\
+1.9\end{array}$ & $\begin{array}{r}4 / \\
+12\end{array}$ & נת & 21.9 & \\
\hline Stat. & $\begin{array}{l}+30 \\
-30\end{array}$ & $\begin{array}{l}+0.02 \\
-0.02\end{array}$ & $\begin{array}{l}+1.9 \\
-1.7\end{array}$ & $\begin{array}{l}+12 \\
-13 \\
-13\end{array}$ & & & \\
\hline Sys. & $\begin{array}{l}+120 \\
-120\end{array}$ & 04 & ${ }_{-0.3}^{+0.4}$ & $\begin{array}{l}+8 \\
-8\end{array}$ & & & \\
\hline B598 & 10730 & 4.52 & 282.5 & 192 & 1.13 & 17.0 & 1 \\
\hline Stat. & $\begin{array}{l}+60 \\
+\end{array}$ & +0.03 & +4.6 & +18 & & & \\
\hline Sys. & $\begin{array}{r}-70 \\
+110\end{array}$ & $\begin{array}{l}-0.03 \\
+0.04 \\
\end{array}$ & $\begin{array}{r}-4.8 \\
+1.0 \\
\end{array}$ & $\begin{array}{l}-15 \\
+1\end{array}$ & & & \\
\hline B711 & 10410 & 3.98 & 267.6 & 17 & 2.54 & 36.4 & 1 \\
\hline Stat. & +30 & +0.02 & +1.6 & +16 & & & \\
\hline Sys. & $\begin{array}{r}-40 \\
+110\end{array}$ & $\begin{array}{l}-0.02 \\
+0.04 \\
\end{array}$ & +1.5 & $\begin{array}{l}-17 \\
+12\end{array}$ & & & \\
\hline B733 & 10280 & $\begin{array}{l}-0.04 \\
4.04\end{array}$ & 351.4 & 278 & 2.83 & 53.2 & 1 \\
\hline Stat. & $\begin{array}{r}+30 \\
-30\end{array}$ & +0.02 & +2.2 & $\begin{array}{r}+7 \\
-7\end{array}$ & & & \\
\hline Sys. & $\begin{array}{r}-30 \\
+110\end{array}$ & 0.01 & $\begin{array}{l}-2.0 \\
+2.4 \\
\end{array}$ & $\begin{array}{l}-7 \\
+9\end{array}$ & & & \\
\hline B1080 & 10700 & 3.89 & 501.5 & $\begin{array}{l}150 \\
\text { D }\end{array}$ & 1.21 & 14.3 & 2 \\
\hline Stat. & +70 & +0.03 & $\begin{array}{r}+4.6 \\
-45\end{array}$ & +21 & & & \\
\hline Sys. & $\begin{array}{l}+110 \\
-110\end{array}$ & +0.04 & $\begin{array}{l}-4.2 \\
+2.2 \\
-12\end{array}$ & +1 & & & \\
\hline B1085 & 11020 & 3. & 483.9 & 319 & 1.27 & 23.9 & 2 \\
\hline Stat. & +40 & +0.03 & +3.7 & +10 & & & \\
\hline Sys. & $\begin{array}{r}-120 \\
+120\end{array}$ & $\begin{array}{l}-0.03 \\
+0.04 \\
+0.04\end{array}$ & $\begin{array}{l}-2.8 \\
+0.9\end{array}$ & $\begin{array}{l}-12 \\
+0 \\
+0\end{array}$ & & & \\
\hline B1139 & 11660 & $\begin{array}{l}-0.04 \\
4.26\end{array}$ & $\begin{array}{l}-0.4 \\
65.7\end{array}$ & 30 & 1.37 & 8.0 & 1 \\
\hline Stat. & +120 & +0.06 & +7.4 & +45 & & & \\
\hline Sys. & $\begin{array}{r}-120 \\
+120\end{array}$ & $\begin{aligned}-0.05 \\
+0.04\end{aligned}$ & $\begin{array}{r}-8.2 \\
+3.4 \\
\end{array}$ & $\begin{array}{r}-30 \\
+15 \\
\end{array}$ & & & \\
\hline & & & & & & & \\
\hline
\end{tabular}

Notes. Statistical uncertainties ("Stat.") are $1 \sigma$ confidence limits based on $\chi^{2}$ statistics. Systematic uncertainties ("Sys.”) cover only the effects induced by additional variations of $1 \%$ in $T_{\text {eff }}$ and 0.04 in $\log (g)$ and are formally taken to be $1 \sigma$ confidence limits (see Irrgang et al. 2014 for details). The quantity $\chi_{\text {red }}^{2}$ is the reduced $\chi^{2}$ at the best fit. The total number of available spectra is denoted in the ' $N$ ' column, whereas the total $\mathrm{S} / \mathrm{N}$ is given as quadratically added $\mathrm{S} / \mathrm{N}$ of all available spectra.

We conclude that most of the program stars are likely MS stars. Under this assumption, stellar masses $M$, ages $\tau$, radii $R$, luminosities $L$, and ratios of actual angular velocity to critical velocity $\Omega / \Omega_{\text {crit }}$ can be derived by comparing the stars' position in the Kiel diagram with theoretical predictions; see Fig. 3. The outcome of this exercise is tabulated in Table 4.

The nature of B598 remains unclear for the moment because its effective temperature places the star below the ZAMS, al- though it is rapidly rotating. Two evolutionary scenarios can explain stars in this region of the Kiel diagram. On the one hand, we note that the locus of the ZAMS is a function of metallicity. The lower the metallicity, the more compact the stars, the higher their surface gravity. Hence, B598 could be a low metallicity MS star of an old stellar population. Such stars are classified as blue stragglers, and correspondingly B598 may be a rejuvenated 2-3 $M_{\odot}$ MS star. Another class of stars are the rare pro- 

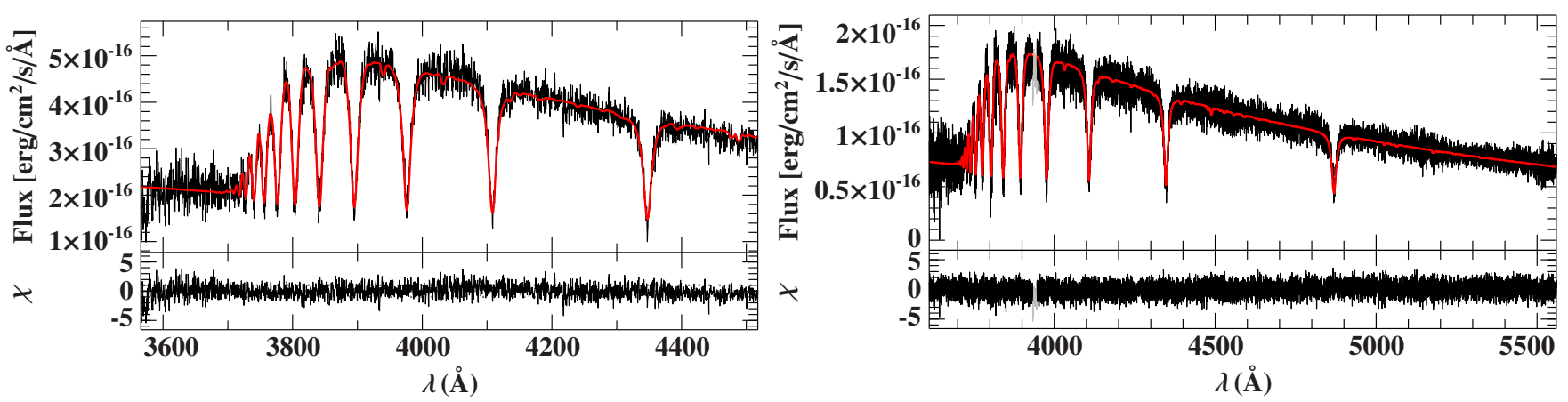

Fig. 1. Comparison of best-fitting model spectrum (red) with observation (black) in the case of B1085. Residuals $\chi$ are shown in the lower panels. The left figure shows one of the available MMT spectra, the quality of which is typical for the sample. The right figure shows an exemplary flux-calibrated X-shooter UVB spectrum. Contrary to the absolute fluxes, the calibration of the relative fluxes is almost identical, demonstrating that our procedure for relative flux-calibration works. Combined with synthetic spectra that properly account for the Balmer jump, this enables us to derive reliable effective temperatures and surface gravities.
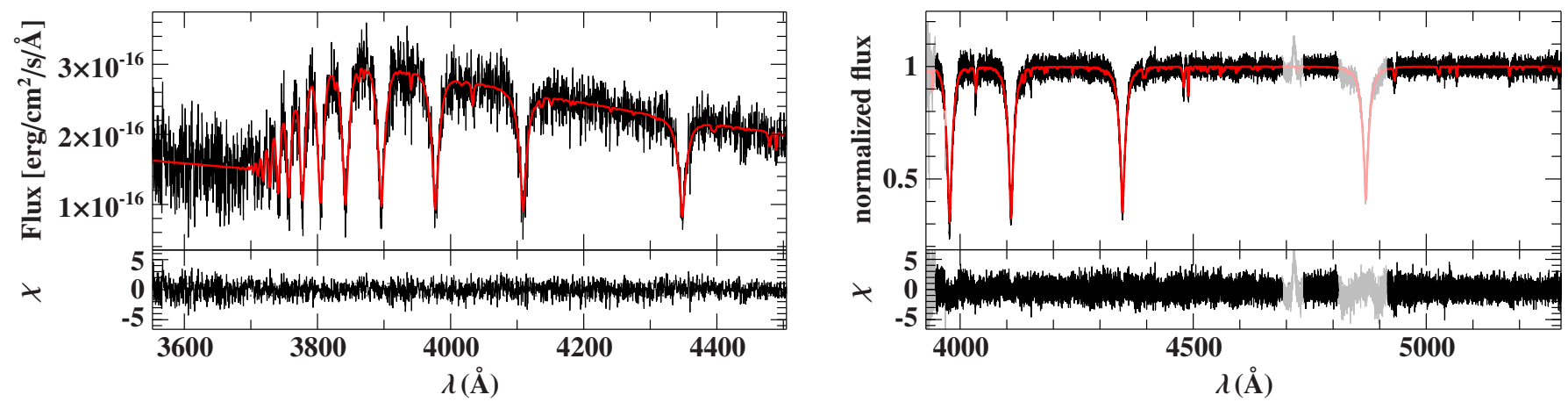

Fig. 2. Same as Fig. 1 but for HVS 5. The left figure shows a flux-calibrated MMT spectrum while the normalized co-added HIRES spectrum is shown in the right figure. Light colors mark regions that have been excluded from fitting, e.g., due to data reduction problems.

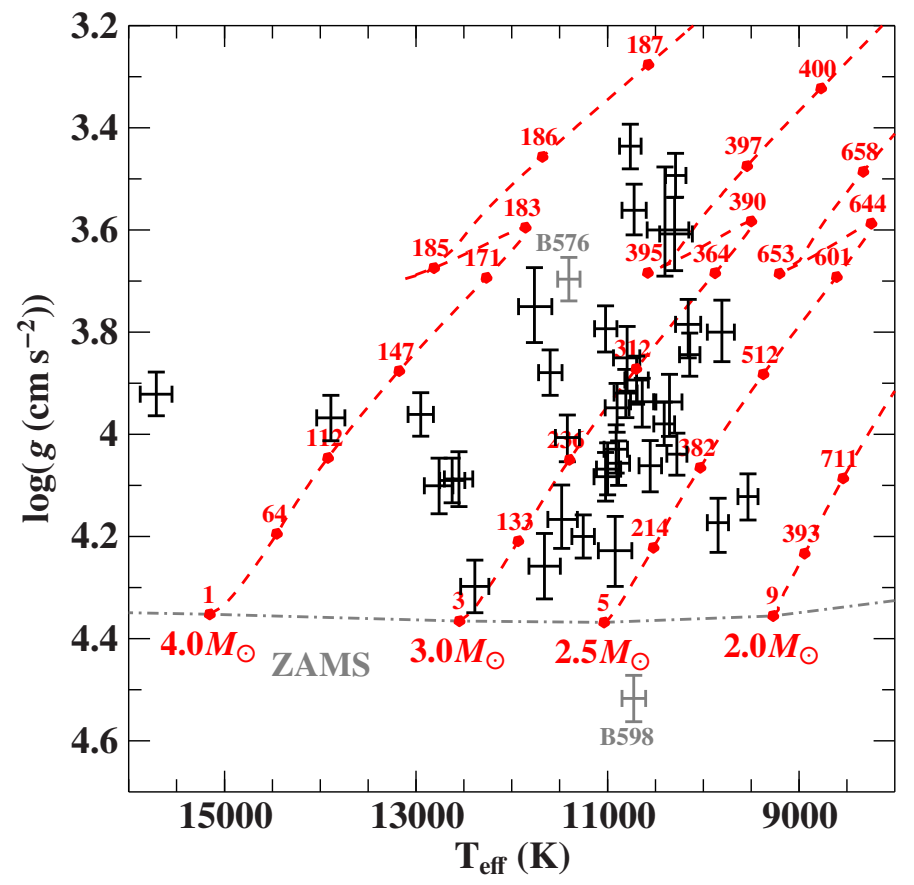

Fig. 3. Position of the program stars in the Kiel diagram. Evolutionary tracks for rotating $\left(\Omega / \Omega_{\text {crit }}=0.4\right)$ MS stars of solar metallicity and different initial masses (Georgy et al. 2013) are overlaid in red. Red filled circles and numbers mark the age in Myr. The locus of the zero-age MS (ZAMS) is indicated as a gray dashed line. Error bars are $1 \sigma$ and cover statistical and systematic uncertainties. The two objects (B576, B598) for which a MS nature is unlikely are marked in gray (see Sect. 6.2.3).
Table 2. Atmospheric and derived stellar parameters for B1085 based on two different sets of spectra.

\begin{tabular}{lrr}
\hline \hline & MMT & X-shooter \\
$T_{\text {eff }}(\mathrm{K})$ & $11020 \pm 120$ & $10890 \pm 120$ \\
$\log (g)(\mathrm{cgs})$ & $3.79 \pm 0.05$ & $3.85 \pm 0.05$ \\
$v_{\mathrm{rad}}\left(\mathrm{km} \mathrm{s}^{-1}\right)$ & $484_{-3}^{+4}$ & $491 \pm 2$ \\
$v \sin (i)\left(\mathrm{km} \mathrm{s}^{-1}\right)$ & $319_{-15}^{+10}$ & $290 \pm 1$ \\
\hline$M\left(M_{\odot}\right)$ & $3.38_{-0.11}^{+0.10}$ & $3.14 \pm 0.1$ \\
$\tau(\mathrm{Myr})$ & $224_{-13}^{+24}$ & $260_{-11}^{+9}$ \\
$d(\mathrm{kpc})$ & $42_{-4}^{+3}$ & $37 \pm 3$ \\
\hline
\end{tabular}

Notes. Uncertainties are $1 \sigma$ and cover statistical as well as systematic effects. The derivations of stellar parameters and distances are outlined in Sect. 3.4 and 4.3.

genitors of extremely low mass (ELM) WDs (see Heber 2016 for details), some of which show surface gravities much lower than typical WDs (as low as $\log (g) \sim 4.8$, Brown et al. 2016; Ratzloff et al. 2019). Both classes of stars are often found in binaries. Giesers et al. (2019) find that more than $50 \%$ of the blue stragglers in the globular cluster NGC 3201 are close binaries, whereas Brown et al. (2016) found about $85 \%$ of the ELM WDs to be short-period binaries. Typically, orbital periods in ELM WD binary systems are found to be on the order of tens of minutes to hours (Brown et al. 2016) and should, thus, lead to observable variations in the radial velocity unless the orbital inclination is very small. Unfortunately, only one single exposure 
Table 3. Atmospheric and derived stellar parameters for HVS 5 based on two different sets of spectra.

\begin{tabular}{lrrr}
\hline \hline & MMT & HIRES & Brown+(2012) \\
$T_{\text {eff }}(\mathrm{K})$ & $12550_{-150}^{+160}$ & $12190_{-260}^{+290}$ & $12000 \pm 350$ \\
$\log (g)(\mathrm{cgs})$ & $4.09 \pm 0.06$ & $4.11_{-0.12}^{+0.11}$ & $3.89 \pm 0.13$ \\
$v_{\mathrm{rad}}\left(\mathrm{km} \mathrm{s}^{-1}\right)$ & $542_{-6}^{+7}$ & $552 \pm 3$ & $552 \pm 3$ \\
$v \sin (i)\left(\mathrm{km} \mathrm{s}^{-1}\right)$ & $123 \pm 19$ & $132_{-2}^{+3}$ & $133 \pm 7$ \\
\hline$M\left(M_{\odot}\right)$ & $3.40_{-0.11}^{+0.10}$ & $3.23_{-0.07}^{+0.09}$ & $3.62 \pm 0.11$ \\
$\tau(\mathrm{Myr})$ & $149_{-26}^{+20}$ & $160_{-70}^{+60}$ & $170 \pm 17$ \\
$d(\mathrm{kpc})$ & $37 \pm 4$ & $34_{-5}^{+7}$ & $44 \pm 4$ \\
\hline
\end{tabular}

Notes. Same as Table 2. Values obtained by Brown et al. (2012) from the same HIRES data are listed in the third column.

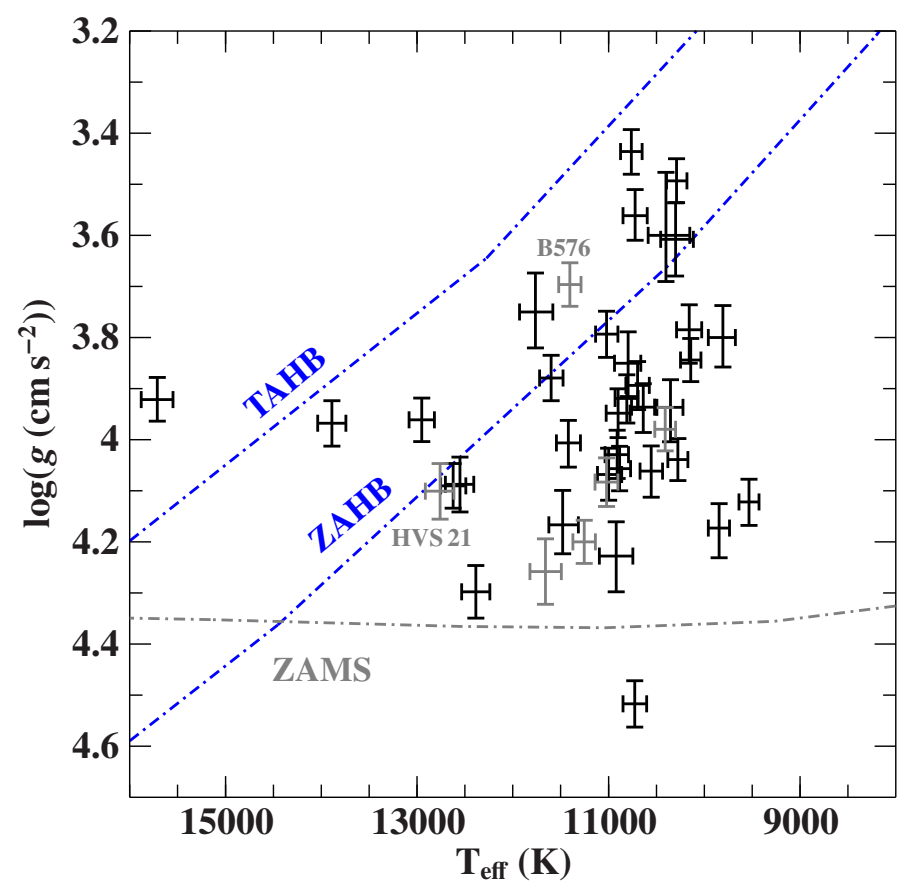

Fig. 4. Same as Fig. 3 but MS tracks are replaced by loci for the zeroand terminal-age horizontal branch (ZAHB, TAHB) for a helium abundance of 0.247 and $[\mathrm{Fe} / \mathrm{H}]=-1.48$ from Dorman et al. (1993). Stars with $v \sin (i)<50 \mathrm{~km} \mathrm{~s}^{-1}$ are displayed in gray.

was taken in the course of the MMT survey, which is why we cannot check whether B598 is radial-velocity variable.

The slowly rotating star B576 is located mid-way in the HB band; see Fig. 4. Anticipating results from the kinematic investigation, it is more likely a low mass BHB star than a MS star; see Sect. 6.2.3.

\subsection{Comparison of spectroscopic results with Paper I}

By reprocessing the spectra (relative flux calibration) we were able to improve the atmospheric parameters of a few stars in comparison with their previous analysis in Paper I. For most stars, these differences are well within the given uncertainties, which is reassuring, because it demonstrates that our results are typically independent of the details of the applied analysis strategy. However, two cases exist where the revision of the parameters is significant enough to be mentioned explicitly.

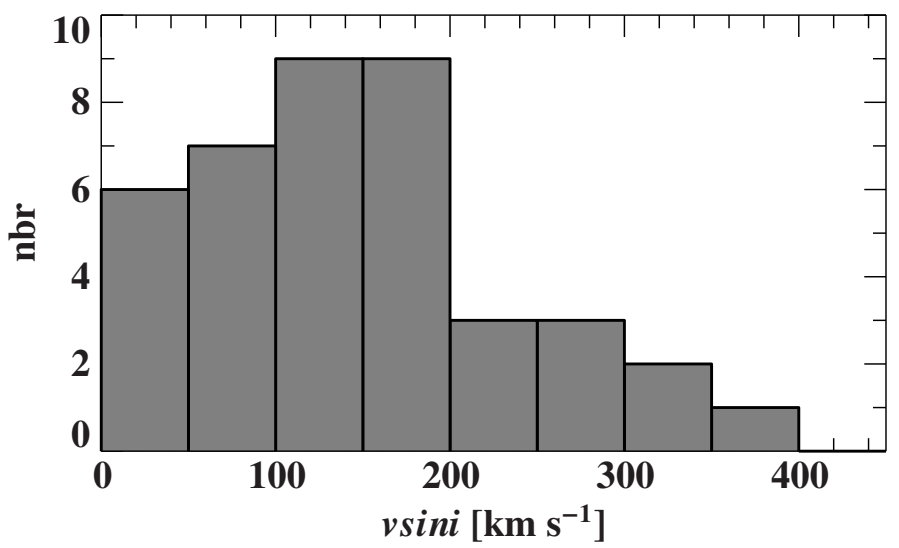

Fig. 5. Histogram showing the distribution of $v \sin (i)$ values for all program stars. Typical individual uncertainties (see Table 1) are smaller than the bin size. Most stars rotate fast and are thus very likely MS stars.

Compared to Paper I, the surface gravity of HVS 5 is now $\sim 0.1$ dex lower. This yields a distance $(37 \pm 4 \mathrm{kpc})$ that is $\sim 6 \mathrm{kpc}$ larger and hence closer to $45 \pm 5.2 \mathrm{kpc}$, the value by Brown et al. (2015). As will be discussed in Sect. 6.2.3, the interpretation of the origin of HVS 5 is quite sensitive to its assumed distance.

In Paper I, we re-classified B711 as an A-type star $\left(T_{\text {eff }}=\right.$ $9170 \pm 250 \mathrm{~K}$ ) based on the shape of the Balmer lines and the wealth of metal lines visible in the spectrum. Fitting the fluxcalibrated data, however, reveals that the height of the Balmer jump is much better reproduced by a higher $T_{\text {eff }}=10410 \pm$ $120 \mathrm{~K}$. Both temperatures can reproduce the spectral shape of the Balmer lines equally well because these lines almost behave the same when spreading out from their peak strength value between 9500-10000 K, which leads to ambiguities in the parameter determination. The presence of many metal lines, which we used as argument for the cooler solution in Paper I due to the fact that we were lacking sufficient information about the height of the Balmer jump, now suggests that B711 could be metal rich.

\section{SEDs and spectrophotometric distances}

As pointed out in Sect. 1, the Gaia parallaxes of our program stars, which all are quite far away, are too uncertain to be of any help. Thus, we have to rely on spectrophotometric distances, which require precise photometry to construct SEDs. Angular diameters and interstellar reddening and extinction result from fits of the observed SEDs by synthetic ones. The spectrophotometric distance can then be derived from the angular diameter, the spectroscopic surface gravity, and the mass from evolutionary models.

\subsection{Photometric data}

Photometric data were compiled from a variety of surveys covering the ultraviolet, the optical, and the infrared mainly using the VizieR ${ }^{1}$ catalog access tool. The following catalogs were queried: For ultraviolet magnitudes the GALEX catalog (Bianchi et al. 2017, with corrections from Wall et al. 2019 for the brightest targets). Optical photometry came from Gaia DR2 (Evans et al. 2018, with corrections and calibrations from Maíz Apellániz \& Weiler 2018), SDSS DR12 (Alam et al. 2015), PanSTARRS1 (Chambers et al. 2016), SkyMapper DR1.1 (Wolf

${ }^{1}$ http://vizier.u-strasbg.fr/viz-bin/VizieR 


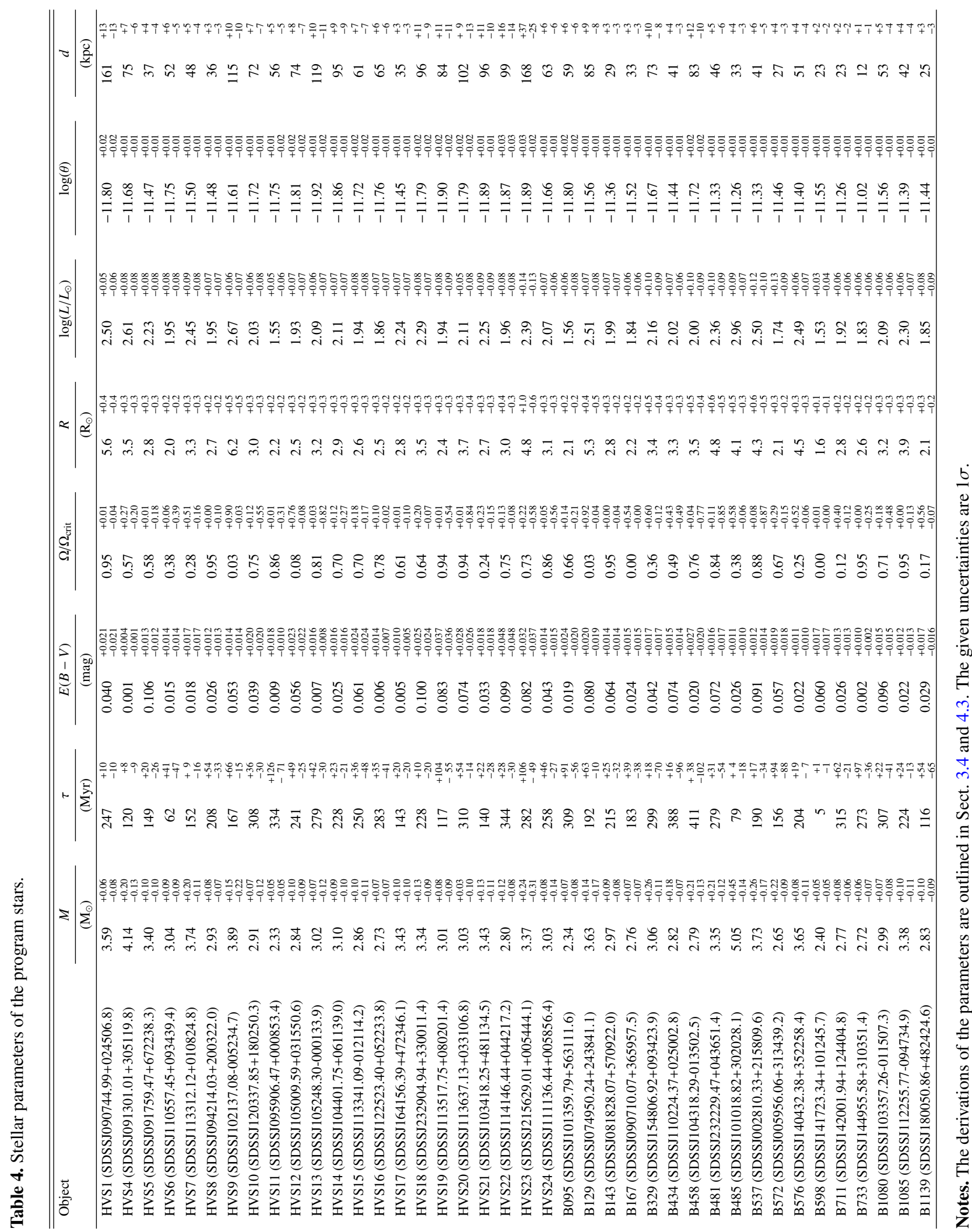




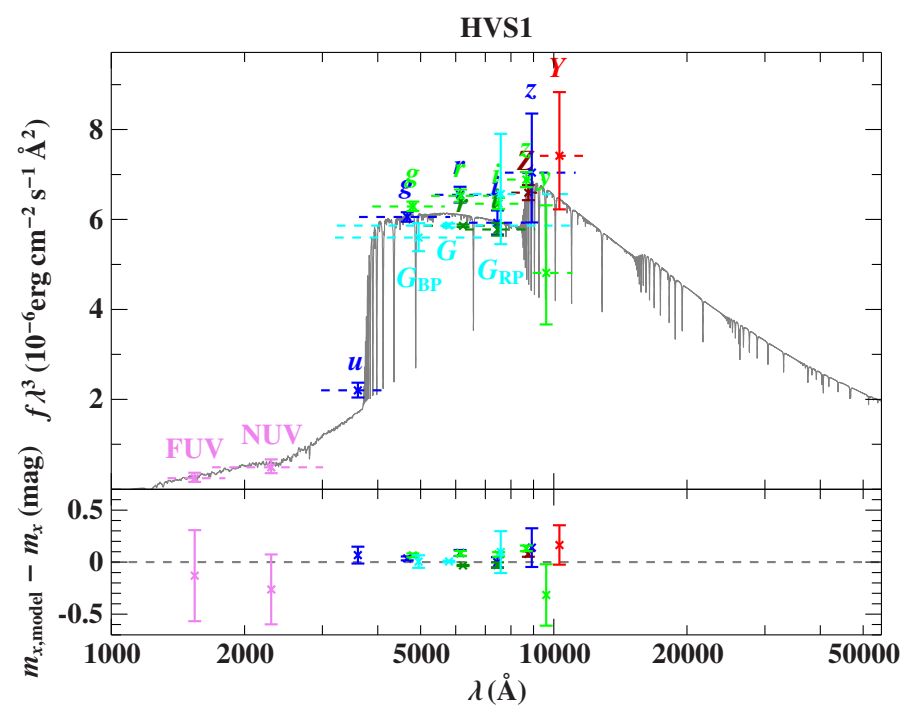

Fig. 6. Comparison of synthetic and observed photometry for HVS 1: The top panel shows the SED. The colored data points (GALEX: violet, SDSS: blue; Pan-STARRS: green; Gaia: cyan; VST-KiDs: dark green; VISTA: dark red; UKIDSS: red) are filter-averaged fluxes which were converted from observed magnitudes (the respective filter widths are indicated by the dashed horizontal lines), while the gray solid line represents a model that is based on the spectroscopic parameters given in Table 1. Only the angular diameter and the color excess were fitted. The flux is multiplied with the wavelength to the power of three to reduce the steep slope of the SED on such a wide wavelength range. The residual panel at the bottom shows the differences between synthetic and observed magnitudes.

et al. 2019), BATC (Zhou 2005), VST-ATLAS-DR3 (Shanks et al. 2015, without the $u$-band due to known zero-point calibration issues), VST-KiDS-DR3 (de Jong et al. 2017), and APASSDR9 (Henden et al. 2015). Infrared magnitudes were taken from UKIDSS-DR9 (Lawrence et al. 2013) and VISTA (Cross et al. 2012). Measurements with large or unknown uncertainties as well as measurements that turned out to be obvious outliers during the fitting with synthetic SEDs have been omitted.

\subsection{Angular diameter and interstellar extinction}

The resulting observed SEDs were compared to synthetic ones based on ATLAs12 model computations (see Sect. 2). For each star, the model parameters were fixed to their respective spectroscopic values (see Sect. 3.4), which is why we were left with only two free fitting parameters, the angular diameter $\Theta$ as distance scaling factor and the color excess $E(B-V)$ as indicator for interstellar reddening and extinction. We used the extinction curve by Fitzpatrick (1999) to account for wavelength-dependent reddening and keep the extinction parameter $R_{V}$ fixed at 3.1, that is, its typical value for the interstellar medium. The best parameter values and their corresponding uncertainties were obtained via $\chi^{2}$ minimization, see Heber et al. (2018) for details. In the fitting procedure only a small fraction of data had to be dismissed as outliers leaving us with an excellent coverage of the optical spectral range (see Figs. 6, 9, and B.1-B.37) and consequently high precision angular diameters. The color excesses are small $(E(B-V) \leq 0.1 \mathrm{mag})$ as expected for stars at high Galactic latitudes.

\subsection{Spectrophotometric distances}

The resulting angular diameters $\Theta=2 R / d$ were combined with the stellar radii $R=(G M / g)^{1 / 2}$ which are based on the surface gravities $g$ from spectroscopy and the stellar masses derived from evolutionary tracks (see Sect. 3.4). This allowed us to calculate the spectrophotometric distances $d$ which are listed in Table 4. For the candidate pre-ELM WD B598 (see Sect. 3.4), we calculated an additional distance assuming a typical ELM mass of $M=0.25 M_{\odot}$, which results in $d=6.5_{-0.9}^{+1.0} \mathrm{kpc}$. We furthermore examined the BHB case for candidate B576 and determined $d=18.7_{-1.5}^{+1.6} \mathrm{kpc}$ based on the assumption of a typical BHB mass of $M=0.5 M_{\odot}$.

\section{Kinematic analysis}

The strategy of the kinematic analysis is identical to that of $\mathrm{Pa}$ per II. Complementing our revised radial velocities and spectrophotometric distances with positions and proper motions measured with Gaia or HST gave us the full six-dimensional phase space information that is needed to calculate the trajectories of the program stars back in time to unravel their (spatial) origin. Unfortunately, proper motion measurements were not available for HVS 11, HVS 14, and HVS 23, which is why the kinematic analysis encompasses only 37 out of the 40 stars in the sample. Propagation of uncertainties in the spectrophotometric distance, radial velocity, and proper motions was achieved using a standard Monte Carlo approach with 1.5 million realizations that accounts also for the correlation in proper motions as provided by Gaia DR2.

\subsection{Proper motions}

Proper motions were mainly taken from Gaia DR2 (Lindegren et al. 2018). We used the "renormalized unit weight error" (RUWE, see Lindegren 2018) as given in the ARI Gaia Data Service $^{2}$ as primary indicator for the quality of the astrometric solution. Unlike other quality indicators, RUWE is by design independent of the color of the object, which makes it the best choice when studying blue stars as done here. For all objects in the sample, RUWE is below the recommended value of 1.4, indicating that the astrometric solutions are well-behaved. For a subsample of 15 stars, pre-Gaia proper motions measured with the HST instruments WFC3 and ACS were available (Brown et al. 2015). As discussed in Paper II, proper motions from both sources are consistent with each other - except for the outlier B711 - suggesting that the Gaia DR2 proper motions of the other 22 program stars are reliable as well. In analogy to Paper II, we chose the more precise measurement when Gaia as well as HST proper motions were available, which implies that we used HST data for HVS 1, HVS 10, HVS 12, and HVS 13 and Gaia DR2 data for B711.

\subsection{Galactic gravitational potentials}

The trajectories of all targets were computed in two different Milky Way mass models which primarily differ in the mass and analytic form of the dark matter halo. Model I is a revision of the popular model by Allen \& Santillan (1991) and Model II is based on the flat rotation curve model by Wilkinson \& Evans (1999). Both models have been calibrated using the same observational constraints (for details see Irrgang et al. 2013) and are consistent

2 http://gaia.ari.uni-heidelberg.de/ 
with latest results based on Gaia DR2 data (see Paper II). In contrast to Paper II, we omit Model III because it predicts escape velocities that are most likely too large.

\subsection{Places of origin}

Tracing back the trajectories of the targets also gave us information about their spatial origin within the Galactic plane. To this end, we considered only those out of the 1.5 million Monte Carlo orbits that cross the Galactic plane within the upper $99 \%$ confidence limit for the respective stellar age. For B598, this limit was set to $100 \mathrm{Myr}$, which clearly exceeds its derived flight time and, thus, did not affect the outcome at all.

\subsection{Ejection velocities}

Although the current Galactic rest-frame velocity provides a good first impression of how extreme the underlying disk ejection event might have been, it may still be misleading because it does not account for the intrinsic rotation of the disk. For instance, stars ejected in direction of Galactic rotation may be boosted by more than $200 \mathrm{~km} \mathrm{~s}^{-1}$ while those ejected against Galactic rotation may be slowed down by the same amount. Consequently, the ejection velocity $v_{\mathrm{ej}, \mathrm{p}}$, that is, the Galactic restframe velocity at plane intersection corrected for Galactic rotation, is a more useful quantity to look at when studying the nature and origin of runaway and HVSs. In particular, it can help to distinguish between the various disk ejection mechanisms outlined in Sect. 1, see, for example, Paper II and Irrgang et al. (2019).

\section{Results of the kinematic analyses}

The detailed results of the kinematic analyses are listed in Tables A.1 and A.2 for both Galactic mass models considered here. The quantities shown there are based on a right-handed Cartesian Galactic coordinate system in which the Sun is located on the negative $x$-axis and the $z$-axis points to the Galactic north pole. Plane-crossing quantities are labeled by the subscript "p" and are based on all orbits that crossed the Galactic plane within the maximum backward integration time, which was set to 15 Gyr. The Galactic rest-frame velocity $v_{\mathrm{Grf}}=\left(v_{x}^{2}+v_{y}^{2}+v_{z}^{2}\right)^{1 / 2}$, the local Galactic escape velocity $v_{\text {esc }}$, the Galactocentric radius $r=\left(x^{2}+y^{2}+z^{2}\right)^{1 / 2}$, the ejection velocity $v_{\mathrm{ej}}$, and the flight time $\tau_{\text {flight }}$ are listed in addition to Cartesian positions and velocities.

\subsection{Flight time vs. evolutionary time}

In order to check whether the program stars are consistent with an ejection scenario, we compare their flight times, which result from tracing back their orbits to the Galactic plane, to their inferred evolutionary ages; see Fig. 7. All stars except B598 have ages that, within uncertainties, exceed their respective flight times, that is, they can reach their present-day position in the Galactic halo within their derived MS lifetimes. The object B598 does not pass this test owing to its location below the ZAMS in the Kiel diagram (see Sect. 3.4), which does not allow for a determination of a reasonable MS age.

\subsection{Places of origin}

In the following, we group the stars in three categories based on their inferred spatial origin. The first consists of stars for which the available data are insufficient to constrain the place of origin

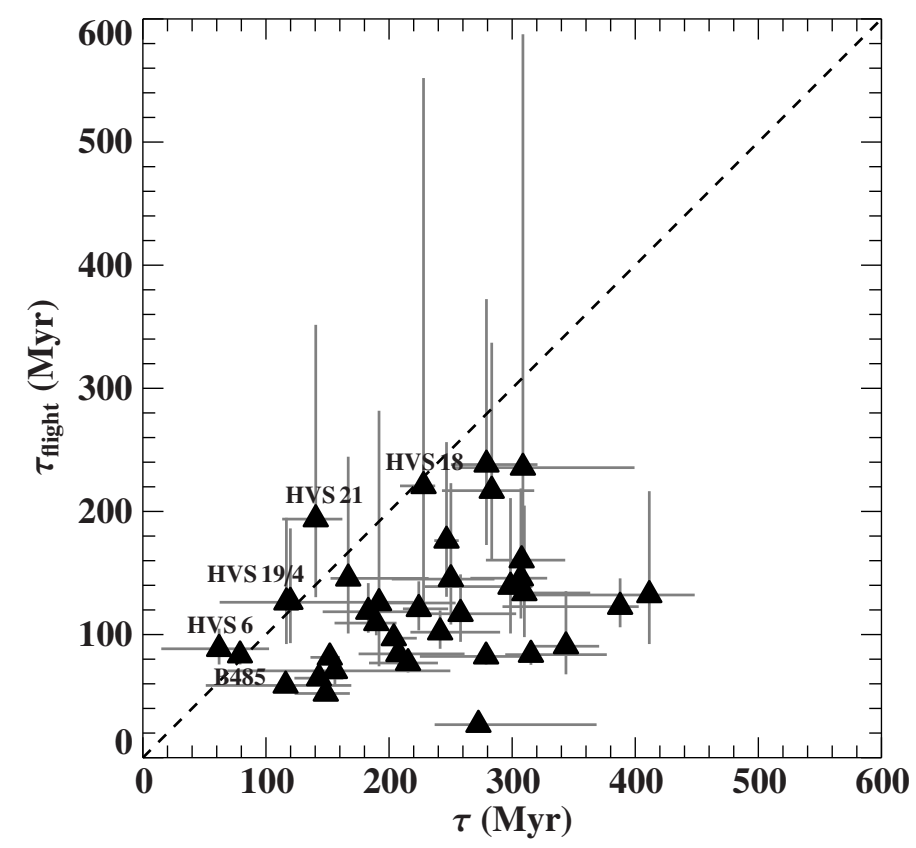

Fig. 7. Time of flight from the Galactic plane to the current position in the halo vs. inferred evolutionary age assuming a single-star MS nature. The dashed line is the identity line. B598 is omitted in this plot because we cannot derive its MS age (see Sect. 3.4). All stars are consistent with an ejection scenario from the Galactic plane.

because the error contours enclose the entire Galactic disk and even more (Sect. 6.2.1). The second category comprises objects whose origin lies far outside the solar circle at the rim of the Galactic disk (Sect. 6.2.2). Finally, the third group consists of the best constrained objects (Sect. 6.2.3). Particularly interesting stars are discussed in separate paragraphs. Unless stated otherwise, numbers are always taken from Table A.1, that is, they are based on Model I for the gravitational potential. A comparison with Model II is presented in Sect. 6.2.4.

\subsubsection{Unconstrained origin}

Owing to the large uncertainties for the kinematic input parameters that are mainly caused by the objects' huge distances, the origin of 19 stars in the sample is not really constrained; see Fig. 8. All of them could possibly stem from the Galactic disk, and in particular from the GC. Because the vast majority of trajectories of most stars intersects the Galactic plane outside of the $20 \mathrm{kpc}$ circle which we use here as a rough boundary for the Galactic disk, the given ejection velocities from the plane should be considered with caution. With the outstanding exception of HVS 22 (see below), the current Galactic restframe velocities in this group lie between $v_{\text {Grf }}=390_{-80}^{+150} \mathrm{~km} \mathrm{~s}^{-1}$ (B129) and $v_{\text {Grf }}=970_{-360}^{+480} \mathrm{~km} \mathrm{~s}^{-1}$ (HVS 20). Apart from HVS 21 $\left(v \sin (i)=47_{-47}^{+80} \mathrm{~km} \mathrm{~s}^{-1}\right)$ and B329 $\left(v \sin (i)=58_{-49}^{+35} \mathrm{~km} \mathrm{~s}^{-1}\right)$, all stars in this group exhibit projected rotational velocities that are significantly larger than $50 \mathrm{~km} \mathrm{~s}^{-1}$, which hints at a MS nature. Moreover, the boundness probability of all stars except B1080 $\left(P_{\mathrm{b}}=67 \%\right)$ is lower than $50 \%$, for most of them it is even equal to zero. Although the most plausible explanation for the presence of those apparently young massive stars in the far-distant Galactic halo is the ejection from the Galactic disk by a very powerful mechanism, the precision of the currently available data is just not high enough to definitely proof or discard it. 


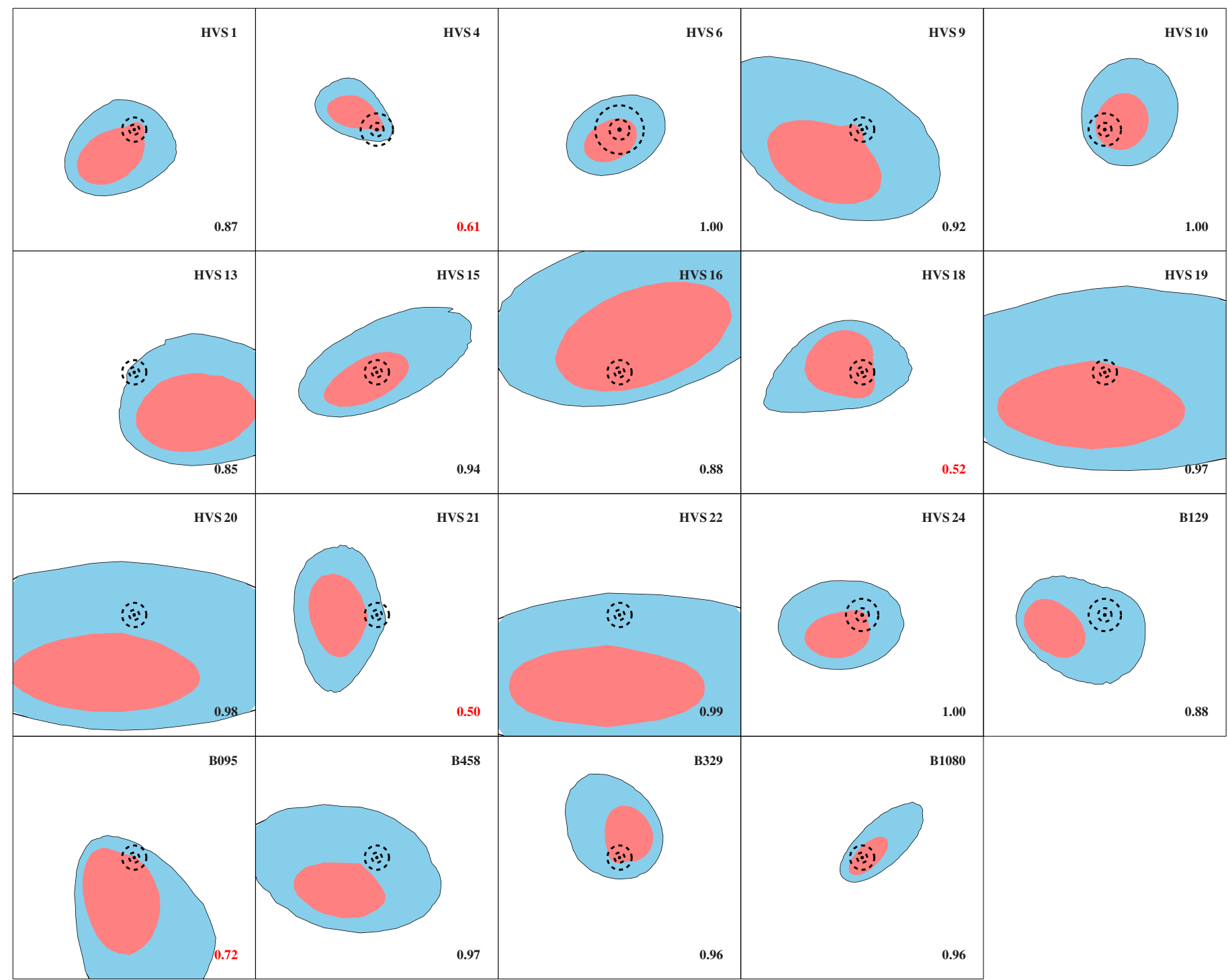

Fig. 8. Galactic plane-crossing locations for those objects whose origin is not constrained. The black rimmed, red and blue shaded areas mark regions where $68 \%$ and $95 \%$ ( $1 \sigma$ and $2 \sigma$ ) of the 1.5 million Monte Carlo trajectories intersect the Galactic plane. Three black circles with different radii are overplotted for reference: a central circle (solid; $1 \mathrm{kpc}$ ), the solar radius (dashed; $8.3 \mathrm{kpc}$ ), and the Galactic disk (dashed; $20 \mathrm{kpc}$ ). To account for the finite lifetimes of the stars, only orbits that cross the Galactic plane within the upper $99 \%$ confidence limit for the respective stellar age are considered. The number in the lower right corner denotes this fraction of orbits and is displayed in red if the age restriction removes more than $20 \%$ of the Monte Carlo trials.

HVS 22 With a current Galactic rest-frame velocity of $v_{\text {Grf }}=$ $1530_{-560}^{+690} \mathrm{~km} \mathrm{~s}^{-1}$, HVS 22 is the star with the most outstanding kinematic properties in the sample. However, its place of origin is completely unconstrained; see Fig. 8. The extreme velocity of HVS 22 is a consequence of its large inferred spectrophotometric distance of $d=99_{-14}^{+16} \mathrm{kpc}$. Key ingredients for the distance determination are the spectroscopic surface gravity and the assumed MS mass. Although the $\mathrm{S} / \mathrm{N}$ of the available spectra is relatively low, there is currently no indication in the spectral fit nor in the SED (see Fig. 9) that the derived surface gravity might be incorrect. Similarly, the projected rotation of $v \sin (i)=156_{-31}^{+32} \mathrm{~km} \mathrm{~s}^{-1}$ as well as the fact that the position of the star in the Kiel diagram (see Fig. 4) is well below the ZAHB support the idea that HVS 22 is indeed a MS star.

Article number, page 10 of 26

\subsubsection{Possible outer rim origin}

For eight stars in the sample, the precision of the kinematic analysis is sufficient to conclude that those stars either stem from the outer rim of the Galactic disk or not from the disk at all; see Fig. 10. The best candidate for an ejection from the disk is HVS 8 albeit its ejection velocity of $v_{\mathrm{ej}, \mathrm{p}}=440_{-20}^{+40} \mathrm{~km} \mathrm{~s}^{-1}$ is close to $\sim 500 \mathrm{~km} \mathrm{~s}^{-1}$, that is, to the upper limit of what classical disk ejection mechanisms are capable of. For all other stars in this group, the majority of the Monte Carlo trajectories intersects the Galactic plane outside of the $20 \mathrm{kpc}$ circle. Consequently and similar to the previous group, it is unclear whether their derived ejection velocities from the Galactic plane are physically meaningful at all. If the stars indeed came from the very outskirts of the Galactic disk, the ejection velocities of HVS 7 $\left(v_{\mathrm{ej}, \mathrm{p}}=530 \pm 30 \mathrm{~km} \mathrm{~s}^{-1}\right)$, HVS $12\left(v_{\mathrm{ej}, \mathrm{p}}=610_{-70}^{+80} \mathrm{~km} \mathrm{~s}^{-1}\right), \mathrm{B} 434$ $\left(v_{\mathrm{ej}, \mathrm{p}}=580 \pm 20 \mathrm{~km} \mathrm{~s}^{-1}\right), \mathrm{B} 481\left(v_{\mathrm{ej}, \mathrm{p}}=630_{-40}^{+50} \mathrm{~km} \mathrm{~s}^{-1}\right)$, and B576 $\left(v_{\mathrm{ej}, \mathrm{p}}=740_{-50}^{+60} \mathrm{~km} \mathrm{~s}^{-1}\right)$ would more or less clearly exceed this 


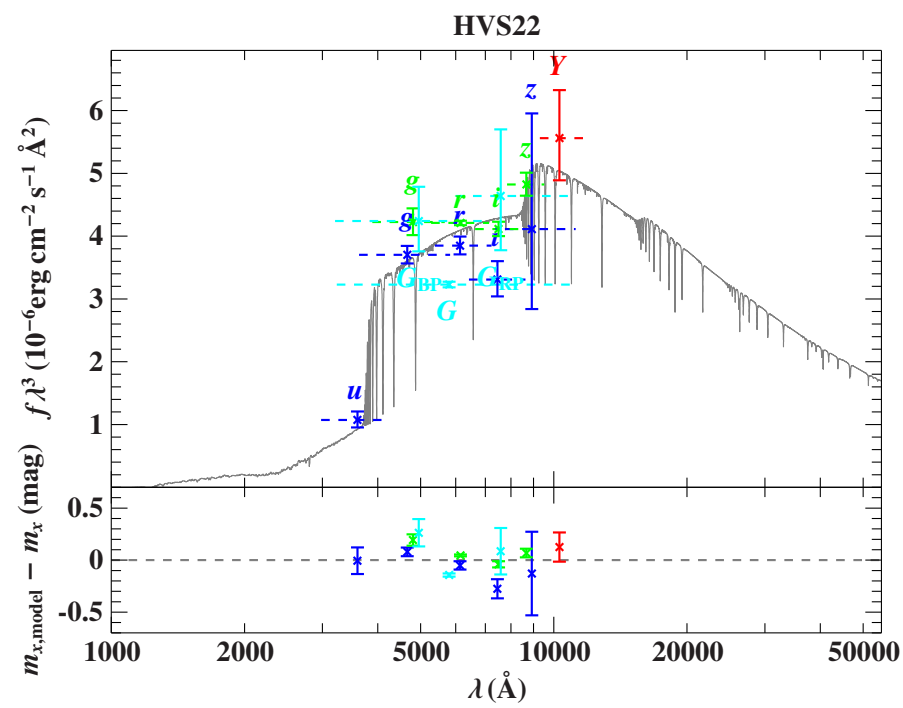

Fig. 9. Same as Fig. 6 but for HVS22. SDSS: blue; Pan-STARRS: green; UKIDSS: red; Gaia: cyan.

aforementioned limit and hence hint at the existence of another powerful but yet neglected ejection channel, see, e.g., Paper II and Irrgang et al. (2019). An alternative explanation would be that these objects either do not originate in the Galactic disk, for example, because they are of extragalactic origin, or that they are not MS stars, which would render our spectrophotometric distance estimation incorrect. However, all stars in this group either rotate fast or lie outside of the BHB band of the Kiel diagram (see Fig. 4), which corroborates the idea that they are indeed MS stars.

Assuming a MS nature, only three stars (B167, B434, B711) have boundness probabilities larger than $50 \%$, that is, most objects in this group are likely unbound.

\subsubsection{Disk origin}

For ten stars in the sample, the precision of the astrometric input data is high enough to conclude that their spatial origin is very likely located within the Galactic disk; see Figs. 11, 14, and 16. It is worthwhile to comment on particularly interesting individual objects and we shall also discuss the case of B576 here, because, assuming a BHB nature, its place of origin is well constrained.

B733 With a derived spectrophotometric distance of $12 \pm 1 \mathrm{kpc}$, $\mathrm{B} 733$ is the second closest object in the sample. Combined with the unprecedented astrometric precision of Gaia, it is possible to pinpoint the star's place of origin to a narrow region close but slightly outside of the solar radius; see Fig. 11. The derived ejection velocity $v_{\mathrm{ej}, \mathrm{p}}=470 \pm 10 \mathrm{~km} \mathrm{~s}^{-1}$ is comparable to the fastest known disk runaway stars (see, e.g., Silva \& Napiwotzki 2011 and Irrgang et al. 2019). Elemental abundances could help us to better understand the object. Unfortunately, the star rotates so fast $\left(v \sin (i)=278_{-10}^{+12} \mathrm{~km} \mathrm{~s}^{-1}\right)$ that a high-precision abundance analysis will be almost impossible even if spectra of much better quality were available.

HVS 17, B485, and B1139 The places of origin for these stars are rather well constrained to lie between the solar circle and the outer rim of the Galaxy $(20 \mathrm{kpc})$. Their ejection velocities $v_{\text {ej,p }}=270-430 \mathrm{~km} \mathrm{~s}^{-1}$ are also comparable to the high-velocity tail of the sample by Silva \& Napiwotzki (2011).

B143 and B572 The Galactic plane-crossing contours for both stars locate their origin somewhat beyond the solar circle. However, the $2 \sigma$ contours come close to the GC. Hence, the possibility of a GC origin should not be completely dismissed. Ejection velocities of $v_{\text {ej,p }}=410_{-50}^{+60}$ and $310_{-40}^{+60} \mathrm{~km} \mathrm{~s}^{-1}$ place them among the fastest disk runaways known.

B537 This star is the only one that likely originates in the inner disk, that is, inside the solar circle. More precise proper motions are needed to confirm or rule out an origin in the GC. The ejection velocity $\left(v_{\text {ej,p }}=460_{-90}^{+210} \mathrm{~km} \mathrm{~s}^{-1}\right)$ is comparable to the most extreme disk runaways known to date.

HVS 5 This object is one of the most interesting program stars because it is both, very extreme but at the same time relatively well constrained. Nevertheless, the conclusions about its spatial origin diverge. While Brown et al. (2018) argue for an ejection from the GC by the Hills mechanism, we discarded this option in Paper II because the GC was not within the region where 95\% of all Monte Carlo orbits intersected the Galactic plane. A major difference between the two kinematic analyses was the assumed distance. Brown et al. (2018) probably used $45 \pm 5.2 \mathrm{kpc}$ (Brown et al. 2015) while we derived $31.2_{-2.5}^{+3.2} \mathrm{kpc}$. Our revised atmospheric parameters now yield $37 \pm 4 \mathrm{kpc}$, which is closer to the value by Brown et al. (2015). In Fig. 12, we illustrate the impact of the different distance estimates on the outcome of the kinematic analysis. Even though the distance estimates are now in better agreement, we can still rule out the GC with more than $2 \sigma$ confidence. With an ejection velocity of $v_{\text {Grf }}=670_{-60}^{+80} \mathrm{~km} \mathrm{~s}^{-1}$, HVS 5 is clearly above the limit of what classical scenarios are capable of.

B598 As already outlined in Sect. 3.4, B598 is a puzzling object because its measured $\log (g)=4.52 \pm 0.05$ seems to be too high to be compatible with a MS nature. The SED of the target (Fig. 13), which covers observations from the far ultraviolet to the infrared, shows that there is no reason to doubt our spectroscopically derived atmospheric parameters. Elemental abundances could be the key to unravel the nature of B598. However, the spectral smearing due to the high projected rotation $\left(v \sin (i)=192_{-15}^{+18} \mathrm{~km} \mathrm{~s}^{-1}\right)$ will make this a very challenging task and require spectra of superb quality. For the time being, we note that if B598 was a MS star, it would be one of our best candidates for the ejection by the Hills mechanism given its large ejection velocity $\left(v_{\mathrm{ej}, \mathrm{p}}=610 \pm 50 \mathrm{~km} \mathrm{~s}^{-1}\right)$ and its inferred place of origin, which encloses the GC; see Fig. 14. However, as discussed in Sect. 3.4, the star is likely an evolved low mass star of $\approx 0.2 M_{\odot}$ in transition from the red giant branch to a low mass helium-core WD. The corresponding trajectory (see Fig. 15) would then be typical of a halo star.

B576 Assuming a MS nature for B576, it would be the only star in the sample for which an origin in the Galactic disk could be ruled out with more than $2 \sigma$ confidence (see Fig. 16). Its current Galactic rest-frame velocity $v_{\text {Grf }}=680_{-60}^{+70} \mathrm{~km} \mathrm{~s}^{-1}$ would then render the object clearly unbound, which would imply that it were just passing through our Milky Way. However, the measured rotational velocity of $v \sin (i)=47_{-16}^{+15} \mathrm{~km} \mathrm{~s}^{-1}$ in combina- 


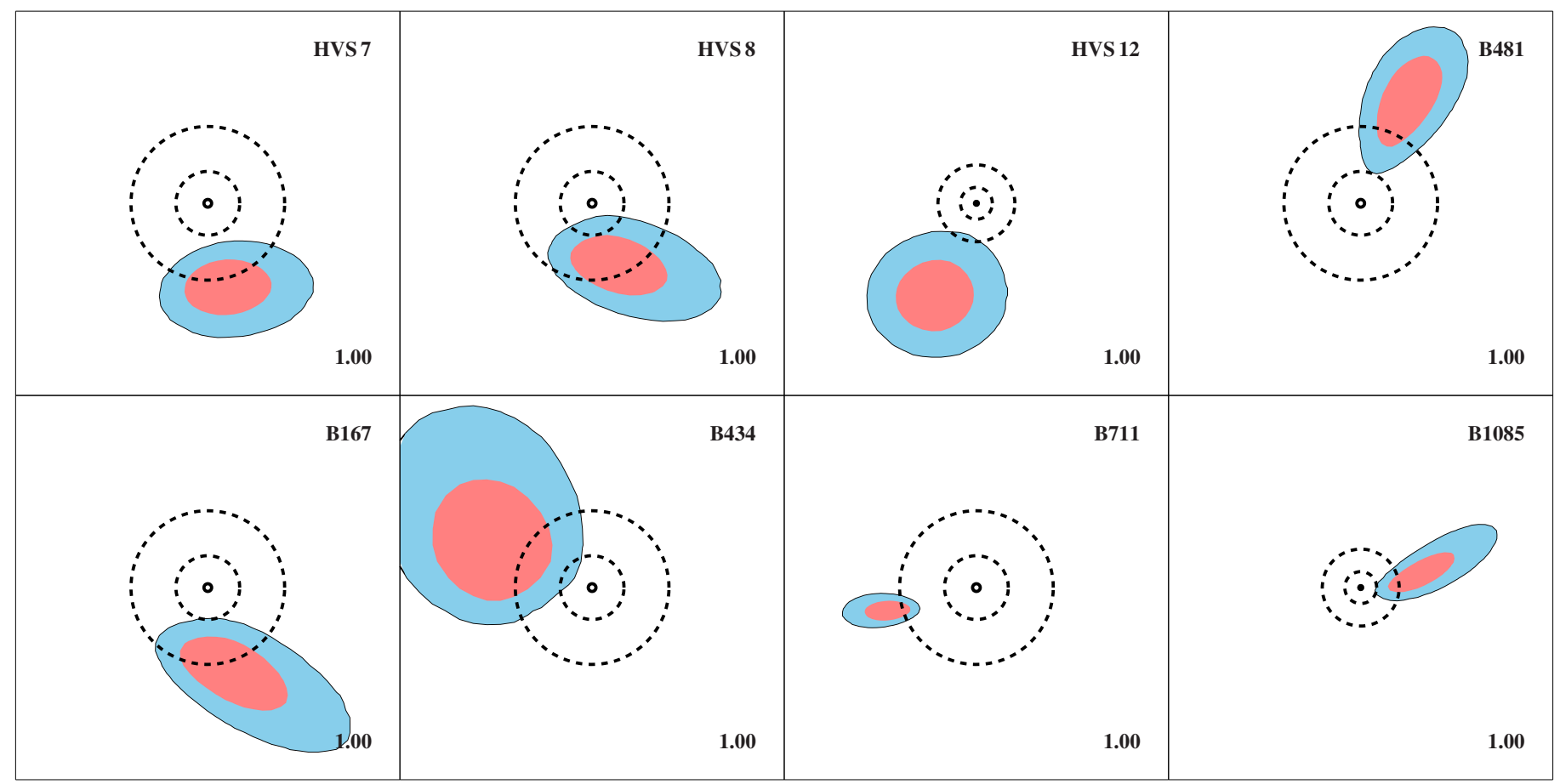

Fig. 10. Same as Fig. 8 but for objects that may stem from the outer rim of the Galactic disk or not from the disk at all.

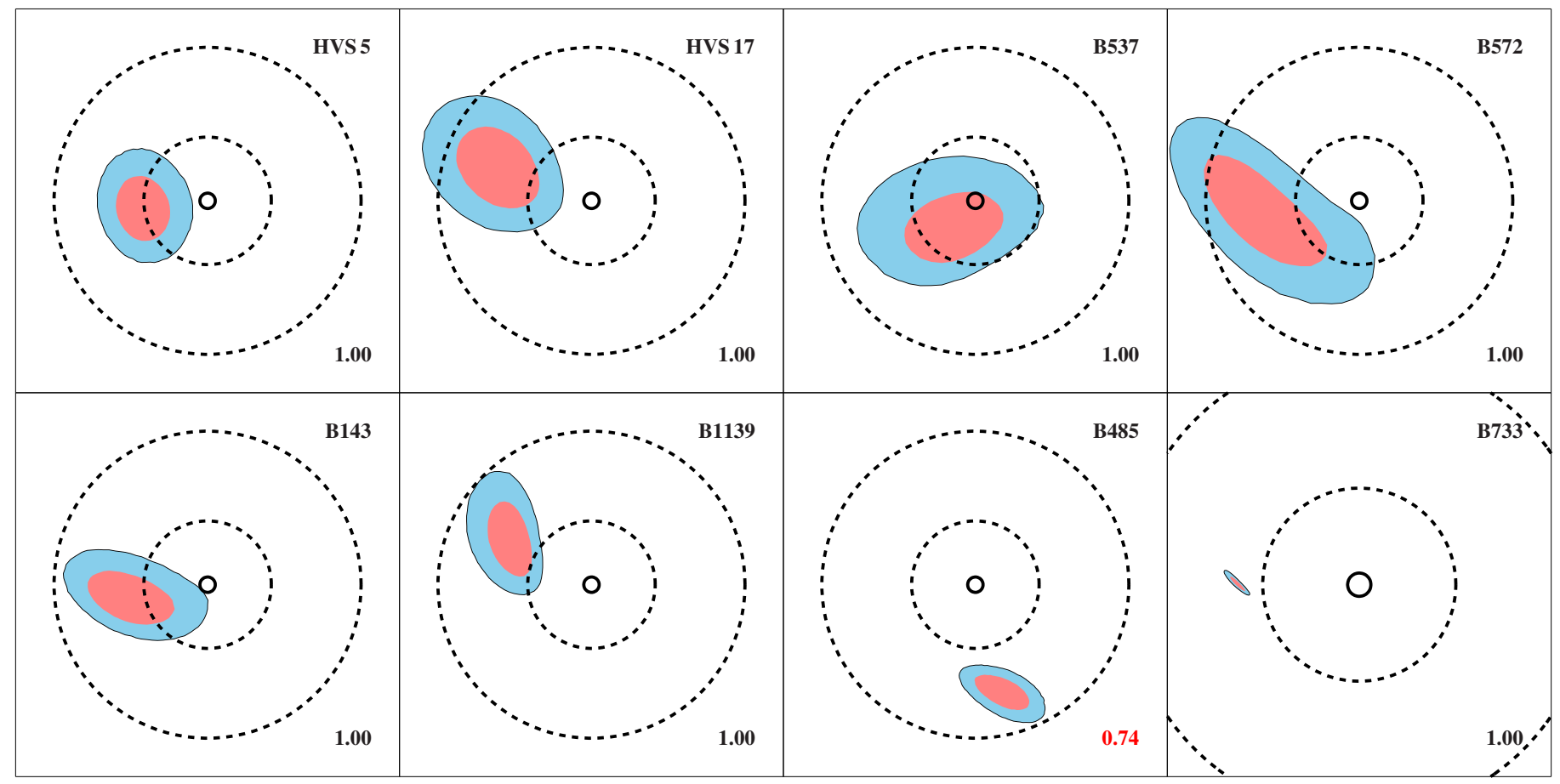

Fig. 11. Same as Fig. 8 but for objects for which an origin in the Galactic disk is very likely.

tion with the inferred atmospheric parameters, which place the object right between the ZAHB and the TAHB in the Kiel diagram (see Fig. 4), make it much more plausible that B576 is actually a low-mass BHB star, which would yield a smaller spectrophotometric distance $\left(18.7_{-1.5}^{+1.6} \mathrm{kpc}\right)$ and hence a lower current Galactic rest-frame velocity $\left(v_{\mathrm{Grf}}=330 \pm 10 \mathrm{~km} \mathrm{~s}^{-1}\right)$. Interestingly, the resulting trajectory (see Figs. 17) would have almost no angular momentum and thus very closely pass the GC, which would be quite uncommon for a halo star. A possible explanation for the lack of angular momentum would be that the star stems from the central region of the Milky Way. The inferred ejection velocity $\left(v_{\mathrm{ej}, \mathrm{p}}=730 \pm 80 \mathrm{~km} \mathrm{~s}^{-1}\right)$ would strongly hint at the Hills mechanism. Combined with how precisely the location of Galactic plane-crossing is known (see Fig. 16), B576 could be the second star after S5-HVS1 (Koposov et al. 2020) for which an origin in the GC could be confirmed. Despite its large ejection velocity, B576 would be gravitationally bound to the Milky Way due to the strong deceleration in the bulge region. Followup observations with large telescopes are needed to unravel the nature of this interesting object, for example, in order to deter- 


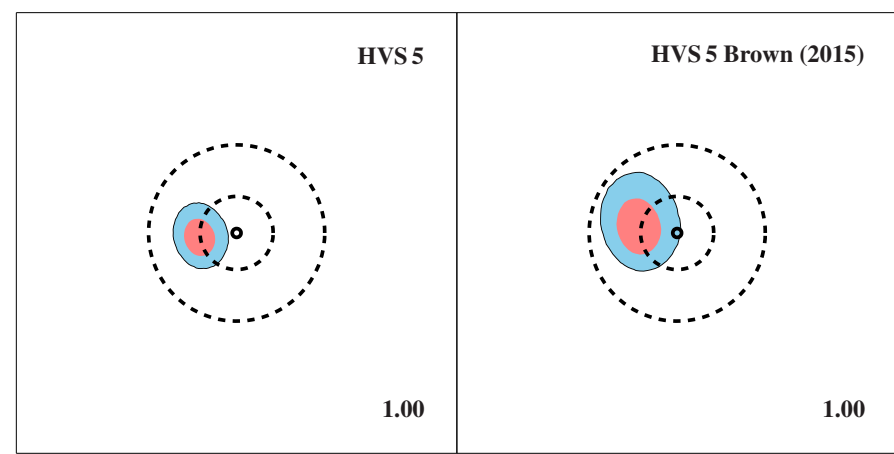

Fig. 12. Same as Fig. 8 but only for HVS 5. The sole difference in the two panels is the underlying distance, which is our value of $37 \pm 4 \mathrm{kpc}$ for the left panel and $45 \pm 5.2 \mathrm{kpc}$ (Brown et al. 2015) for the right panel. The smaller distance renders an origin in the GC even more unlikely.

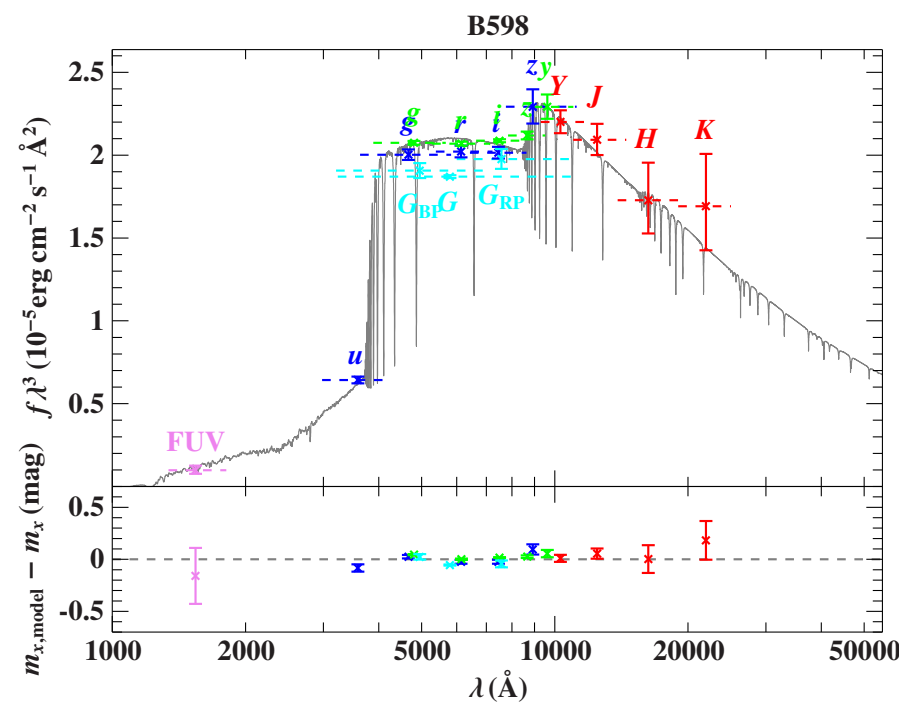

Fig. 13. Same as Fig. 6 but for B598. SDSS: blue; Pan-STARRS: green; UKIDSS: red; Gaia: cyan; GALEX: violet.

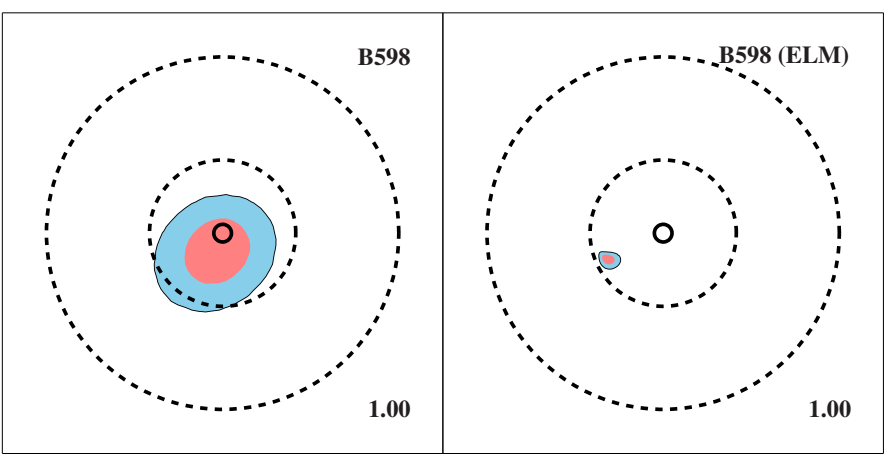

Fig. 14. Same as Fig. 8 but only for B598. The sole difference in the two panels is the underlying distance, which is $23 \pm 2 \mathrm{kpc}$ assuming a MS nature (left panel) and $6.5_{-0.9}^{+1.0} \mathrm{kpc}$ assuming a pre-ELM WD nature (right panel). A three-dimensional representation of the trajectory for the ELM version is shown in Fig. 15.

mine whether the chemical composition in the star's atmosphere is characteristic of BHB stars.

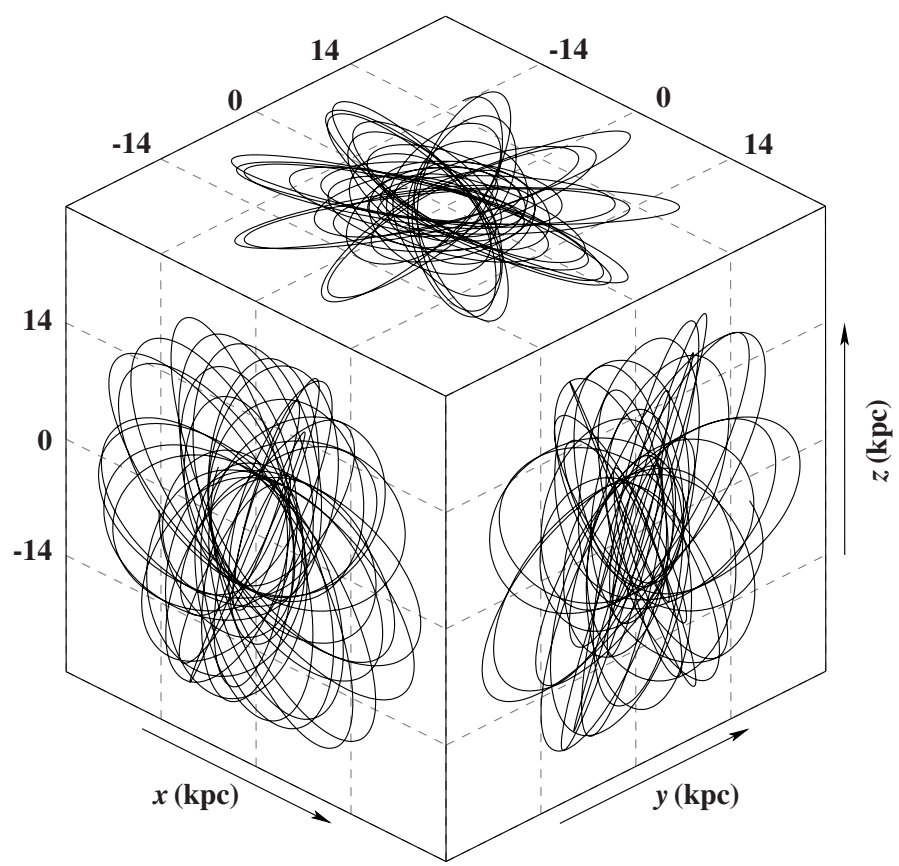

Fig. 15. Three-dimensional orbit of B598 assuming a typical (pre-)ELM WD mass of $0.2 M_{\odot}$ in the Galactic Cartesian coordinate system introduced in Sect. 6. The orbit is calculated $15 \mathrm{Gyr}$ back in time using Model I and is typical of a halo star.

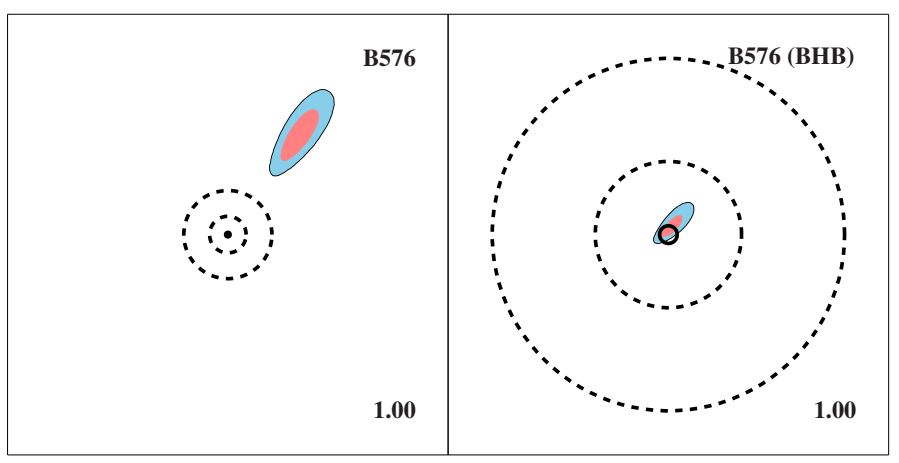

Fig. 16. Same as Fig. 8 but only for B576. The sole difference in the two panels is the underlying distance, which is $51 \pm 4 \mathrm{kpc}$ assuming a MS nature (left panel) and $18.7_{-15}^{+1.6} \mathrm{kpc}$ assuming a BHB nature (right panel). While the MS option suggests an extragalactic origin, the BHB option points to a GC origin. A three-dimensional representation of the trajectory for the BHB version is shown in Fig. 17.

\subsubsection{Bound Probabilities in different Galactic mass models}

The original MMT HVS sample identified 42 B-type stars whose Galactic rest-frame radial velocity exceeds $+275 \mathrm{~km} \mathrm{~s}^{-1}$, sixteen of which were considered bound to the Galaxy as indicated by their name starting with the letter "B". With new proper motions from Gaia DR2 being available, it is worthwhile to reconsider the bound probabilities of the sample. Whether a star is bound to the Galaxy or not is determined by the Galactic potential, in particular the mass of the Galactic dark matter halo.

The (analytic) representations for the different Galactic components that we use are consistent with various Gaia DR2 based studies (see Sect. 5.2). Except for three stars (B485, B576, B1085), all stars originally considered bound likely remain bound (probability $P_{\mathrm{b}}>5 \%$ ) irrespective of the choice of the Galactic mass model (see Tables A.1 and A.2). With $P_{\mathrm{b}}=$ $2 \%, \mathrm{~B} 485$ and B1085 would likely be unbound in the lighter 


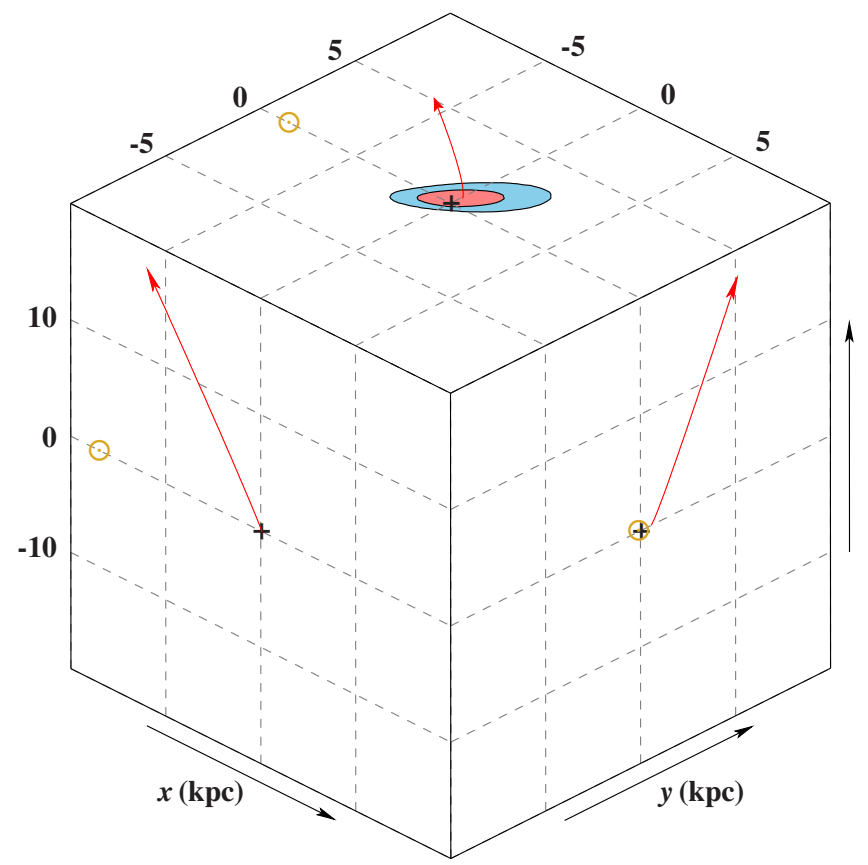

Fig. 17. Three-dimensional orbit (red line; the arrow indicates the current position of the star) of B576 assuming a typical BHB mass of $0.5 M_{\odot}$ in the Galactic Cartesian coordinate system introduced in Sect. 6. The meaning of the shaded areas is identical to Fig. 8. The positions of the Sun and the GC are marked by a yellow $\odot$ and a black + , respectively.

mass model II. B576 would be clearly unbound $\left(P_{\mathrm{b}}=0 \%\right)$ in both Galactic potentials if it were a MS star. However, it is more probable that the star is actually an evolved star of low mass that is bound to the Galaxy (Sect. 6.2.3).

It is worthwhile to also reconsider the stars originally considered unbound. We find two objects (HVS 15, HVS 24) that are possibly bound $\left(P_{\mathrm{b}}>5 \%\right)$ in both Galactic potentials and another four (HVS 7, HVS 8, HVS 16, HVS 17) for which this is the case at least in Model I.

\subsection{Discussion}

The main goal of our investigation was to pin down the place of origin of the program stars, determine their ejection velocities, and identify the ejection channel. The Hills mechanism would require the stars to be ejected from the GC. As demonstrated in Sect. 6.2.1, data quality is insufficient to provide constraints for 19 stars. When more precise measurements are available (Sects. 6.2.2 and 6.2.3) the favored places of origin are in the Galactic disk, for some it may even be its outer part rather than the inner. The GC is actually excluded for 16 stars with a significance of $2 \sigma$ or more. There remain two objects (B537 and B576) that may have been ejected from the GC. In particular, the star B576, which is most likely a BHB star, appears to be ejected close to the GC.

Ejection velocities have been derived for all stars of the kinematic sample. Those discussed in Sects. 6.2.1 and 6.2.2, however, have to be taken with a grain of salt because their places of origin are quite uncertain. Therefore we restrain the discussion here to the most reliable results (see Sect. 6.2.3). The ejection velocities for the eight stars (HVS 5, HVS 17, B143, B485, B572, B598, B733, and B1139) for which we excluded an origin in the GC and favor the Galactic disk, range from $270 \mathrm{~km} \mathrm{~s}^{-1}$ to
$670 \mathrm{~km} \mathrm{~s}^{-1}$ with HVS 5 being the fastest at $670_{-60}^{+80} \mathrm{~km} \mathrm{~s}^{-1}$. Ejection velocities in excess of $\sim 500 \mathrm{~km} \mathrm{~s}^{-1}$ are at variance with predictions of classical scenarios (binary supernova or dynamical cluster ejection; see Irrgang et al. 2019 for a detailed discussion). Interaction with intermediate-mass black holes have been suggested as a viable ejection process. However, evidence for the existence of intermediate-mass black holes is lacking.

The potential BHB star B576 is of particular interest because its ejection velocity of $730 \pm 80 \mathrm{~km} \mathrm{~s}^{-1}$ exceeds even that of HVS 5. Combined with its probable GC origin, this suggests that B576 has been ejected by the Hills mechanism. The highest velocity in the sample is that of HVS 22, which exceeds $1000 \mathrm{~km} \mathrm{~s}^{-1}$. However, its place of origin remains unconstrained. Nevertheless, the extraordinarily high speed favors the Hills mechanism and, hence, the GC. Its velocity is solely superseded by S5-HVS1, which is the only HVS for which a GC origin has been inferred beyond any reasonable doubt (Koposov et al. 2020).

\section{Summary and conclusion}

We carried out an extensive analysis of the sample of HVSs of Brown et al. (2014) using their spectra taken with the MMT, which we flux calibrated anew. State-of-the-art model atmospheres that take non-LTE effects into account were used to perform quantitative spectroscopic analyses of $40 \mathrm{HVS}$ candidates. Applying a well-tested fitting technique, we derived effective temperatures, surface gravities, and projected rotational velocities. The location of the stars on the predicted MS band along with their high projected rotational velocities supports the MS nature of all but two objects. B576 turns out to be most likely a BHB star and B598 is probably a very low-mass $\left(0.2 M_{\odot}\right)$ stripped red giant star evolving into a helium-core WD. Comparing the atmospheric parameters to predictions from evolutionary models, masses and ages were derived. SEDs were constructed to derive the spectrophotometric distances, which are the most important ingredients for a kinematic study but cannot be measured precisely enough by Gaia because the objects are too distant. However, the second data release of the Gaia mission provided proper motions of unprecedented precision and accuracy. Following the procedure already applied to 14 HVSs in Paper II, we studied the trajectories of 37 HVS candidates in two different Galactic gravitational potentials to trace their place of origin in the Galaxy. While the available data are still not precise enough to constrain the place of origin for 19 program stars, a group of eight stars unexpectedly appears to come from the outer rim of the Galactic disk. Nine stars (including B576) are identified to stem from the Galactic disk while B598 shows typical kinematics of a halo star. For almost all targets with reasonably wellconstrained spatial origin, the GC is discarded as possible place of origin. The most notable exception is the BHB star B576, the place of origin of which coincides very well with the GC. In addition, its very high ejection velocity of $730 \pm 80 \mathrm{~km} \mathrm{~s}^{-1}$ points to the Hills' slingshot as the most likely mechanism for acceleration. HVS 22 is by far the most extreme object in the sample. Although its origin is unconstrained, its current very high Galactic rest-frame velocity of $1530_{-560}^{+690} \mathrm{~km} \mathrm{~s}^{-1}$ hints at the Hills mechanism as the most plausible explanation.

Acknowledgements. We thank Warren Brown for providing the MMT spectra, Stephan Geier for organizing the X-shooter spectrum of B1085, and John E. Davis for the development of the SLXFIG module used to prepare the figures in this paper. Based on observations made with ESO Telescopes at the La Silla Paranal Observatory under programme ID 0102.D-0092(A). AI and UH acknowledge funding by the Deutsche Forschungsgemeinschaft (DFG) through 
grant IR190/1-1 and HE1356/71-1. This research has made use of the Keck Observatory Archive (KOA), which is operated by the W. M. Keck Observatory and the NASA Exoplanet Science Institute (NExScI), under contract with the National Aeronautics and Space Administration. This research has made use of NASA's Astrophysics Data System. This research has made use of the VizieR catalogue access tool, CDS, Strasbourg, France. This work has made use of data from the European Space Agency (ESA) mission Gaia (https://www. cosmos.esa.int/gaia), processed by the Gaia Data Processing and Analysis Consortium (DPAC, https://www. cosmos. esa.int/web/gaia/dpac/ consortium). Funding for the DPAC has been provided by national institutions, in particular the institutions participating in the Gaia Multilateral Agreement. Funding for SDSS-III has been provided by the Alfred P. Sloan Foundation, the Participating Institutions, the National Science Foundation, and the U.S. Department of Energy Office of Science. The SDSS-III web site is http: //www. sdss3.org/. SDSS-III is managed by the Astrophysical Research Consortium for the Participating Institutions of the SDSS-III Collaboration including the University of Arizona, the Brazilian Participation Group, Brookhaven National Laboratory, University of Cambridge, University of Florida, the French Participation Group, the German Participation Group, the Instituto de Astrofisica de Canarias, the Michigan State/Notre Dame/JINA Participation Group, Johns Hopkins University, Lawrence Berkeley National Laboratory, Max Planck Institute for Astrophysics, New Mexico State University, New York University, Ohio State University, Pennsylvania State University, University of Portsmouth, Princeton University, the Spanish Participation Group, University of Tokyo, University of Utah, Vanderbilt University, University of Virginia, University of Washington, and Yale University. The Pan-STARRS1 Surveys were made possible through contributions by the Institute for Astronomy, the University of Hawaii, the Pan-STARRS Project Office, the Max-Planck Society and its participating institutes, the Max Planck Institute for Astronomy, Heidelberg and the Max Planck Institute for Extraterrestrial Physics, Garching, The Johns Hopkins University, Durham University, the University of Edinburgh, the Queen's University Belfast, the Harvard-Smithsonian Center for Astrophysics, the Las Cumbres Observatory Global Telescope Network Incorporated, the National Central University of Taiwan, the Space Telescope Science Institute, and the National Aeronautics and Space Administration under Grant No. NNX08AR22G issued through the Planetary Science Division of the NASA Science Mission Directorate, the National Science Foundation Grant No. AST-1238877, the University of Maryland, Eotvos Lorand University (ELTE), and the Los Alamos Nationa Laboratory.The Pan-STARRS1 Surveys are archived at the Space Telescope Science Institute (STScI) and can be accessed through MAST, the Mikulski Archive for Space Telescopes. Additional support for the Pan-STARRS1 public science archive is provided by the Gordon and Betty Moore Foundation. The national facility capability for SkyMapper has been funded through ARC LIEF gran LE130100104 from the Australian Research Council, awarded to the University of Sydney, the Australian National University, Swinburne University of Technology, the University of Queensland, the University of Western Australia, the University of Melbourne, Curtin University of Technology, Monash University and the Australian Astronomical Observatory. SkyMapper is owned and operated by The Australian National University's Research School of Astronomy and Astrophysics. The survey data were processed and provided by the SkyMapper Team at ANU. The SkyMapper node of the All-Sky Virtual Observatory (ASVO) is hosted at the National Computational Infrastructure (NCI). Development and support the SkyMapper node of the ASVO has been funded in part by Astronomy Australia Limited (AAL) and the Australian Government through the Commonwealth's Education Investment Fund (EIF) and National Collaborative Research Infrastructure Strategy (NCRIS), particularly the National eResearch Collaboration Tools and Resources (NeCTAR) and the Australian National Data Service Projects (ANDS). This publication makes use of data products from the AAVSO Photometric All Sky Survey (APASS). Funded by the Robert Martin Ayers Sciences Fund and the National Science Foundation. Based on data products from observations made with ESO Telescopes at the La Silla Paranal Observatory under programme IDs 177.A-3016, 177.A-3017 and 177.A-3018, and on data products produced by Target/OmegaCEN, INAF-OACN, INAF-OAPD and the KiDS production team, on behalf of the KiDS consortium. OmegaCEN an the KiDS production team acknowledge support by NOVA and NWO-M grants. Members of INAF-OAPD and INAF-OACN also acknowledge the support from the Department of Physics \& Astronomy of the University of Padova, and of the Department of Physics of Univ. Federico II (Naples). This work is based in part on data obtained as part of the UKIRT Infrared Deep Sky Survey. We have used data from the VISTA Data Flow System pipeline processing and science archive, which are described in Irwin et al. (2004), Hambly et al. (2008) and Cross et al. (2012).

\section{References}

Abadi, M. G., Navarro, J. F., \& Steinmetz, M. 2009, ApJ, 691, L63 Alam, S., Albareti, F. D., Allende Prieto, C., et al. 2015, ApJS, 219, 12
Allen, C. \& Santillan, A. 1991, Rev. Mexicana Astron. Astrofis., 22, 255 Astraatmadja, T. L. \& Bailer-Jones, C. A. L. 2016, ApJ, 832, 137 Bailer-Jones, C. A. L. 2015, PASP, 127, 994

Bailer-Jones, C. A. L., Rybizki, J., Fouesneau, M., Mantelet, G., \& Andrae, R. 2018, AJ, 156, 58

Behr, B. B. 2003, ApJS, 149, 101

Bianchi, L., Shiao, B., \& Thilker, D. 2017, VizieR Online Data Catalog, II/335 Blaauw, A. 1961, Bull. Astron. Inst. Netherlands, 15, 265

Bohlin, R. C., Gordon, K. D., \& Tremblay, P. E. 2014, PASP, 126, 711

Boubert, D., Erkal, D., Evans, N. W., \& Izzard, R. G. 2017, MNRAS, 469, 2151 Boubert, D. \& Evans, N. W. 2016, ApJ, 825, L6

Boubert, D., Guillochon, J., Hawkins, K., et al. 2018, MNRAS, 479, 2789

Boubert, D., Strader, J., Aguado, D., et al. 2019, MNRAS, 486, 2618

Bromley, B. C., Kenyon, S. J., Brown, W. R., \& Geller, M. J. 2018, ApJ, 868, 25 Brown, W. R. 2015, ARA\&A, 53, 15

Brown, W. R., Anderson, J., Gnedin, O. Y., et al. 2015, ApJ, 804, 49

Brown, W. R., Cohen, J. G., Geller, M. J., \& Kenyon, S. J. 2012, ApJ, 754, L2

Brown, W. R., Geller, M. J., \& Kenyon, S. J. 2009, ApJ, 690, 1639

Brown, W. R., Geller, M. J., \& Kenyon, S. J. 2014, ApJ, 787, 89

Brown, W. R., Geller, M. J., Kenyon, S. J., \& Kurtz, M. J. 2005, ApJ, 622, L33

Brown, W. R., Geller, M. J., Kenyon, S. J., \& Kurtz, M. J. 2006, ApJ, 640, L35

Brown, W. R., Gianninas, A., Kilic, M., Kenyon, S. J., \& Allende Prieto, C. 2016, ApJ, 818, 155

Brown, W. R., Lattanzi, M. G., Kenyon, S. J., \& Geller, M. J. 2018, ApJ, 866, 39

Butler, K. \& Giddings, J. R. 1985, in Newsletter of Analysis of Astronomical Spectra, No. 9 (Univ. London)

Chambers, K. C., Magnier, E. A., Metcalfe, N., et al. 2016, arXiv e-prints, arXiv: 1612.05560

Cross, N. J. G., Collins, R. S., Mann, R. G., et al. 2012, A\&A, 548, A119

Cui, X.-Q., Zhao, Y.-H., Chu, Y.-Q., et al. 2012, Research in Astronomy and Astrophysics, 12, 1197

de Jong, J. T. A., Verdoes Kleijn, G. A., Erben, T., et al. 2017, A\&A, 604, A134

Dorman, B., Rood, R. T., \& O'Connell, R. W. 1993, ApJ, 419, 596

Du, C., Li, H., Yan, Y., et al. 2019, ApJS, 244, 4

Edelmann, H., Napiwotzki, R., Heber, U., Christlieb, N., \& Reimers, D. 2005, ApJ, 634, L181

Erkal, D., Boubert, D., Gualandris, A., Evans, N. W., \& Antonini, F. 2019, MNRAS, 483, 2007

Evans, D. W., Riello, M., De Angeli, F., et al. 2018, A\&A, 616, A4

Fitzpatrick, E. L. 1999, PASP, 111, 63

Gaia Collaboration, Brown, A. G. A., Vallenari, A., et al. 2018, A\&A, 616, A1

Geier, S., Fürst, F., Ziegerer, E., et al. 2015, Science, 347, 1126

Georgy, C., Ekström, S., Granada, A., et al. 2013, A\&A, 553, A24

Giddings, J. R. 1981, PhD thesis, , University of London, (1981)

Giesers, B., Kamann, S., Dreizler, S., et al. 2019, A\&A, 632, A3

Greenstein, J. L. 1966, ApJ, 144, 496

Greenstein, J. L. \& Sargent, A. I. 1974, ApJS, 28, 157

Gvaramadze, V. V., Gualandris, A., \& Portegies Zwart, S. 2009, MNRAS, 396, 570

Heber, U. 2016, PASP, 128, 082001

Heber, U., Irrgang, A., \& Schaffenroth, J. 2018, Open Astronomy, 27, 35

Heber, U., Moehler, S., Schmidt, J. H. K., et al. 1997, in The Third Conference on Faint Blue Stars, ed. A. G. D. Philip, J. Liebert, R. Saffer, \& D. S. Hayes, 87

Henden, A. A., Levine, S., Terrell, D., \& Welch, D. L. 2015, in American Astronomical Society Meeting Abstracts, Vol. 225, American Astronomical Society Meeting Abstracts \#225, 336.16

Hills, J. G. 1988, Nature, 331, 687

Hirsch, H. A., Heber, U., O’Toole, S. J., \& Bresolin, F. 2005, A\&A, 444, L61

Huang, Y., Liu, X. W., Zhang, H. W., et al. 2017, ApJ, 847, L9

Hubeny, I., Hummer, D. G., \& Lanz, T. 1994, A\&A, 282, 151

Hummer, D. G. \& Mihalas, D. 1988, ApJ, 331, 794

Irrgang, A., Geier, S., Heber, U., Kupfer, T., \& Fürst, F. 2019, A\&A, 628, L5

Irrgang, A., Kreuzer, S., \& Heber, U. 2018a, A\&A, 620, A48

Irrgang, A., Kreuzer, S., Heber, U., \& Brown, W. 2018b, A\&A, 615, L5

Irrgang, A., Przybilla, N., Heber, U., et al. 2014, A\&A, 565, A63

Irrgang, A., Wilcox, B., Tucker, E., \& Schiefelbein, L. 2013, A\&A, 549, A137

Keenan, F. P. \& Dufton, P. L. 1983, MNRAS, 205, 435

Koposov, S. E., Boubert, D., Li, T. S., et al. 2020, MNRAS, 491, 2465

Kurucz, R. L. 1993, SYNTHE spectrum synthesis programs and line data

Kurucz, R. L. 1996, in Astronomical Society of the Pacific Conference Series,

Vol. 108, M.A.S.S., Model Atmospheres and Spectrum Synthesis, ed. S. J. Adelman, F. Kupka, \& W. W. Weiss, 160

Lawrence, A., Warren, S. J., Almaini, O., et al. 2013, VizieR Online Data Cata$\log$, II $/ 319$

Li, T. S., Koposov, S. E., Zucker, D. B., et al. 2019, MNRAS, 490, 3508

Li, Y.-B., Luo, A. L., Zhao, G., et al. 2018, AJ, 156, 87

Lindegren, L. 2018, Re-normalising the astrometric chi-square in Gaia DR2, GAIA-C3-TN-LU-LL-124, wwW.rssd.esa.int/doc_fetch.php? id $=3757412$ 
Lindegren, L., Hernández, J., Bombrun, A., et al. 2018, A\&A, 616, A2

Lynn, B. B., Keenan, F. P., Dufton, P. L., et al. 2004a, MNRAS, 353, 633

Lynn, B. B., Keenan, F. P., Dufton, P. L., et al. 2004b, MNRAS, 349, 821

Maíz Apellániz, J. \& Weiler, M. 2018, A\&A, 619, A180

Marchetti, T., Rossi, E. M., \& Brown, A. G. A. 2019, MNRAS, 490, 157

Moehler, S., Modigliani, A., Freudling, W., et al. 2014, A\&A, 568, A9

Oh, S. \& Kroupa, P. 2016, A\&A, 590, A107

Patat, F., Moehler, S., O’Brien, K., et al. 2011, A\&A, 527, A91

Perets, H. B. \& Šubr, L. 2012, ApJ, 751, 133

Piffl, T., Williams, M., \& Steinmetz, M. 2011, A\&A, 535, A70

Portegies Zwart, S. F. 2000, ApJ, 544, 437

Poveda, A., Ruiz, J., \& Allen, C. 1967, Boletin de los Observatorios Tonantzintla y Tacubaya, 4,86

Przybilla, N., Nieva, M.-F., \& Butler, K. 2011, in Journal of Physics Conference

Series, Vol. 328, Journal of Physics Conference Series, 012015

Przybilla, N., Nieva, M. F., Heber, U., et al. 2008, A\&A, 480, L37

Raddi, R., Hollands, M. A., Koester, D., et al. 2019, MNRAS, 489, 1489

Ratzloff, J. K., Barlow, B. N., Kupfer, T., et al. 2019, ApJ, 883, 51

Saffer, R. A., Keenan, F. P., Hambly, N. C., Dufton, P. L., \& Liebert, J. 1997, ApJ, 491, 172

Shanks, T., Metcalfe, N., Chehade, B., et al. 2015, MNRAS, 451, 4238

Shen, K. J., Boubert, D., Gänsicke, B. T., et al. 2018, ApJ, 865, 15

Silva, M. D. V. \& Napiwotzki, R. 2011, MNRAS, 411, 2596

Tauris, T. M. 2015, MNRAS, 448, L6

Tobin, W. 1987, in IAU Colloq. 95: Second Conference on Faint Blue Stars, ed.

A. G. D. Philip, D. S. Hayes, \& J. W. Liebert, $149-158$

Tremblay, P. E. \& Bergeron, P. 2009, ApJ, 696, 1755

Vennes, S., Nemeth, P., Kawka, A., et al. 2017, Science, 357, 680

Vernet, J., Dekker, H., D’Odorico, S., et al. 2011, A\&A, 536, A105

Vogt, S. S., Allen, S. L., Bigelow, B. C., et al. 1994, Society of Photo-Optical Instrumentation Engineers (SPIE) Conference Series, Vol. 2198, HIRES: the high-resolution echelle spectrometer on the Keck 10-m Telescope, ed. D. L. Crawford \& E. R. Craine, 362

Wall, R. E., Kilic, M., Bergeron, P., et al. 2019, MNRAS, 489, 5046

Wilkinson, M. I. \& Evans, N. W. 1999, MNRAS, 310, 645

Wisotzki, L., Koehler, T., Groote, D., \& Reimers, D. 1996, A\&AS, 115, 227

Wolf, C., Onken, C. A., Luvaul, L. C., et al. 2019, VizieR Online Data Catalog, II $/ 358$

York, D. G., Adelman, J., Anderson, John E., J., et al. 2000, AJ, 120, 1579

Zheng, Z., Carlin, J. L., Beers, T. C., et al. 2014, ApJ, 785, L23

Zhou, X. 2005, Journal of Korean Astronomical Society, 38, 203

Zwicky, F. 1957, Morphological astronomy 
Appendix A: Kinematic Tables 
Table A.1. Kinematic quantities for the program stars based on Model I.

\begin{tabular}{|c|c|c|c|c|c|c|c|c|c|c|c|c|c|c|c|c|c|}
\hline Object & $x$ & (kpc) & $z$ & $v_{x}$ & $v_{y}$ & $\begin{array}{r}v_{z} \\
(\mathrm{~km} \mathrm{~s}\end{array}$ & $\begin{array}{l}v_{\text {Grf }} \\
-1\end{array}$ & $v_{\mathrm{Grf}}-v_{\mathrm{esc}}$ & $\begin{array}{r}P_{\mathrm{b}} \\
(\%)\end{array}$ & $x_{\mathrm{p}}$ & $\frac{y_{\mathrm{p}}}{(\mathrm{kpc})}$ & $z_{\mathrm{p}}$ & $r_{\mathrm{p}}$ & $v_{x, \mathrm{p}}$ & $\frac{v_{y, p}}{(k}$ & $\frac{v_{z, \mathrm{p}}{ }^{2}}{\left.\mathrm{~m} \mathrm{~s}^{-1}\right)}$ & $\begin{array}{l}v_{\mathrm{Grf}, \mathrm{p}} \\
)\end{array}$ \\
\hline$\overline{\text { HVS1 }}$ & $\begin{array}{ll}-101.4 \\
\end{array}$ & $2-100.9$ & 83.5 & $=0$ & $\overline{-340}$ & $\overline{450}$ & $\overline{710}$ & $\overline{400}$ & $\overline{0 .}$ & -26.5 & -34.5 & 0.0 & $\overline{c 66.1}$ & -450 & $\begin{array}{ll}-400 \\
\end{array}$ & 2480 & $\overline{780}$ \\
\hline Stat. & & $\begin{array}{c}+8.2 \\
+8.5\end{array}$ & & ${ }_{-160}^{+160}$ & ${ }_{-140}^{+130}$ & $\begin{array}{l}+170 \\
+170\end{array}$ & $\begin{array}{l}+70 \\
-40\end{array}$ & ${ }_{-40}^{+70}$ & & ${ }_{-37.6}^{+59.8}$ & ${ }_{-31.7}^{+50.8}$ & ${ }_{-0.0}^{+0.0}$ & $+\begin{array}{l}+33.0 \\
+32.0\end{array}$ & $\begin{array}{l}{ }_{-110}^{+170} \\
-\end{array}$ & ${ }_{-100}^{+150}$ & ${ }_{-100}^{+150}$ & ${ }_{-30}^{+40}$ \\
\hline HVS4 & -61.9 & -14.1 & 50.8 & -360 & -300 & 360 & 630 & 230 & 0 & -9.8 & 23.0 & 0.0 & 43.1 & -450 & -250 & 440 & 680 \\
\hline Stat. & & +1.1 & +4.5 & $\begin{array}{r}+180 \\
-180\end{array}$ & ${ }_{-180}^{+170}$ & +160 $+{ }_{-160}^{160}$ & $++_{-60}^{+110}$ & $\begin{array}{l}+110 \\
-60\end{array}$ & & $\begin{array}{l}+51.6 \\
-320\end{array}$ & 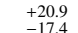 & ${ }_{-0}^{+0.0}$ & +27.6 & $\begin{array}{l}+210 \\
-90\end{array}$ & ++140 & ${ }_{-1120}^{+110}$ & ++70 \\
\hline HVS5 & -32.1 & 15.9 & 22.9 & $\begin{array}{r}-180 \\
-400\end{array}$ & $\begin{array}{r}-180 \\
310\end{array}$ & $\begin{array}{l}-160 \\
410\end{array}$ & $\begin{array}{l}-600 \\
650\end{array}$ & 190 & 0 & $\begin{array}{l}-32.0 \\
-8.6\end{array}$ & $\begin{array}{l}-17.4 \\
-1.1\end{array}$ & $\begin{array}{r}-0.0 \\
0.0\end{array}$ & $\begin{array}{l}-21.4 \\
9.1\end{array}$ & $\begin{array}{l}-510 \\
-510\end{array}$ & 330 & $\begin{array}{r}-120 \\
460\end{array}$ & 760 \\
\hline & +2 & ${ }_{-1.5}^{+1.7}$ & ${ }_{-2.1}^{+2.4}$ & ${ }_{-30}^{+30}$ & ${ }_{-50}^{+50}$ & $\begin{array}{l}+30 \\
+30\end{array}$ & ${ }_{-10}^{+10}$ & ${ }_{-20}^{+20}$ & & ${ }_{-2.3}^{+2.4}$ & ${ }_{-2.7}^{+2.9}$ & ${ }_{-0}^{+0.0}$ & +2.3 & ${ }_{-50}^{+40}$ & $+{ }_{-30}^{+40}$ & ${ }_{-20}^{+20}$ & $+{ }_{-20}^{+30}$ \\
\hline HVS5 (Brown 2015) & -37.6 & $\begin{array}{r}-1.5 \\
19.5\end{array}$ & 28.1 & $\begin{array}{l}-30 \\
-420\end{array}$ & 270 & $\begin{array}{r}-30 \\
420\end{array}$ & 650 & 210 & 0 & $\begin{array}{l}-2.3 \\
-8.8\end{array}$ & $\begin{array}{l}-2.7 \\
1.6\end{array}$ & $\begin{array}{r}-0.0 \\
0.0\end{array}$ & $\begin{array}{l}-2.3 \\
9.8\end{array}$ & $\begin{array}{l}-530 \\
-530\end{array}$ & $\begin{array}{l}-30 \\
310\end{array}$ & 480 & 770 \\
\hline & & ${ }_{-2.3}^{+2.3}$ & $\begin{array}{l}+3.3 \\
-3.3\end{array}$ & ${ }_{-40}^{+40}$ & ${ }_{-70}^{+60}$ & $+{ }_{-30}^{+40}$ & ${ }_{-10}^{+10}$ & ${ }_{-20}^{+20}$ & & $\begin{array}{l}+3.5 \\
-3.3\end{array}$ & $\begin{array}{l}+4.6 \\
-40\end{array}$ & +0.0 & +3.5 & +50 & +30 & +20 & +40 \\
\hline HVS6 & -20.4 & -23.6 & 45.0 & -150 & -150 & 450 & 530 & $\begin{array}{r}-20 \\
90\end{array}$ & 0 & $\begin{array}{l}-3.3 \\
-4.4\end{array}$ & $\begin{array}{l}-4.0 \\
-7.0\end{array}$ & $\begin{array}{r}-0.0 \\
0.0\end{array}$ & 17.2 & -220 & -240 & 560 & 640 \\
\hline Stat. & & & +4.5 & ${ }_{-160}^{+160}$ & ${ }_{-120}^{+120}$ & +80 & $\begin{array}{l}+60 \\
-30\end{array}$ & $\begin{array}{l}+60 \\
{ }_{-30}\end{array}$ & & $\begin{array}{r}+15.0 \\
-139\end{array}$ & $\begin{array}{l}+12.7 \\
{ }_{-112}\end{array}$ & +0.0 & $\begin{array}{l}+11.4 \\
-91\end{array}$ & $\begin{array}{r}+150 \\
+\quad 80\end{array}$ & $\begin{array}{l}+130 \\
+130\end{array}$ & +40 & $\begin{array}{r}+50 \\
+50\end{array}$ \\
\hline HVS7 & -11.1 & -25.1 & 40.3 & $\begin{array}{l}-100 \\
-200\end{array}$ & $\begin{array}{r}-120 \\
-10\end{array}$ & 450 & 500 & $\begin{array}{l}-30 \\
50\end{array}$ & 7 & $\begin{array}{r}r 3.9 \\
6.0\end{array}$ & $\begin{array}{r}-21.2 \\
-21.8\end{array}$ & $\begin{array}{r}-0.0 \\
0.0\end{array}$ & 23.8 & $\begin{array}{r}-80 \\
-200\end{array}$ & $\begin{array}{l}-60 \\
-100\end{array}$ & $\begin{array}{r}-50 \\
510\end{array}$ & 560 \\
\hline St & +0.3 & $\begin{array}{l}+2.1 \\
-2.5\end{array}$ & $\begin{array}{r}+3.9 \\
-3.3\end{array}$ & $\begin{array}{l}+90 \\
+90\end{array}$ & $\begin{array}{l}{ }_{-50}^{50} \\
-50\end{array}$ & $\begin{array}{l}{ }_{-40}^{40} \\
\text {. }\end{array}$ & $\begin{array}{l}{ }_{-40}^{+50} \\
\end{array}$ & $\begin{array}{l}{ }_{-40}^{+50} \\
\end{array}$ & .. & $\begin{array}{l}+8.2 \\
-7.0\end{array}$ & ${ }_{-4.9}^{4.7}$ & ${ }_{-0.0}^{+0.0}$ & $\begin{array}{l}+5.4 \\
-4.7\end{array}$ & $\begin{array}{l}+70 \\
{ }_{-80}\end{array}$ & $\begin{array}{l}+60 \\
-60\end{array}$ & ${ }_{-20}^{+30}$ & $\begin{array}{l}+30 \\
-20\end{array}$ \\
\hline HVS8 & -2 & $\begin{array}{l}-2.5 \\
\end{array}$ & 26.3 & -410 & $\begin{array}{r}-30 \\
80\end{array}$ & 260 & 500 & 40 & 18 & 8.5 & -16.1 & 0.0 & 19.1 & -450 & $\begin{array}{l}-60 \\
-40\end{array}$ & 350 & 570 \\
\hline Stat. & & $\begin{array}{l}-1.0 \\
1.1\end{array}$ & ${ }_{-2.0}^{+2.2}$ & $\begin{array}{l}{ }_{-60}^{+60} \\
-60\end{array}$ & $\begin{array}{l}+60 \\
-60\end{array}$ & $\begin{array}{l}+40 \\
-40\end{array}$ & $\begin{array}{l}{ }_{-40}^{50} \\
-40\end{array}$ & $\begin{array}{l}+50 \\
-40\end{array}$ & & $\begin{array}{l}+9.8 \\
-7.5\end{array}$ & $\begin{array}{l}{ }_{-5.4}^{4.9} \\
\end{array}$ & ${ }_{-0.0}^{+0.0}$ & $\begin{array}{l}+8.2 \\
+8.7 \\
-5.7\end{array}$ & $\begin{array}{l}+30 \\
-40\end{array}$ & $\begin{array}{l}+70 \\
-70\end{array}$ & ${ }_{-40}^{+30}$ & $\begin{array}{l}+20 \\
-10\end{array}$ \\
\hline HVS9 & -44.8 & -70.6 & 80.9 & 50 & -170 & 520 & 710 & 350 & 0 & -47.8 & -40.5 & $\begin{array}{r}-0.0 \\
0.0\end{array}$ & 94.7 & $\begin{array}{r}-40 \\
0\end{array}$ & -230 & 550 & 710 \\
\hline St & & ${ }_{-7.4}^{+7.1}$ & $\begin{array}{l}+8.5 \\
-8.1\end{array}$ & $\begin{array}{l}+420 \\
-420\end{array}$ & $\begin{array}{l}+300 \\
{ }_{-300}^{3}\end{array}$ & $\begin{array}{l}+250 \\
+250\end{array}$ & $\begin{array}{l}+280 \\
-180\end{array}$ & $\begin{array}{l}+280 \\
-180\end{array}$ & 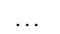 & $\begin{array}{l}{ }_{-610}^{70.8} \\
\end{array}$ & $\begin{array}{l}+78.1 \\
-449\end{array}$ & +0.0 & $\begin{array}{r}+49.2 \\
-374\end{array}$ & $\begin{array}{r}+440 \\
-35\end{array}$ & $\begin{array}{l}+310 \\
+-240\end{array}$ & $\begin{array}{l}+230 \\
-190\end{array}$ & $\begin{array}{c}+270 \\
-120\end{array}$ \\
\hline$\$ 10$ & -14.5 & $\begin{array}{l}-16.4 \\
-16.8\end{array}$ & $\begin{array}{r}-8.1 \\
70.2\end{array}$ & $\begin{array}{l}-420 \\
-250\end{array}$ & $\begin{array}{r}-190 \\
-190\end{array}$ & $\begin{array}{l}-250 \\
360\end{array}$ & 500 & $\begin{array}{r}-180 \\
90\end{array}$ & 1 & $\begin{array}{l}-61.0 \\
24.8\end{array}$ & $\begin{array}{l}-41.9 \\
14.1\end{array}$ & $\begin{array}{r}-0.0 \\
0.0\end{array}$ & $\begin{array}{l}-3.4 \\
35.9\end{array}$ & $\begin{array}{r}-190 \\
-190\end{array}$ & $\begin{array}{l}-240 \\
-160\end{array}$ & $\begin{array}{r}-190 \\
490\end{array}$ & $\begin{array}{l}-5120 \\
570\end{array}$ \\
\hline St & & $\begin{array}{l}+1.6 \\
-1.6\end{array}$ & $\begin{array}{l}+6.6 \\
-6.64\end{array}$ & $\begin{array}{l}+130 \\
-140\end{array}$ & $\begin{array}{l}+140 \\
-110\end{array}$ & $\begin{array}{l}+40 \\
-40\end{array}$ & $\begin{array}{l}+90 \\
-60\end{array}$ & $\begin{array}{l}+90 \\
-60\end{array}$ & & $\begin{array}{l}+24.7 \\
-190\end{array}$ & $\begin{array}{l}+27.0 \\
-195\end{array}$ & ${ }_{-00}^{+0.0}$ & $\begin{array}{l}+27.7 \\
-19 .\end{array}$ & $\begin{array}{r}+80 \\
-130\end{array}$ & $\begin{array}{l}+70 \\
+120\end{array}$ & $\begin{array}{l}+60 \\
+60\end{array}$ & $\begin{array}{l}+50 \\
-20\end{array}$ \\
\hline 12 & $\begin{array}{r}-0.6 \\
-26.2\end{array}$ & $\begin{array}{l}-1.6 \\
-42.1\end{array}$ & 59.5 & $\begin{array}{l}-140 \\
-50\end{array}$ & $\begin{array}{r}-150 \\
70\end{array}$ & $\begin{array}{l}-40 \\
550\end{array}$ & $\begin{array}{l}-60 \\
570\end{array}$ & $\begin{array}{l}-60 \\
170\end{array}$ & 0 & $\begin{array}{r}-19.0 \\
-19.4\end{array}$ & $\begin{array}{r}-19.5 \\
-46.5\end{array}$ & $\begin{array}{r}-0.0 \\
0.0\end{array}$ & 52.1 & $\begin{array}{l}-130 \\
-80\end{array}$ & $\begin{array}{r}-120 \\
10\end{array}$ & 580 & 600 \\
\hline & & ${ }_{-4.5}^{+4.0}$ & +6.4 & ${ }_{-130}^{+130}$ & $\begin{array}{l}+110 \\
{ }_{-110}\end{array}$ & $\begin{array}{l}+80 \\
-80\end{array}$ & $\begin{array}{l}+100 \\
-80\end{array}$ & $\begin{array}{l}+100 \\
-80\end{array}$ & & $\begin{array}{l}{ }_{-13.0}^{+13.6} \\
\text {. }\end{array}$ & $\begin{array}{l}+12.2 \\
-12.1\end{array}$ & ${ }_{-0.0}^{+0.0}$ & $\begin{array}{l}+12.3 \\
-12.3\end{array}$ & $\begin{array}{l}+130 \\
{ }_{-120}\end{array}$ & $\begin{array}{l}+120 \\
{ }_{-120}\end{array}$ & $\begin{array}{l}+80 \\
+80\end{array}$ & $\begin{array}{l}+80 \\
+-50\end{array}$ \\
\hline 13 & -32.4 & $\begin{array}{l}-72.1 \\
-4.5\end{array}$ & 92.7 & $\begin{array}{r}-130 \\
-660\end{array}$ & -40 & 340 & 780 & 430 & 0 & $\begin{array}{l}123.0 \\
123.6\end{array}$ & -53.3 & $\begin{array}{r}-0.0 \\
0.0\end{array}$ & $\begin{array}{l}-1.36 .7 \\
\end{array}$ & $\begin{array}{r}-120 \\
-610\end{array}$ & $\begin{array}{l}-120 \\
-100\end{array}$ & $\begin{array}{l}-70 \\
400\end{array}$ & $\begin{array}{l}-50 \\
760\end{array}$ \\
\hline & & & $\begin{array}{l}+7.6 \\
+-8.6\end{array}$ & $\begin{array}{l}+220 \\
{ }_{-230}\end{array}$ & $\begin{array}{l}+200 \\
{ }_{-200}^{2}\end{array}$ & $\begin{array}{l}+150 \\
-150\end{array}$ & $\begin{array}{l}+210 \\
-{ }_{-180}\end{array}$ & $\begin{array}{l}+220 \\
-180\end{array}$ & 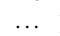 & $\begin{array}{l}+122.7 \\
-655\end{array}$ & $\begin{array}{l}+77.0 \\
-43.2\end{array}$ & ${ }_{-00}^{+0.0}$ & $\begin{array}{l}+111.9 \\
-555\end{array}$ & $\begin{array}{l}+220 \\
{ }_{-240}\end{array}$ & $\begin{array}{l}+210 \\
{ }_{-190}\end{array}$ & $\begin{array}{r}+130 \\
+140\end{array}$ & $\begin{array}{l}+210 \\
-160\end{array}$ \\
\hline HVS15 & -10.5 & -34.2 & 50.7 & $\begin{array}{l}-200 \\
-60\end{array}$ & $\begin{array}{l}-160 \\
\end{array}$ & 280 & 450 & $\begin{array}{r}-100 \\
30\end{array}$ & 41 & $\begin{array}{l}-65.5 \\
-0.1\end{array}$ & $\begin{array}{l}-45.2 \\
-3.7\end{array}$ & $\begin{array}{r}-0.0 \\
0.0\end{array}$ & $\begin{array}{r}-53.5 \\
-44.6\end{array}$ & $\begin{array}{l}-240 \\
-80\end{array}$ & $\begin{array}{l}-190 \\
-240\end{array}$ & $\begin{array}{r}-140 \\
410\end{array}$ & $\begin{array}{l}-160 \\
510\end{array}$ \\
\hline & $\begin{array}{l}+0.3 \\
0.3\end{array}$ & $\begin{array}{l}+3.6 \\
-4.1\end{array}$ & ${ }_{-5.3}^{6.1}$ & $\begin{array}{l}+340 \\
-350\end{array}$ & $\begin{array}{l}+190 \\
-190\end{array}$ & $\begin{array}{l}{ }^{+140} \\
-140\end{array}$ & $\begin{array}{l}+210 \\
-100\end{array}$ & $\begin{array}{l}+210 \\
{ }_{-100}^{210}\end{array}$ & 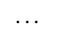 & $\begin{array}{l}{ }_{-42.4}^{63.4} \\
-n^{2}\end{array}$ & $\begin{array}{l}{ }_{-28.7}^{+48.6} \\
\text {. }\end{array}$ & ${ }_{-0.0}^{+0.0}$ & $\begin{array}{l}+50.2 \\
-25.1\end{array}$ & $\begin{array}{l}+300 \\
-240\end{array}$ & $\begin{array}{l}+190 \\
+990\end{array}$ & $\begin{array}{c}+80 \\
{ }_{-140}^{80}\end{array}$ & $\begin{array}{l}+130 \\
-\quad 50\end{array}$ \\
\hline HVS16 & -1.5 & -24.2 & 60.4 & -270 & -470 & 210 & 680 & 260 & 10 & 51.7 & 76.7 & 0.0 & 126.2 & -210 & -420 & 300 & 640 \\
\hline & +0.7 & $\begin{array}{l}+2.22 \\
-2.2\end{array}$ & $\begin{array}{l}{ }_{-5.5}^{5.5} \\
-5.3\end{array}$ & $\begin{array}{l}{ }_{-480}^{4} 880 \\
-4\end{array}$ & $\begin{array}{l}{ }_{-250}^{240} \\
{ }_{-25}\end{array}$ & $\begin{array}{l}+90 \\
+100 \\
-100\end{array}$ & $\begin{array}{l}+350 \\
+3230 \\
-230\end{array}$ & $\begin{array}{l}+360 \\
-230\end{array}$ & & $\begin{array}{l}{ }_{-}^{+123.7} . \\
-93.3\end{array}$ & $\begin{array}{l}+128.2 \\
-59.7\end{array}$ & ${ }_{-0.0}^{+0.0}$ & $\begin{array}{l}+159.0 \\
-77.1\end{array}$ & $\begin{array}{l}{ }^{+340} \\
-490\end{array}$ & $\begin{array}{l}+210 \\
-240\end{array}$ & $\begin{array}{l}+110 \\
-110\end{array}$ & $\begin{array}{l}+340 \\
-150\end{array}$ \\
\hline 817 & $\begin{array}{l}-0.0 \\
-0.8\end{array}$ & 25.6 & 23.3 & 190 & 280 & $\begin{array}{l}-100 \\
310\end{array}$ & 460 & $\begin{array}{l}-200 \\
-20\end{array}$ & 83 & $\begin{array}{l}-12.3 \\
\end{array}$ & 4.2 & $\begin{array}{l}-0.0 \\
0.0\end{array}$ & 13.4 & $\begin{array}{l}-400 \\
110\end{array}$ & $\begin{array}{l}-240 \\
380\end{array}$ & $\begin{array}{l}-1100 \\
400\end{array}$ & $\begin{array}{l}-150 \\
560\end{array}$ \\
\hline $\mathrm{St}$ & & ${ }_{-20}^{+2.1}$ & ${ }_{-1.8}^{+1.9}$ & $\begin{array}{l}+60 \\
-60\end{array}$ & $\begin{array}{l}{ }_{-40}^{3} \\
\end{array}$ & $\begin{array}{l}+30 \\
+-30\end{array}$ & $\begin{array}{l}+20 \\
-20\end{array}$ & $\begin{array}{l}+30 \\
{ }_{-20}\end{array}$ & & $\begin{array}{r}+3.4 \\
-3.8\end{array}$ & $\begin{array}{l}+3.7 \\
-3.4\end{array}$ & ${ }_{-00}^{+0.0}$ & +4.1 & $\begin{array}{l}+70 \\
-70\end{array}$ & $\begin{array}{l}+40 \\
-40\end{array}$ & $\begin{array}{l}+30 \\
+20\end{array}$ & $\begin{array}{l}+30 \\
-10\end{array}$ \\
\hline & -28.7 & 83.5 & $\begin{array}{r}-1.8 \\
-43.3\end{array}$ & $\begin{array}{r}-60 \\
30\end{array}$ & 470 & $\begin{array}{l}-30 \\
-130\end{array}$ & 560 & $\begin{array}{l}-20 \\
190\end{array}$ & 0 & $\begin{array}{l}-34.2 \\
-34.8\end{array}$ & $\begin{array}{l}-37.4 \\
-27.6\end{array}$ & $\begin{array}{r}-0.0 \\
0.0\end{array}$ & 77.3 & $\begin{array}{l}-70 \\
-70\end{array}$ & $\begin{array}{r}-40 \\
470\end{array}$ & -240 & 570 \\
\hline St & & $\begin{array}{l}+8.7 \\
-75\end{array}$ & $\begin{array}{l}+3.9 \\
-4.5\end{array}$ & $\begin{array}{l}+300 \\
-300\end{array}$ & $\begin{array}{l}+130 \\
{ }_{-130}\end{array}$ & $\begin{array}{l}+200 \\
{ }_{-200}\end{array}$ & $\begin{array}{l}+160 \\
-90\end{array}$ & $\begin{array}{l}+160 \\
-900\end{array}$ & & $\begin{array}{r}+64.9 \\
-704\end{array}$ & $\begin{array}{r}+63.2 \\
+-197\end{array}$ & ${ }_{-0}^{+0.0}$ & $\begin{array}{l}+185.5 \\
-404\end{array}$ & $\begin{array}{l}+310 \\
{ }_{-160}\end{array}$ & $\begin{array}{l}+80 \\
-60\end{array}$ & $\begin{array}{l}+140 \\
{ }_{-130}\end{array}$ & $\begin{array}{r}+100 \\
-70\end{array}$ \\
\hline & $\begin{array}{l}-2.1 \\
-17.6\end{array}$ & $\begin{array}{r}-7.5 \\
-36.9\end{array}$ & 77.0 & $\begin{array}{l}-300 \\
-230\end{array}$ & $\begin{array}{r}-1130 \\
90\end{array}$ & $\begin{array}{l}-200 \\
560\end{array}$ & $\begin{array}{l}-90 \\
920\end{array}$ & 540 & 0 & 11.9 & $\begin{array}{l}-191.7 \\
-44.5\end{array}$ & $\begin{array}{r}-0.0 \\
0.0\end{array}$ & $\begin{array}{l}-40.4 \\
98.1\end{array}$ & $\begin{array}{l}-160 \\
-210\end{array}$ & $\begin{array}{l}-60 \\
50\end{array}$ & $\begin{array}{r}-130 \\
610\end{array}$ & 910 \\
\hline Stat & & ${ }_{-4.5}^{+4.5}$ & $\begin{array}{l}+9.3 \\
-9.2\end{array}$ & $\begin{array}{l}+750 \\
-760\end{array}$ & $\begin{array}{l}{ }_{-400}^{4410} \\
{ }^{2}\end{array}$ & $\begin{array}{l}+220 \\
+220\end{array}$ & $\begin{array}{l}+4700 \\
-300\end{array}$ & $\begin{array}{l}+470 \\
-300\end{array}$ & 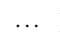 & $\begin{array}{r}+130.9 \\
-86.3\end{array}$ & ${ }_{-40.8}^{+67.2}$ & ${ }_{-0.0}^{+0.0}$ & $\begin{array}{l}+86.5 \\
-44.4\end{array}$ & $\begin{array}{r}+700 \\
+730 \\
-730\end{array}$ & $\begin{array}{l}+410 \\
-460\end{array}$ & $\begin{array}{l}+200 \\
{ }_{-200}\end{array}$ & $\begin{array}{l}+450 \\
+460\end{array}$ \\
\hline 20 & -15.0 & -50.8 & 90.2 & $\begin{array}{r}-100 \\
40\end{array}$ & 300 & 620 & 970 & 600 & 0 & -18.8 & -86.8 & $\begin{array}{r}-0.0 \\
0.0\end{array}$ & 127.3 & $\begin{array}{r}r, 50 \\
10\end{array}$ & 260 & 650 & 960 \\
\hline $\mathrm{St}_{2}$ & $\begin{array}{l}+0.9 \\
-0.7\end{array}$ & $\begin{array}{l}+6.3 \\
{ }_{-46}\end{array}$ & $\begin{array}{r}+8.2 \\
{ }_{-11 .}\end{array}$ & $\begin{array}{l}+720 \\
-720\end{array}$ & $\begin{array}{l}+410 \\
{ }_{-440}\end{array}$ & $\begin{array}{l}+240 \\
+240\end{array}$ & $\begin{array}{l}+480 \\
-360\end{array}$ & $\begin{array}{l}+480 \\
-360\end{array}$ & & $\begin{array}{r}+111.3 \\
{ }_{-926}\end{array}$ & $\begin{array}{l}+61.5 \\
{ }_{-37.5}\end{array}$ & ${ }_{-00}^{+0.0}$ & $\begin{array}{l}+59.9 \\
-452\end{array}$ & $\begin{array}{r}+720 \\
-6770\end{array}$ & $\begin{array}{l}+420 \\
-410\end{array}$ & $\begin{array}{l}+230 \\
{ }_{-200}\end{array}$ & $+4+40$ \\
\hline 21 & $\begin{array}{r}-0.1 \\
-60.2\end{array}$ & $\begin{array}{l}-4.6 \\
13.6\end{array}$ & $\begin{array}{l}-11.1 \\
79.8\end{array}$ & $\begin{array}{l}-120 \\
-130\end{array}$ & 200 & 360 & 590 & $\begin{array}{l}-300 \\
220\end{array}$ & 0 & $\begin{array}{r}-92.6 \\
-28.4\end{array}$ & -22.3 & $\begin{array}{r}-0.0 \\
0.0\end{array}$ & 87.3 & $\begin{array}{l}-200 \\
-200\end{array}$ & $\begin{array}{l}-410 \\
150\end{array}$ & $\begin{array}{l}-200 \\
450\end{array}$ & 590 \\
\hline $\mathrm{St}$ & $\begin{array}{l}+5.3 \\
-6.2\end{array}$ & ${ }_{-1.4}^{+1.7}$ & $\begin{array}{l}{ }_{-8.1}^{+9.5} \\
\end{array}$ & $\begin{array}{l}+290 \\
+290\end{array}$ & $\begin{array}{l}+370 \\
{ }_{-3}^{3}\end{array}$ & $\begin{array}{l}+_{-220}^{220} \\
-20\end{array}$ & $\begin{array}{l}+250 \\
-{ }_{-150}\end{array}$ & ${ }_{-150}^{+250}$ & , & $\begin{array}{r}+108.8 \\
-50.9\end{array}$ & $\begin{array}{l}{ }_{-120.6}^{+60.7} \\
\end{array}$ & ${ }_{-0.0}^{+0.0}$ & $\begin{array}{l}+95.1 \\
-4.1 .7\end{array}$ & $\begin{array}{l}+310 \\
{ }_{-190}^{3}\end{array}$ & $\begin{array}{l}+330 \\
-290\end{array}$ & $\begin{array}{l}+160 \\
+200\end{array}$ & $\begin{array}{l}+200 \\
-770\end{array}$ \\
\hline HVS22 & -13.7 & -45.4 & 86.2 & -380 & 730 & 910 & 1530 & 1150 & 0 & 21.1 & -108.5 & 0.0 & 139.1 & $\begin{array}{l}-370 \\
-370\end{array}$ & 700 & 920 & 1520 \\
\hline & $\begin{array}{l}+0.8 \\
-0.9\end{array}$ & $\begin{array}{l}+6.5 \\
-6.6\end{array}$ & $\begin{array}{l}+14.4 \\
-12.3\end{array}$ & $\begin{array}{l}{ }_{-970}^{+950} \\
\end{array}$ & $\begin{array}{l}{ }_{-560}^{+590} \\
{ }^{2}\end{array}$ & $\begin{array}{l}+320 \\
-310 \\
-310\end{array}$ & $\begin{array}{l}{ }_{-560}^{690} \\
{ }^{6}\end{array}$ & $\begin{array}{l}+690 \\
-6560\end{array}$ & & $\begin{array}{l}+114.2 \\
-83.0\end{array}$ & $\begin{array}{l}+46 . \\
-39 .\end{array}$ & ${ }_{-0.0}^{+0.0}$ & $\begin{array}{l}{ }_{-43.6}^{62.9} \\
\end{array}$ & $\begin{array}{l}{ }^{+9300} \\
-9600\end{array}$ & $\begin{array}{l}{ }^{+600} \\
-560\end{array}$ & $\begin{array}{l}+320 \\
-290\end{array}$ & $\begin{array}{l}+680 \\
-6500\end{array}$ \\
\hline HVS24 & -17.1 & -35.4 & 51.2 & 80 & -90 & 390 & 460 & 40 & 33 & -23.1 & -20.6 & $\begin{array}{r}-0.0 \\
0.0\end{array}$ & $\begin{array}{l}-4.0 .0 \\
40.1\end{array}$ & 10 & $\begin{array}{l}-300 \\
-170\end{array}$ & $\begin{array}{l}-290 \\
460\end{array}$ & $\begin{array}{l}5300 \\
520\end{array}$ \\
\hline & ${ }_{-0.8}^{+0.8}$ & $\begin{array}{l}+3.2 \\
+30\end{array}$ & $\begin{array}{l}{ }_{-46}^{+4.4} \\
\end{array}$ & $\begin{array}{l}+230 \\
+230\end{array}$ & $\begin{array}{l}+140 \\
{ }_{-150}^{14}\end{array}$ & $\begin{array}{l}{ }_{-1110}^{+110} \\
-10\end{array}$ & $\begin{array}{l}+140 \\
-80\end{array}$ & $\begin{array}{l}+140 \\
-80\end{array}$ & $\ldots$ & $\begin{array}{l}+26.9 \\
-260\end{array}$ & $\begin{array}{l}+23.7 \\
-17 .\end{array}$ & ${ }_{-0.0}^{+0.0}$ & $\begin{array}{l}+20.5 \\
-192\end{array}$ & $\begin{array}{r}+250 \\
-177\end{array}$ & $\begin{array}{l}+160 \\
-120\end{array}$ & +80 & $\begin{array}{l}+90 \\
-40\end{array}$ \\
\hline B095 & -43.6 & 16.1 & 45.3 & $\begin{array}{l}-230 \\
-120\end{array}$ & $\begin{array}{l}-150 \\
470\end{array}$ & $\begin{array}{l}-1100 \\
100\end{array}$ & 550 & 130 & 22 & $\begin{array}{l}-26.0 \\
-6.0\end{array}$ & $\begin{array}{r}-82.2 \\
-82.2\end{array}$ & $\begin{array}{r}-0.0 \\
0.0\end{array}$ & 95.5 & $\begin{array}{l}-180 \\
-180\end{array}$ & $\begin{array}{l}-120 \\
350\end{array}$ & $\begin{array}{l}-60 \\
220\end{array}$ & $\begin{array}{l}-40 \\
480\end{array}$ \\
\hline & 35 & $\begin{array}{l}{ }_{-16}^{+1.6} \\
\end{array}$ & $\begin{array}{l}+4.5 \\
-4.5\end{array}$ & $\begin{array}{l}+200 \\
-200\end{array}$ & $\begin{array}{l}+230 \\
+-230\end{array}$ & $\begin{array}{l}{ }^{+180} \\
-180\end{array}$ & $\begin{array}{l}+210 \\
-{ }_{-170}\end{array}$ & $\begin{array}{r}+210 \\
-170\end{array}$ & & $\begin{array}{l}+115.3 \\
-443\end{array}$ & $\begin{array}{l}+61 . \\
-197\end{array}$ & ${ }^{+0.0}$ & $\begin{array}{l}+216.9 \\
-493\end{array}$ & $\begin{array}{l}+190 \\
-100\end{array}$ & $\begin{array}{l}+210 \\
-190\end{array}$ & $\begin{array}{l}+130 \\
+{ }_{-130}\end{array}$ & +150 \\
\hline & -84.1 & $\begin{array}{r}-1.0 \\
-21.8\end{array}$ & 33.8 & -190 & $\begin{array}{l}-250 \\
-60\end{array}$ & 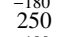 & $\begin{array}{l}-170 \\
390\end{array}$ & $\begin{array}{r}-170 \\
10\end{array}$ & 47 & $\begin{array}{l}-44.3 \\
-54.8\end{array}$ & $\begin{array}{l}-107.1 \\
-10.7\end{array}$ & $\begin{array}{r}-0.0 \\
0.0\end{array}$ & $\begin{array}{r}-49.3 \\
67.9\end{array}$ & $\begin{array}{r}-100 \\
-260\end{array}$ & $\begin{array}{l}-190 \\
-90\end{array}$ & $\begin{array}{r}-130 \\
270\end{array}$ & 470 \\
\hline $\mathrm{St}$ & $\begin{array}{l}+6.8 \\
-69\end{array}$ & ${ }_{-20}^{+2.0}$ & $\begin{array}{l}+3.1 \\
-3.1\end{array}$ & $\begin{array}{l}+120 \\
-120\end{array}$ & $\begin{array}{l}+200 \\
{ }_{-200}^{2}\end{array}$ & $\begin{array}{l}+190 \\
-190\end{array}$ & $\begin{array}{l}+150 \\
-80\end{array}$ & $\begin{array}{l}+150 \\
-80\end{array}$ & & $\begin{array}{l}+73.2 \\
-23.3\end{array}$ & $\begin{array}{l}+21.8 \\
-244\end{array}$ & +0.0 & +19.8 & $\begin{array}{l}+150 \\
{ }_{-1}^{1} 0\end{array}$ & $\begin{array}{l}+150 \\
-170\end{array}$ & $\begin{array}{r}+180 \\
-110\end{array}$ & $\begin{array}{l}+110 \\
-50\end{array}$ \\
\hline & -30.8 & 7.9 & 16.1 & $\begin{array}{r}-120 \\
-200\end{array}$ & 120 & $\begin{array}{l}-190 \\
180\end{array}$ & 290 & $\begin{array}{l}-190 \\
-190\end{array}$ & 100 & $\begin{array}{l}-23.3 \\
-10.2\end{array}$ & $\begin{array}{l}-24.4 \\
-1.9\end{array}$ & $\begin{array}{r}-0.0 \\
0.0\end{array}$ & $\begin{array}{l}-263 \\
10.6\end{array}$ & $\begin{array}{r}-3120 \\
-370\end{array}$ & $\begin{array}{l}-170 \\
120\end{array}$ & $\begin{array}{l}-110 \\
240\end{array}$ & $\begin{array}{l}-50 \\
460\end{array}$ \\
\hline $\mathrm{St}$ & ${ }_{-20}^{+1.8}$ & +0.7 & $\begin{array}{l}+1.5 \\
+1.3\end{array}$ & ${ }_{-20}^{+20}$ & $\begin{array}{l}{ }_{-30}^{+30} \\
\end{array}$ & $\begin{array}{l}+30 \\
+-30\end{array}$ & $\begin{array}{l}+10 \\
-10\end{array}$ & $\begin{array}{r}+10 \\
-10\end{array}$ & & $\begin{array}{l}+4.0 \\
-4.6\end{array}$ & ${ }_{-22}^{+2.4}$ & ${ }_{-00}^{+0.0}$ & $\begin{array}{l}+3.3 \\
{ }_{-3}\end{array}$ & $\begin{array}{l}+50 \\
+-60\end{array}$ & $\begin{array}{l}+20 \\
-20\end{array}$ & $\begin{array}{l}+20 \\
-10\end{array}$ & $\begin{array}{l}+50 \\
-40\end{array}$ \\
\hline B1 1 & -32.5 & $\begin{array}{l}-0.7 \\
-2.7\end{array}$ & 22.0 & $\begin{array}{l}-280 \\
-280\end{array}$ & $\begin{array}{l}-310 \\
210\end{array}$ & 130 & 370 & $\begin{array}{l}-100 \\
-100\end{array}$ & 99 & $\begin{array}{r}-3.6 \\
8.3\end{array}$ & -22.1 & $\begin{array}{r}-0.0 \\
0.0\end{array}$ & 24.2 & $\begin{array}{l}-60 \\
-360\end{array}$ & $\begin{array}{l}-20 \\
70\end{array}$ & 230 & 430 \\
\hline $\mathrm{St}$ & ${ }_{-2.0}^{+1.8}$ & ${ }_{-0.3}^{+0.2}$ & $\begin{array}{l}{ }_{-1.7}^{1.8} \\
-\end{array}$ & $\begin{array}{l}{ }_{-40}^{40} \\
-40\end{array}$ & $\begin{array}{l}{ }_{-50}^{+50} \\
\end{array}$ & $\begin{array}{l}{ }_{-40}^{40} \\
-40\end{array}$ & ${ }_{-40}^{+40}$ & $\begin{array}{l}+40 \\
-40\end{array}$ & 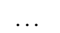 & $\begin{array}{l}+11.0 \\
-83\end{array}$ & $\begin{array}{r}+5.8 \\
-5.4\end{array}$ & ${ }_{-00}^{+0.0}$ & $\begin{array}{l}+10.5 \\
-667\end{array}$ & ${ }_{-10}^{+10}$ & $\begin{array}{l}+60 \\
-60\end{array}$ & $\begin{array}{l}+30 \\
+30\end{array}$ & $+{ }_{-20}^{+10}$ \\
\hline B. & 40.7 & $\begin{array}{l}-0.3 \\
16.6\end{array}$ & 51.5 & $\begin{array}{l}-40 \\
160\end{array}$ & $\begin{array}{l}-500 \\
\end{array}$ & 330 & 480 & 70 & 33 & 12.6 & 45.2 & $\begin{array}{r}-0.0 \\
0.0\end{array}$ & 57.2 & 220 & -160 & 390 & 000 \\
\hline $\mathrm{St}$ & $\begin{array}{l}{ }_{-5.3}^{6.3} \\
\text {. }\end{array}$ & ${ }_{-1.8}^{+2.1}$ & $\begin{array}{l}{ }_{-5.6}^{+6.6} \\
\end{array}$ & $\begin{array}{l}+160 \\
-160\end{array}$ & ${ }_{-220}^{+2210}$ & $\begin{array}{l}+^{+160} \\
-150\end{array}$ & $\begin{array}{l}+19 \\
-14\end{array}$ & $\begin{array}{l}+190 \\
-140\end{array}$ & & $\begin{array}{l}+24.9 \\
-41.7\end{array}$ & $\begin{array}{l}+36 . \\
-28.6\end{array}$ & ${ }_{-0.0}^{+0.0}$ & $\begin{array}{l}+34.5 \\
-25.2\end{array}$ & $\begin{array}{l}+100 \\
-160\end{array}$ & $\begin{array}{l}+220 \\
-240\end{array}$ & $\begin{array}{l}+1130 \\
-110\end{array}$ & $\begin{array}{l}+160 \\
+\quad 70 \\
-70\end{array}$ \\
\hline B434 & -16.2 & -22.8 & 33.7 & 130 & -280 & 210 & 38 & -80 & 92 & -25.4 & 14.7 & 0.0 & 30.8 & 0 & -280 & 310 & 430 \\
\hline & ${ }_{-0.7}^{+0.6}$ & $\begin{array}{l}+1.7 \\
{ }_{-2.1}\end{array}$ & $\begin{array}{l}{ }_{-2.4}^{3} .1 \\
\end{array}$ & $\begin{array}{l}{ }_{-80}^{+80} \\
-\end{array}$ & $\begin{array}{l}+60 \\
-60\end{array}$ & ${ }_{-40}^{40}$ & $\begin{array}{l}{ }_{-40}^{+50} \\
-40\end{array}$ & $\begin{array}{l}{ }_{-40}^{+60} \\
\end{array}$ & & $\begin{array}{r}+9.4 \\
-10.5\end{array}$ & $\begin{array}{l}+12.6 \\
-99.0\end{array}$ & ${ }_{-0.0}^{+0.0}$ & $\begin{array}{l}+12.5 \\
-9.5\end{array}$ & $\begin{array}{l}+90 \\
{ }_{-90}^{+90}\end{array}$ & $\begin{array}{l}{ }_{-40}^{330} \\
\end{array}$ & $\begin{array}{l}{ }_{-40}^{+30} \\
\end{array}$ & $\begin{array}{l}+20 \\
-10\end{array}$ \\
\hline D & -26.8 & -52.5 & 61.5 & 170 & -20 & 430 & 570 & 180 & 17 & -45.1 & -44.8 & $\begin{array}{r}-0.0 \\
0.0\end{array}$ & 79.8 & 110 & $\begin{array}{l}-40 \\
-80\end{array}$ & $\begin{array}{l}-40 \\
460\end{array}$ & 570 \\
\hline & $\begin{array}{l}{ }_{-23}^{+2.0} \\
\end{array}$ & $\begin{array}{l}+5.7 \\
-64\end{array}$ & $\begin{array}{l}+7.5 \\
-67\end{array}$ & $\begin{array}{l}+360 \\
{ }_{-350}\end{array}$ & $\begin{array}{l}+220 \\
{ }_{-220}\end{array}$ & $\begin{array}{l}+210 \\
+200\end{array}$ & $\begin{array}{l}+27 \\
-19\end{array}$ & $\begin{array}{l}{ }_{-190}^{280} \\
-\end{array}$ & 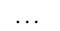 & $\begin{array}{l}+49.4 \\
-462\end{array}$ & $\begin{array}{l}+48.8 \\
-265\end{array}$ & ${ }_{-00}^{+0.0}$ & $\begin{array}{l}+33.6 \\
+29.6\end{array}$ & $\begin{array}{l}{ }_{-}^{3} 370 \\
-300\end{array}$ & $\begin{array}{l}+240 \\
-200\end{array}$ & $\begin{array}{l}+190 \\
+-140\end{array}$ & $\begin{array}{l}+260 \\
+260\end{array}$ \\
\hline B481 & -6.1 & 28.7 & -36.4 & -220 & -30 & -400 & 460 & 10 & 45 & $\begin{array}{l}-46.2 \\
12.5\end{array}$ & 27.5 & $\begin{array}{r}-0.0 \\
0.0\end{array}$ & 30.6 & $\begin{array}{l}-2100 \\
-20\end{array}$ & 60 & $\begin{array}{l}-140 \\
-450\end{array}$ & $\begin{array}{l}-130 \\
500\end{array}$ \\
\hline & +0.3 & $\begin{array}{l}{ }_{-3.1}^{+3.0} \\
\end{array}$ & $\begin{array}{l}+3.9 \\
{ }_{-3.7}\end{array}$ & $\begin{array}{l}{ }_{-80}^{70} \\
-x^{2}\end{array}$ & $\begin{array}{l}{ }_{-60}^{+60} \\
\end{array}$ & $\begin{array}{l}{ }_{-50}^{50} \\
-50\end{array}$ & $\begin{array}{l}+80 \\
-70\end{array}$ & $\begin{array}{l}+90 \\
{ }_{-70}^{90}\end{array}$ & & $\begin{array}{l}+6.0 \\
-5.4\end{array}$ & $\begin{array}{l}+7.7 \\
-7.6\end{array}$ & ${ }_{-00}^{+0.0}$ & $\begin{array}{r}+8.5 \\
-8.5\end{array}$ & $\begin{array}{l}+70 \\
+-70\end{array}$ & +80 & $\begin{array}{l}+40 \\
+40\end{array}$ & $\begin{array}{l}+60 \\
-40\end{array}$ \\
\hline$B_{2}$ & -26.8 & $\begin{array}{l}-6.1 \\
-6.0\end{array}$ & 27.4 & -330 & 140 & 270 & 450 & $\begin{array}{l}-20 \\
-20\end{array}$ & 91 & 4.2 & -14.7 & 0.0 & 15.4 & $\begin{array}{l}-390 \\
-390\end{array}$ & $\begin{array}{l}-80 \\
20\end{array}$ & 380 & 540 \\
\hline $\mathrm{St}$ & & ${ }_{-06}^{+0.5}$ & ${ }_{-2.1}^{2+.4}$ & $\begin{array}{l}+30 \\
+30\end{array}$ & ${ }_{-20}^{+20}$ & $\begin{array}{l}+20 \\
-20\end{array}$ & ${ }_{-20}^{+20}$ & $\begin{array}{l}+20 \\
{ }_{-20}\end{array}$ & & $\begin{array}{l}+3.4 \\
-2.8\end{array}$ & ${ }_{-2.0}^{+1.7}$ & ${ }_{-0.0}^{+0.0}$ & $\begin{array}{l}+2.8 \\
-2.1\end{array}$ & $\begin{array}{l}+10 \\
{ }_{-10}^{10}\end{array}$ & $\begin{array}{l}+30 \\
+30\end{array}$ & ${ }_{-20}^{+10}$ & $\begin{array}{l}+10 \\
-10\end{array}$ \\
\hline B5 & -22.0 & $\begin{array}{r}-0.6 \\
28.2\end{array}$ & -26.8 & $\begin{array}{l}-120 \\
-120\end{array}$ & 240 & -180 & 320 & -130 & 100 & $\begin{array}{l}-2.8 \\
\end{array}$ & $\begin{array}{l}-2 . \\
-3.1\end{array}$ & $\begin{array}{r}-0.0 \\
0.0\end{array}$ & 5.5 & $\begin{array}{l}-10 \\
-300\end{array}$ & 300 & -370 & 570 \\
\hline $\mathrm{St}$ & $\begin{array}{l}+1.6 \\
-{ }_{-1.9}\end{array}$ & $\begin{array}{l}{ }_{-3.3}^{3.8} \\
-3.3\end{array}$ & $\begin{array}{l}+3.1 \\
+3.7 \\
-3\end{array}$ & $\begin{array}{l}{ }_{-50}^{+50} \\
-50\end{array}$ & $\begin{array}{l}+30 \\
{ }_{-30}^{3}\end{array}$ & $\begin{array}{l}+20 \\
-30\end{array}$ & ${ }_{-20}^{+20}$ & $\begin{array}{l}+20 \\
-20\end{array}$ & & $\begin{array}{l}+3.8 \\
-4.7\end{array}$ & $\begin{array}{l}+3.1 \\
-2 .\end{array}$ & ${ }_{-0.0}^{+0.0}$ & $\begin{array}{l}+3.8 \\
-28\end{array}$ & $\begin{array}{l}+80 \\
-50\end{array}$ & $\begin{array}{l}+60 \\
-50\end{array}$ & $\begin{array}{l}{ }_{-90}^{60} \\
\end{array}$ & $\begin{array}{l}+70 \\
-60\end{array}$ \\
\hline B. & -21.6 & 18.9 & -14.0 & -70 & 250 & -170 & 320 & -170 & 100 & -12.5 & -1. & 0.0 & 13.2 & $\begin{array}{l}-220 \\
\end{array}$ & 300 & -230 & 430 \\
\hline Stat & $\begin{array}{l}+1.4 \\
-20\end{array}$ & $\begin{array}{l}+2.9 \\
-20\end{array}$ & $\begin{array}{l}+1.5 \\
-21.5\end{array}$ & $\begin{array}{l}{ }_{-50}^{50} \\
\end{array}$ & $\begin{array}{l}+30 \\
+30\end{array}$ & $\begin{array}{l}+50 \\
-50\end{array}$ & + & $\begin{array}{l}+30 \\
-20\end{array}$ & $\ldots$ & $\begin{array}{l}{ }_{-48.8}^{5.8} \\
-n^{2}\end{array}$ & $\begin{array}{l}{ }_{-47}^{4.8} \\
\end{array}$ & ${ }_{-00}^{+0.0}$ & $\begin{array}{l}{ }_{-4.5}^{4.5} \\
\end{array}$ & $\begin{array}{l}{ }_{-90}^{+80} \\
\end{array}$ & +20 & $\begin{array}{l}{ }_{-30}^{+20} \\
\end{array}$ & $\begin{array}{l}+50 \\
-30\end{array}$ \\
\hline B57 & $\begin{array}{l}-1 . \\
-1 .\end{array}$ & $\begin{array}{l}-2.0 \\
14.1\end{array}$ & $\begin{array}{l}-2.1 \\
48.9\end{array}$ & $\begin{array}{r}-360 \\
-360\end{array}$ & $\begin{array}{l}-350 \\
-350\end{array}$ & $\begin{array}{l}-50 \\
460\end{array}$ & & 240 & 0 & $\begin{array}{r}-4.8 \\
32.9\end{array}$ & $\begin{array}{l}-4.7 \\
46.0\end{array}$ & $\begin{array}{r}-0.0 \\
0.0\end{array}$ & 56.8 & $\begin{array}{r}-330 \\
-330\end{array}$ & $\begin{array}{l}-390 \\
-390\end{array}$ & 510 & 670 \\
\hline & -0 & $\begin{array}{l}{ }_{-1.1}^{1.1} \\
\end{array}$ & $\begin{array}{l}+3.8 \\
-3.6\end{array}$ & $\begin{array}{l}+50 \\
-50\end{array}$ & $\begin{array}{l}+60 \\
-60\end{array}$ & $\begin{array}{l}+30 \\
-20\end{array}$ & $\begin{array}{l}+7 \\
-6\end{array}$ & $\begin{array}{l}+70 \\
-70\end{array}$ & & +6.11 & $\begin{array}{l}+8.2 \\
-7.2\end{array}$ & ${ }_{-00}^{+0.0}$ & $\begin{array}{l}+9.6 \\
+89\end{array}$ & $\begin{array}{l}+50 \\
-50\end{array}$ & $\begin{array}{l}+60 \\
-70\end{array}$ & $\begin{array}{l}+20 \\
-20\end{array}$ & +60 \\
\hline & $\begin{array}{l}-6.0 \\
-6.0\end{array}$ & $\begin{array}{l}-1.1 \\
5.2\end{array}$ & 17.8 & $\begin{array}{l}-310 \\
-110\end{array}$ & $\begin{array}{r}-60 \\
70\end{array}$ & 300 & 330 & -200 & 100 & 0.1 & 0.6 & $\begin{array}{r}-0.0 \\
0.0\end{array}$ & 1.0 & $\begin{array}{l}-50 \\
-170\end{array}$ & $\begin{array}{l}-70 \\
200\end{array}$ & 590 & 650 \\
\hline Stat & & ${ }_{-0.4}^{+0.5}$ & ${ }_{-1.4}^{+1.6}$ & ${ }_{-20}^{+20}$ & $\begin{array}{l}{ }_{-30}^{+30} \\
-30\end{array}$ & $\begin{array}{l}+10 \\
-10\end{array}$ & - & $\begin{array}{l}+20 \\
-20\end{array}$ & & -0.8 & ${ }_{-0}^{+1}$ & -0.0 & $\begin{array}{l}+1.0 \\
-0.6\end{array}$ & $\begin{array}{l}+60 \\
-110\end{array}$ & $\begin{array}{l}{ }_{-70}^{40} \\
\end{array}$ & $\begin{array}{l}{ }_{-40}^{60} \\
-40\end{array}$ & $\begin{array}{l}+80 \\
-80\end{array}$ \\
\hline B598 & 1. & -0.5 & 20.4 & 40 & 50 & 300 & 3 & $\begin{array}{l}-210 \\
-210\end{array}$ & 100 & $\begin{array}{l}-0.8 \\
-0.7\end{array}$ & $\begin{array}{l}-0.8 \\
-2.1\end{array}$ & $\begin{array}{r}-0.0 \\
0.0\end{array}$ & 3.4 & 30 & -20 & 550 & 550 \\
\hline & +0.7 & +0.1 & +1.4 & $\begin{array}{l}{ }_{-60}^{+60} \\
\text {. }\end{array}$ & $\begin{array}{l}{ }_{-60}^{60} \\
-60\end{array}$ & +30 & + & $\begin{array}{l}+30 \\
-20\end{array}$ & & ${ }_{-2.6}^{+2.4}$ & ${ }_{-2.2}^{+2 .}$ & ${ }_{-00}^{+0.0}$ & $\begin{array}{l}+2.5 \\
-19\end{array}$ & ${ }_{-40}^{+40}$ & ${ }_{-40}^{+40}$ & ${ }_{-6}^{+6}$ & $\begin{array}{l}+60 \\
-60\end{array}$ \\
\hline B598 (ELI & $\begin{array}{l}-0.1 \\
-5.5\end{array}$ & $\begin{array}{l}-0.1 \\
-0.1\end{array}$ & $\begin{array}{r}-1.3 \\
5.8\end{array}$ & $\begin{array}{l}-600 \\
110\end{array}$ & $\begin{array}{l}-60 \\
190\end{array}$ & 270 & 350 & $\begin{array}{l}-260 \\
-260\end{array}$ & 100 & $\begin{array}{l}-2.6 \\
-6.7\end{array}$ & $\begin{array}{r}-2.6 \\
-3.4\end{array}$ & $\begin{array}{r}-0.0 \\
0.0\end{array}$ & 7.5 & $\begin{array}{r}40 \\
0\end{array}$ & $\begin{array}{l}-40 \\
160\end{array}$ & $\begin{array}{r}-600 \\
340\end{array}$ & $\begin{array}{l}-60 \\
380\end{array}$ \\
\hline & $5+05$ & +0.1 & +0 & ${ }_{-20}^{+20}$ & ${ }_{-20}^{+20}$ & $\begin{array}{l}{ }_{-10}^{+10} \\
-\end{array}$ & + & ${ }_{-10}^{+20}$ & & ${ }_{-0.5}^{+0.6}$ & ${ }_{-0 .}^{+0 .}$ & ${ }_{-0.0}^{+0.0}$ & $+{ }_{-0.5}^{+0.4}$ & ${ }_{-20}^{+20}$ & ${ }_{-30}^{+20}$ & ${ }_{-20}^{+20}$ & +20 \\
\hline B711 & 1 & 0.4 & 20.8 & 340 & 90 & 150 & 380 & -150 & 100 & -23.4 & $\begin{array}{l}-0 . \\
-6 .\end{array}$ & 0.0 & 24.3 & 210 & 60 & 290 & 370 \\
\hline Sta & +0 & ${ }_{-0.1}^{+0.1}$ & +1.6 & $\begin{array}{l}{ }_{-30}^{+30} \\
-30\end{array}$ & $\begin{array}{l}{ }_{-30}^{+30} \\
-30\end{array}$ & ${ }_{-20}^{+20}$ & $\begin{array}{l}+20 \\
-20\end{array}$ & $\begin{array}{l}+30 \\
-20\end{array}$ & & $\begin{array}{l}+3.5 \\
-4.4\end{array}$ & +1 & ${ }_{-0.0}^{+0.0}$ & $\begin{array}{l}+4.4 \\
-3.5\end{array}$ & $\begin{array}{l}+30 \\
{ }_{-30}^{3}\end{array}$ & +20 & $\begin{array}{l}+20 \\
-20\end{array}$ & $\begin{array}{l}+10 \\
-10\end{array}$ \\
\hline B73. & -4.9 & 4.0 & 11.0 & 260 & 150 & 360 & 47 & -100 & 100 & -11.0 & -0. & 0.0 & 11.0 & 160 & 170 & 430 & 490 \\
\hline Stat & ${ }_{-0.3}^{+0.3}$ & ${ }_{-0.3}^{+0.3}$ & ${ }_{-0.8}^{+0.8}$ & $\begin{array}{l}+20 \\
+20\end{array}$ & $\begin{array}{l}+20 \\
-20\end{array}$ & $\begin{array}{l}+10 \\
{ }_{-10}^{+10}\end{array}$ & ${ }_{-1}^{+1}$ & $\begin{array}{l}+10 \\
+10\end{array}$ & & $\begin{array}{l}{ }_{-0.5}^{+0.5} \\
\text {. }\end{array}$ & $\begin{array}{l}+0.5 \\
-0.5\end{array}$ & ${ }_{-00}^{+0.0}$ & 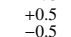 & $\begin{array}{l}+20 \\
+20\end{array}$ & $\begin{array}{l}+20 \\
-20\end{array}$ & ${ }_{-10}^{+10}$ & $\begin{array}{l}+10 \\
+10\end{array}$ \\
\hline & $\begin{array}{l}-0.3 .3 \\
-2.1\end{array}$ & $\begin{array}{l}-0.3 \\
-33.7\end{array}$ & $\begin{array}{r}-0.8 \\
38.2\end{array}$ & -250 & -230 & $\begin{array}{l}-10 \\
180\end{array}$ & $\overline{4}$ & $\begin{array}{l}-10 \\
-30\end{array}$ & 67 & 15 & 1. & $\begin{array}{r}-0.0 \\
0.0\end{array}$ & 24.4 & -210 & -290 & 350 & 500 \\
\hline Stat. & ${ }_{-1.2}^{+1.1}$ & $\begin{array}{l}+2.5 \\
-28\end{array}$ & $\begin{array}{l}+3.2 \\
-3.9\end{array}$ & ${ }_{-130}^{+130}$ & $\begin{array}{l}+100 \\
{ }_{-1}^{100}\end{array}$ & $\begin{array}{l}{ }_{-1110}^{110} \\
-110\end{array}$ & \pm & $\begin{array}{l}+90 \\
-50\end{array}$ &.. & $\begin{array}{r}+35.0 \\
-1176\end{array}$ & $\begin{array}{l}+32 . \\
-18\end{array}$ & ${ }_{-00}^{+0.0}$ & $\begin{array}{l}+40.9 \\
-142\end{array}$ & $\begin{array}{l}+60 \\
-80\end{array}$ & $\begin{array}{l}+50 \\
-40\end{array}$ & $\begin{array}{l}+70 \\
-710 \\
-120\end{array}$ & $\begin{array}{l}+60 \\
-40\end{array}$ \\
\hline & $\begin{array}{l}-1.25 \\
-8.5\end{array}$ & -28.7 & 31.1 & $\begin{array}{r}-130 \\
-380\end{array}$ & $\begin{array}{l}-260 \\
-260\end{array}$ & $\begin{array}{l}1100 \\
190\end{array}$ & 5 & 40 & 21 & 34.5 & 18. & 0.0 & 35.9 & -280 & -320 & 300 & 520 \\
\hline Stat. & ${ }_{-0.1}^{+0.1}$ & ${ }_{-2.5}^{2.3 .3}$ & + & $\begin{array}{l}{ }_{-60}^{+60} \\
\text {. }\end{array}$ & $\begin{array}{l}+30 \\
{ }_{-40}\end{array}$ & $\begin{array}{l}{ }_{-30}^{30} \\
-30\end{array}$ & $\begin{array}{l}{ }_{-50}^{+50} \\
\end{array}$ & ${ }_{-50}^{+60}$ & $\cdots$ & 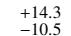 & +8 & ${ }_{-00}^{+0.0}$ & 年- & $\begin{array}{l}+60 \\
-70\end{array}$ & +20 & $\begin{array}{l}+40 \\
-40\end{array}$ & $\begin{array}{l}+30 \\
-20\end{array}$ \\
\hline B1139 & -2.8 & 21.9 & 12.0 & 160 & 200 & 170 & 310 & -200 & 100 & -10.9 & 5.8 & 0.0 & 12.6 & 70 & 330 & 230 & 410 \\
\hline Stat. & ${ }_{-06}^{+0.7}$ & $\begin{array}{l}+2.6 \\
-23\end{array}$ & ${ }_{-1.3}^{+1.4}$ & ${ }_{-30}^{40}$ & $\begin{array}{l}+20 \\
-20\end{array}$ & $\begin{array}{l}+30 \\
+30\end{array}$ & ${ }_{-20}^{+20}$ & $\begin{array}{r}+30 \\
-20\end{array}$ & & $\begin{array}{l}+1.8 \\
+-22\end{array}$ & +3 & ${ }_{-0.0}^{+0.0}$ & $\begin{array}{l}+3.0 \\
+25\end{array}$ & $\begin{array}{l}+50 \\
{ }_{-50}\end{array}$ & $\begin{array}{l}+30 \\
+30\end{array}$ & $\begin{array}{l}+20 \\
-20\end{array}$ & +20 \\
\hline
\end{tabular}

Notes. Results and statistical uncertainties ("Stat." row) are given as median values and $1 \sigma$ confidence limits. Quantities are described in Sect. 6. Article number, page 18 of 26 
Table A.2. Kinematic quantities for the program stars based on Model II.

\begin{tabular}{|c|c|c|c|c|c|c|c|c|c|c|c|c|c|c|c|c|c|}
\hline Object & $x$ & $\begin{array}{r}y \\
(\mathrm{kpc}) \\
\end{array}$ & $z$ & $v_{x}$ & $v_{y}$ & $\begin{array}{c}v_{z} \\
\left(\mathrm{~km} \mathrm{~s}^{-}\right. \\
\end{array}$ & $\begin{array}{l}\left.v_{\text {Grf }}^{-1}\right) \\
\end{array}$ & $v_{\mathrm{Grf}}-v_{\mathrm{esc}}$ & $\begin{array}{r}P_{\mathrm{b}} \\
-(\%) \\
\end{array}$ & $x_{\mathrm{p}}$ & $\begin{array}{c}y_{\mathrm{p}} \\
(\mathrm{kpc}) \\
\end{array}$ & $z_{\mathrm{p}}$ & $r_{\mathrm{p}}$ & $v_{x, \mathrm{p}}$ & & & $\begin{array}{l}v_{\mathrm{Grf}, \mathrm{p}} \\
{ }^{2}\end{array}$ \\
\hline 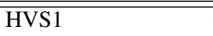 & $\begin{array}{ll}-101.3 \\
\end{array}$ & $\begin{array}{ll}-100.9 \\
\end{array}$ & 83.5 & \begin{tabular}{c|}
-390 \\
\end{tabular} & $\begin{array}{ll}-340 \\
\end{array}$ & 4450 & 7710 & $\overline{4440}$ & $\overline{0}$ & $\begin{array}{c}-26.8 \\
-1\end{array}$ & 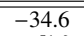 & 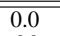 & $\overline{c 66.7}$ & $\begin{array}{c}-440 \\
\end{array}$ & 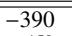 & 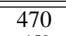 & $\overline{7770}$ \\
\hline Sta & $+{ }_{-6.9}^{+7.6}$ & & $\begin{array}{l}+6.2 \\
-6.8\end{array}$ & ${ }_{-160}^{+160}$ & ${ }_{-140}^{+130}$ & $\begin{array}{l}+170 \\
-170\end{array}$ & ${ }_{-40}^{+70}$ & ${ }_{-40}^{+70}$ & & $\begin{array}{l}+60.9 \\
-37.7\end{array}$ & $\begin{array}{l}+51.6 \\
-31.7\end{array}$ & ${ }_{-0.0}^{+0.0}$ & $++_{-32.1}^{+33.2}$ & $\begin{array}{l}+170 \\
-110\end{array}$ & $\begin{array}{l}+150 \\
-100\end{array}$ & ${ }_{-110}^{+150}$ & 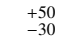 \\
\hline HVS4 & -61.9 & -14.1 & 50.8 & -360 & -300 & 360 & 630 & 280 & & -10.0 & 23.5 & 0.0 & 43.8 & -440 & -260 & 440 & 670 \\
\hline Stat. & & +1 & $\begin{array}{l}+4.5 \\
-3.9\end{array}$ & ${ }_{-180}^{+180}$ & $\begin{array}{l}+170 \\
-180\end{array}$ & $\begin{array}{l}+160 \\
-160\end{array}$ & 10 & $\begin{array}{l}+110 \\
-60\end{array}$ & & $\begin{array}{l}+53.0 \\
-32.1\end{array}$ & +21.4 & +0.0 & +28.2 & +210 & $+{ }_{-200}^{+150}$ & ${ }_{-120}^{+110}$ & ++80 \\
\hline HVS5 & -32.1 & $\begin{array}{r}-1.3 \\
15.9\end{array}$ & 22.9 & $\begin{array}{r}-480 \\
-400\end{array}$ & $\begin{array}{l}-180 \\
300\end{array}$ & $\begin{array}{l}-160 \\
410\end{array}$ & $\begin{array}{l}-600 \\
650\end{array}$ & 240 & 0 & $\begin{array}{l}-32.1 \\
-8.6\end{array}$ & $\begin{array}{l}-17.6 \\
-1.0\end{array}$ & $\begin{array}{c}-0.0 \\
0.0\end{array}$ & $\begin{aligned}-21.6 \\
9.1\end{aligned}$ & $\begin{array}{l}-590 \\
-510\end{array}$ & 320 & $\begin{array}{l}-120 \\
460\end{array}$ & 760 \\
\hline & +2 & ${ }_{-1.5}^{+1.7}$ & ${ }_{-2.1}^{+2.4}$ & ${ }_{-30}^{+30}$ & $\begin{array}{l}+50 \\
-50\end{array}$ & $\begin{array}{l}+30 \\
+30\end{array}$ & ${ }_{-10}^{+10}$ & ${ }_{-20}^{+20}$ & & ${ }_{-2.3}^{+2.4}$ & $\begin{array}{l}+3.0 \\
-2.7\end{array}$ & $+{ }_{-0.0}^{+0.0}$ & $\begin{array}{l}+2.3 \\
-2.3\end{array}$ & ${ }_{-50}^{+40}$ & ${ }_{-30}^{+40}$ & ${ }_{-20}^{+20}$ & +30 \\
\hline HVS5 (Brown 2015) & -37.5 & $\begin{array}{l}-1.5 \\
19.5\end{array}$ & 28.1 & -420 & 260 & $\begin{array}{r}-30 \\
420\end{array}$ & 650 & 260 & 0 & $\begin{array}{l}-2.3 \\
-8.8\end{array}$ & $\begin{array}{l}-2.7 \\
1.8\end{array}$ & $\begin{aligned}-0.0 \\
0.0\end{aligned}$ & $\begin{array}{l}-2.3 \\
9.9\end{array}$ & $\begin{array}{l}-520 \\
-520\end{array}$ & $\begin{array}{l}-30 \\
310\end{array}$ & 470 & 760 \\
\hline & & & $\begin{array}{l}+3.3 \\
-3.3\end{array}$ & +40 & $\begin{array}{l}+60 \\
-70\end{array}$ & +40 & ${ }_{-10}^{+10}$ & +20 & & $\begin{array}{l}+3.5 \\
{ }_{-3.3}\end{array}$ & ${ }_{-40}^{+4.6}$ & +0.0 & $\begin{array}{l}+3.5 \\
-3.3\end{array}$ & ${ }_{-50}^{+50}$ & ${ }_{-50}^{+40}$ & ${ }_{-20}^{+20}$ & +30 \\
\hline HVS6 & -20.3 & -23.6 & 45.0 & -150 & -150 & 450 & 530 & 140 & 0 & $\begin{array}{l}-3.3 \\
-4.4\end{array}$ & $\begin{array}{l}-7.0 \\
-7.0\end{array}$ & 0.0 & 17.3 & -220 & -230 & 560 & 640 \\
\hline Stat & +1.1 & & $\begin{array}{l}{ }_{-4.1}^{4.5} \\
.\end{array}$ & ${ }_{-160}^{+160}$ & ${ }_{-120}^{+120}$ & 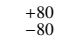 & ${ }_{-30}^{+60}$ & ${ }_{-30}^{+60}$ & & $\begin{array}{l}+15.2 \\
-14.0\end{array}$ & ${ }_{-11.3}^{+12.9}$ & $+{ }_{-0.0}^{+0.0}$ & $\begin{array}{l}+11.5 \\
-9.1\end{array}$ & $\begin{array}{l}+150 \\
-80\end{array}$ & $\begin{array}{l}+130 \\
+60\end{array}$ & $\begin{array}{l}+40 \\
-50\end{array}$ & $\begin{array}{l}+50 \\
-40\end{array}$ \\
\hline HVS7 & -11.1 & -25.1 & 40.3 & $\begin{array}{l}-200 \\
-200\end{array}$ & $\begin{array}{r}-{ }^{-120} \\
0\end{array}$ & 450 & 500 & $\begin{array}{l}-30 \\
100\end{array}$ & 0 & $\begin{array}{r}-14.0 \\
6.1\end{array}$ & $\begin{array}{r}-21.3 \\
-21.9\end{array}$ & $\begin{array}{c}-0.0 \\
0.0\end{array}$ & $\begin{array}{r}-9.1 \\
23.9\end{array}$ & $\begin{array}{l}-80 \\
-200\end{array}$ & $\begin{array}{l}-60 \\
-90\end{array}$ & $\begin{array}{l}510 \\
510\end{array}$ & 560 \\
\hline St & $\begin{array}{l}+0.3 \\
-0.3\end{array}$ & & $\begin{array}{l}+3.9 \\
-3.3\end{array}$ & $\begin{array}{l}+90 \\
+90\end{array}$ & $+{ }_{-50}^{+50}$ & $\begin{array}{l}{ }_{-40}^{40} \\
\text {. }\end{array}$ & ${ }_{-40}^{+50}$ & $\begin{array}{l}{ }_{-40}^{50} \\
-40\end{array}$ & & $\begin{array}{l}+8.3 \\
-7.1\end{array}$ & ${ }_{-50}^{+4.7}$ & $\begin{array}{l}+0.0 \\
-0.0\end{array}$ & $\begin{array}{l}{ }_{-4.8}^{+5.5} \\
\text {. }\end{array}$ & ${ }_{-80}^{+70}$ & $\begin{array}{l}+60 \\
-60\end{array}$ & $\begin{array}{l}+30 \\
+20\end{array}$ & $\begin{array}{l}+30 \\
-20\end{array}$ \\
\hline H & -29.7 & -13.2 & 26.3 & -410 & 80 & 260 & 500 & 80 & 0 & 8.6 & -16.2 & 0.0 & 19.2 & -440 & -40 & 350 & 570 \\
\hline Stat. & $\begin{array}{l}+1.6 \\
-1.8\end{array}$ & ${ }_{-1.1}^{+1.0}$ & ${ }_{-2.0}^{+2.2}$ & $\begin{array}{l}{ }_{-60}^{60} \\
-60\end{array}$ & $\begin{array}{l}{ }_{-60}^{60} \\
-60\end{array}$ & ${ }_{-40}^{+40}$ & ${ }_{-40}^{+50}$ & $\begin{array}{r}{ }_{-40}^{50} \\
-40\end{array}$ & & $\begin{array}{r}+9.9 \\
-7.6\end{array}$ & ${ }_{-5.5}^{+4.9}$ & $\begin{array}{l}+0.0 \\
-0.0\end{array}$ & $\begin{array}{l}+8.4 \\
-8.8\end{array}$ & $\begin{array}{l}+30 \\
-40\end{array}$ & $\begin{array}{l}+70 \\
-70\end{array}$ & $\begin{array}{l}+30 \\
{ }_{-40}^{3}\end{array}$ & $\begin{array}{l}+20 \\
-10\end{array}$ \\
\hline VS9 & -44.7 & -70.6 & 80.9 & 50 & -180 & 520 & 710 & 400 & & -48.3 & $\begin{array}{l}-3.3 \\
-40.8\end{array}$ & $\begin{array}{c}-0.0 \\
0.0\end{array}$ & 95.3 & $\begin{array}{r}-40 \\
0\end{array}$ & -220 & 550 & 710 \\
\hline Stat & & ${ }_{-7.4}^{+7.1}$ & $\begin{array}{l}+8.5 \\
-8.1\end{array}$ & ${ }_{-420}^{+420}$ & $\begin{array}{l}+300 \\
{ }_{-3000}\end{array}$ & $\begin{array}{l}+250 \\
-250\end{array}$ & ${ }_{-180}^{+280}$ & $\begin{array}{l}{ }_{-180}^{280} \\
-\end{array}$ & & $\begin{array}{l}+71.5 \\
-61.6\end{array}$ & $\begin{array}{l}+79.2 \\
-420\end{array}$ & $\begin{array}{l}+0.0 \\
-0.0\end{array}$ & $\begin{array}{l}+50.2 \\
+-37.3\end{array}$ & $\begin{array}{l}+440 \\
-360\end{array}$ & ${ }_{-250}^{+310}$ & $\begin{array}{l}+240 \\
+{ }_{-190}\end{array}$ & $\begin{array}{l}+270 \\
+{ }_{-130}\end{array}$ \\
\hline & -14.5 & $\begin{array}{l}-1.4 \\
-16.8\end{array}$ & $\begin{array}{r}-8.1 \\
70.2\end{array}$ & $\begin{array}{l}-250 \\
-250\end{array}$ & $\begin{array}{l}-300 \\
-190\end{array}$ & 360 & $\begin{array}{l}-180 \\
500\end{array}$ & $\begin{array}{l}-180 \\
140\end{array}$ & 0 & $\begin{array}{l}-61.6 \\
25.4\end{array}$ & $\begin{array}{l}-42.0 \\
14.6\end{array}$ & $\begin{array}{r}-0.0 \\
0.0\end{array}$ & 36.9 & $\begin{array}{r}-360 \\
-190\end{array}$ & $\begin{array}{l}-250 \\
-160\end{array}$ & $\begin{array}{l}-1900 \\
480\end{array}$ & $\begin{array}{l}-5150 \\
570\end{array}$ \\
\hline Stat & +0.6 & ${ }_{-1.6}^{+1.6}$ & $\begin{array}{l}+6.6 \\
-6.4\end{array}$ & ${ }_{-140}^{+130}$ & $\begin{array}{l}+140 \\
-150\end{array}$ & ${ }_{-40}^{40}$ & $\begin{array}{l}+90 \\
+60\end{array}$ & $\begin{array}{l}+90 \\
-60\end{array}$ & & $\begin{array}{l}+25.3 \\
-19.5\end{array}$ & $\begin{array}{l}+27.9 \\
-20.0\end{array}$ & ${ }_{-0.0}^{+0.0}$ & $\begin{array}{r}+28.5 \\
-19.6\end{array}$ & ${ }_{-130}^{+90}$ & $\begin{array}{l}+70 \\
-120\end{array}$ & $\begin{array}{l}{ }_{-60}^{60} \\
-60\end{array}$ & ${ }_{-20}^{+50}$ \\
\hline & $\begin{array}{r}-0.66 \\
-26.1\end{array}$ & $\begin{array}{l}-1.66 \\
-42.1\end{array}$ & 59.5 & $\begin{array}{l}-140 \\
-50\end{array}$ & $\begin{array}{r}-150 \\
70\end{array}$ & 550 & 570 & 220 & 0 & $\begin{array}{l}-19.5 \\
-19.5\end{array}$ & $\begin{array}{l}-20.0 \\
-46.7\end{array}$ & $\begin{array}{r}-0.0 \\
0.0\end{array}$ & 52.3 & $\begin{array}{l}-130 \\
-80\end{array}$ & $\begin{array}{r}-120 \\
20\end{array}$ & $\begin{array}{l}-60 \\
580\end{array}$ & 590 \\
\hline $\mathrm{St}$ & & $\begin{array}{l}+4.0 \\
-4.5\end{array}$ & $\begin{array}{l}+6.4 \\
-5.6\end{array}$ & $\begin{array}{l}{ }_{-130}^{+130} \\
\text {. }\end{array}$ & $\begin{array}{l}+110 \\
-110\end{array}$ & $\begin{array}{l}+80 \\
-80\end{array}$ & $\begin{array}{l}00 \\
80\end{array}$ & $\begin{array}{l}+100 \\
-80\end{array}$ & & ${ }_{-13.1}^{+13.7}$ & ${ }_{-12.1}^{+12.2}$ & ${ }_{-0.0}^{+0.0}$ & $\begin{array}{l}+12.3 \\
+12.3 \\
\end{array}$ & $\begin{array}{l}{ }_{-120}^{+130} \\
\end{array}$ & $\begin{array}{l}+120 \\
{ }_{-120}\end{array}$ & $\begin{array}{l}+80 \\
+{ }_{-70}\end{array}$ & $\begin{array}{l}+90 \\
+90\end{array}$ \\
\hline 13 & -32.3 & $\begin{array}{l}-72.1 \\
\end{array}$ & 92.7 & $\begin{array}{l}-130 \\
-660\end{array}$ & $\begin{array}{l}-110 \\
-40\end{array}$ & 340 & 780 & 470 & 0 & $\begin{array}{l}-15.1 \\
126.5\end{array}$ & $\begin{array}{l}-12.1 \\
-54.2\end{array}$ & $\begin{array}{rll}-0.0 & 1\end{array}$ & 149.6 & $\begin{array}{l}-120 \\
-620\end{array}$ & $\begin{array}{l}-120 \\
-90\end{array}$ & $\begin{array}{l}-70 \\
390\end{array}$ & 770 \\
\hline & ${ }_{-20}^{+2.3}$ & ${ }_{-59}^{+6.7}$ & $\begin{array}{l}+7.6 \\
-86\end{array}$ & $\begin{array}{l}+220 \\
+230\end{array}$ & ${ }_{-200}^{+200}$ & $\begin{array}{l}+150 \\
-150\end{array}$ & $\begin{array}{l}{ }_{-180}^{+210} \\
\end{array}$ & $\begin{array}{l}+210 \\
-180\end{array}$ & & $\begin{array}{l}+130.0 \\
-673\end{array}$ & $\begin{array}{l}+79.1 \\
-432\end{array}$ & + & $\begin{array}{l}+119.1 \\
-569 .\end{array}$ & $\begin{array}{l}{ }_{-240}^{230} \\
\end{array}$ & $\begin{array}{l}+210 \\
-190\end{array}$ & $\begin{array}{l}+130 \\
+-140\end{array}$ & $\begin{array}{l}+210 \\
+2160\end{array}$ \\
\hline HVS15 & -10.4 & -34.2 & 50.7 & -60 & -170 & 280 & 460 & $\begin{array}{r}-r 180 \\
80\end{array}$ & 22 & $\begin{array}{l}-67.3 \\
-0.1\end{array}$ & $\begin{array}{l}-43.2 \\
-3.7\end{array}$ & $\begin{array}{c}-0.0 \\
0.0\end{array}$ & $\begin{array}{r}-36.9 \\
45.4\end{array}$ & $\begin{array}{l}-240 \\
-80\end{array}$ & $\begin{array}{l}-190 \\
-240\end{array}$ & $\begin{array}{l}-140 \\
400\end{array}$ & $\begin{array}{l}-160 \\
500\end{array}$ \\
\hline & ${ }_{-0.3}^{+0.3}$ & $\begin{array}{l}{ }_{-4.1}^{3} .6 \\
\end{array}$ & $\begin{array}{l}+6.1 \\
-5.3\end{array}$ & $\begin{array}{l}+340 \\
+350\end{array}$ & $\begin{array}{l}+190 \\
-190\end{array}$ & $\begin{array}{l}+140 \\
-140\end{array}$ & $\begin{array}{l}+210 \\
-100\end{array}$ & $\begin{array}{l}+210 \\
-100\end{array}$ & & $\begin{array}{l}{ }_{-43.1}^{+65.5} \\
\end{array}$ & $\begin{array}{l}+50.5 \\
-29.0\end{array}$ & ${ }_{-0.0}^{+0.0}$ & ${ }_{-25.5}^{+52.1}$ & $\begin{array}{l}+300 \\
-3250\end{array}$ & $\begin{array}{l}{ }_{-100}^{+200} \\
\text { ton }\end{array}$ & $\begin{array}{l}+80 \\
{ }_{-140}^{80}\end{array}$ & $\begin{array}{l}+140 \\
-50\end{array}$ \\
\hline HVS16 & -1.5 & -24.2 & 60.4 & -270 & -470 & 210 & 680 & 310 & 4 & 53.6 & 79.6 & 0.01 & 130.9 & -210 & -430 & 290 & 650 \\
\hline & $\begin{array}{l}{ }_{-0.6}^{+0.7} \\
\end{array}$ & ${ }_{-2.2}^{+2.2}$ & $\begin{array}{l}+5.5 \\
-5.3\end{array}$ & $\begin{array}{l}{ }_{-480}^{4} 880 \\
-480\end{array}$ & ${ }_{-250}^{+240}$ & $\begin{array}{l}+990 \\
-100\end{array}$ & $\begin{array}{l}+350 \\
-230\end{array}$ & $\begin{array}{l}+360 \\
-230\end{array}$ & & $\begin{array}{l}+128.2 \\
-96.9\end{array}$ & $\begin{array}{l}+136.7 \\
-62.2\end{array}$ & ${ }_{-0.0}^{+0.0}+$ & $\begin{array}{l}+168.7 \\
-80.2\end{array}$ & $\begin{array}{l}+350 \\
-490\end{array}$ & $\begin{array}{l}+210 \\
-250\end{array}$ & $\begin{array}{l}+110 \\
-110\end{array}$ & $\begin{array}{l}+350 \\
+360 \\
-160\end{array}$ \\
\hline & $\begin{array}{l}-0.8 \\
-0.8\end{array}$ & 25.6 & 23.3 & 190 & $\begin{array}{l}-270 \\
270\end{array}$ & 310 & 460 & 30 & 2 & -12.3 & 4.4 & 0.0 & 13.5 & $\begin{array}{l}-490 \\
120\end{array}$ & $\begin{array}{l}-250 \\
370\end{array}$ & $\begin{array}{l}-1100 \\
390\end{array}$ & $\begin{array}{l}-160 \\
550\end{array}$ \\
\hline Stat & ${ }_{-06}^{+0.7}$ & ${ }_{-20}^{+2.1}$ & $\begin{array}{l}{ }_{-1.8}^{+1.9} \\
\end{array}$ & $\begin{array}{l}+60 \\
-60\end{array}$ & $\begin{array}{l}+30 \\
+40\end{array}$ & $\begin{array}{l}+30 \\
+30\end{array}$ & ${ }_{-20}^{+20}$ & $\begin{array}{l}+30 \\
+20\end{array}$ & & $\begin{array}{r}+3.4 \\
-3.8\end{array}$ & $\begin{array}{l}+3.7 \\
-35\end{array}$ & $+{ }_{-0.0}^{+0.0}$ & $\begin{array}{l}+4.1 \\
-3.7\end{array}$ & $\begin{array}{l}+70 \\
+70\end{array}$ & ${ }_{-40}^{40}$ & $\begin{array}{l}+30 \\
+30\end{array}$ & $\begin{array}{l}+30 \\
+10\end{array}$ \\
\hline & $\begin{array}{l}-28.6 \\
\end{array}$ & 83.5 & $\begin{array}{l}-1.8 \\
-43.3\end{array}$ & $\begin{array}{l}-60 \\
30\end{array}$ & 460 & $\begin{array}{l}-30 \\
-130\end{array}$ & 560 & 240 & 0 & $\begin{array}{l}-25.2 \\
-3.8\end{array}$ & -25.7 & $\begin{array}{r}-0.0 \\
0.0\end{array}$ & 77.4 & $\begin{array}{l}-10 \\
-60\end{array}$ & 470 & $\begin{array}{l}-30 \\
-230\end{array}$ & 570 \\
\hline Stat & & $\begin{array}{l}+8.7 \\
-75\end{array}$ & $\begin{array}{l}+3.9 \\
-45\end{array}$ & $\begin{array}{l}+300 \\
-300\end{array}$ & $\begin{array}{l}+130 \\
-130\end{array}$ & $\begin{array}{l}+200 \\
-200\end{array}$ & $\begin{array}{l}+160 \\
-90\end{array}$ & $\begin{array}{l}+160 \\
-90\end{array}$ & & $\begin{array}{l}+65.6 \\
+-721\end{array}$ & $\begin{array}{l}+62.4 \\
+-1932\end{array}$ & + & $\begin{array}{l}+188.1 \\
-401\end{array}$ & ${ }_{-170}^{+310}$ & $\begin{array}{l}+80 \\
-70\end{array}$ & $\begin{array}{l}+140 \\
+-130\end{array}$ & $\begin{array}{l}+110 \\
-60\end{array}$ \\
\hline & -17.5 & $\begin{array}{r}-36.9 \\
\end{array}$ & 77.0 & $\begin{array}{l}-230 \\
-230\end{array}$ & $\begin{array}{r}-150 \\
90\end{array}$ & 560 & 920 & 580 & 0 & 12.0 & $\begin{array}{l}-193.2 \\
-44.7\end{array}$ & 0.0 & $\begin{array}{r}-40.1 \\
98.8\end{array}$ & $\begin{array}{l}-170 \\
-220\end{array}$ & 50 & $\begin{array}{l}-130 \\
600\end{array}$ & 920 \\
\hline $\mathrm{St}$ & $\begin{array}{l}+1.1 \\
-1.2\end{array}$ & $\begin{array}{l}{ }_{-4.5}^{4.5} \\
\end{array}$ & $\begin{array}{l}+9.3 \\
-9.2\end{array}$ & $\begin{array}{l}+750 \\
-760\end{array}$ & 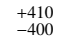 & +2200 & $\begin{array}{l}{ }_{-300}^{4470} \\
\end{array}$ & $\begin{array}{l}{ }_{-300}^{470} \\
\text {. }\end{array}$ & & $\begin{array}{r}+132.9 \\
-87.0\end{array}$ & $\begin{array}{l}{ }_{-40.8}^{+68.0} \\
\end{array}$ & ${ }_{-0.0}^{+0.0}$ & $\begin{array}{l}+88.2 \\
{ }_{-44.6}\end{array}$ & $\begin{array}{l}+700 \\
+740\end{array}$ & $\begin{array}{l}+410 \\
-460\end{array}$ & $\begin{array}{l}+200 \\
+200\end{array}$ & $\begin{array}{l}+450 \\
+450\end{array}$ \\
\hline 20 & -15.0 & $\begin{array}{l}-50.8 \\
\end{array}$ & 90.2 & 40 & 300 & 620 & 970 & 650 & 0 & -19.0 & -87.3 & $\begin{array}{cll}0.0 & 1\end{array}$ & $\begin{array}{l}-124.0 \\
\end{array}$ & 20 & 270 & 650 & 960 \\
\hline St: & $\begin{array}{l}+0.9 \\
{ }_{-0.7}^{0.9}\end{array}$ & $\begin{array}{l}+6.3 \\
+6.6\end{array}$ & $\begin{array}{l}+8.2 \\
-11.1\end{array}$ & $\begin{array}{l}+720 \\
-720\end{array}$ & $\begin{array}{l}+410 \\
-400\end{array}$ & $\begin{array}{l}+240 \\
-2440\end{array}$ & ${ }_{-360}^{4+80}$ & $\begin{array}{l}+480 \\
-460\end{array}$ & & $\begin{array}{l}+112.7 \\
-93.3\end{array}$ & $\begin{array}{l}+61.7 \\
-37.4\end{array}$ & ${ }_{-0.0}^{+0.0}$ & $\begin{array}{l}+60.7 \\
{ }_{-45.2}^{6}\end{array}$ & $\begin{array}{l}+720 \\
-670\end{array}$ & $\begin{array}{l}+420 \\
-410\end{array}$ & $\begin{array}{l}+230 \\
{ }_{-200}\end{array}$ & $+\overbrace{-340}^{+470}$ \\
\hline$\$ 21$ & -60.2 & $\begin{array}{r}-4.0 \\
13.6\end{array}$ & 79.8 & -130 & 200 & 360 & 590 & 270 & 0 & $\begin{array}{l}-29.3 \\
\end{array}$ & -22.2 & $\begin{array}{c}-0.0 \\
0.0\end{array}$ & 88.4 & $\begin{array}{l}-670 \\
-190\end{array}$ & $\begin{array}{l}-410 \\
150\end{array}$ & 440 & 590 \\
\hline & +5.3 & ${ }_{-1.4}^{+1.7}$ & ${ }_{-8.1}^{+9.5}$ & $\begin{array}{l}+290 \\
+290\end{array}$ & $\begin{array}{l}+370 \\
-370\end{array}$ & $+{ }_{-220}^{+220}$ & $\begin{array}{l}+250 \\
-150\end{array}$ & $\begin{array}{l}+250 \\
-150\end{array}$ & & $\begin{array}{l}+111.5 \\
-50.8\end{array}$ & $\begin{array}{l}+\quad 61.5 \\
-124.5\end{array}$ & $\begin{array}{l}{ }_{-0.0}^{+0.0} \\
\end{array}$ & $\begin{array}{l}+99.4 \\
-41.9\end{array}$ & $\begin{array}{l}+310 \\
{ }_{-200}\end{array}$ & $\begin{array}{l}+340 \\
-300\end{array}$ & $\begin{array}{l}+170 \\
-200\end{array}$ & $\begin{array}{l}+200 \\
+200\end{array}$ \\
\hline 22 & -13.7 & -45.4 & 86.2 & -380 & 720 & 910 & 1530 & 1200 & 0 & 21.2 & -108.8 & $\begin{array}{lll}0.01 & 1\end{array}$ & 139.5 & -370 & 700 & 920 & 1520 \\
\hline & $\begin{array}{l}{ }_{-0.9}^{0.8} \\
\end{array}$ & $\begin{array}{l}+6.5 \\
-7.6\end{array}$ & $\begin{array}{l}+14.4 \\
-12.3\end{array}$ & $\begin{array}{l}+950 \\
{ }_{-970}\end{array}$ & $\begin{array}{l}+590 \\
-560\end{array}$ & $\begin{array}{l}+320 \\
-3310\end{array}$ & $\begin{array}{l}+690 \\
-560\end{array}$ & $\begin{array}{l}+690 \\
+560\end{array}$ & & $\begin{array}{r}+114.9 \\
-83.4\end{array}$ & $\begin{array}{l}{ }_{-39.1}^{46.5} \\
\text {. }\end{array}$ & ${ }_{-0.0}^{+0.0}$ & $\begin{array}{r}+63.3 \\
{ }_{-43.6}\end{array}$ & $\begin{array}{l}{ }_{-970}^{+930} \\
\text {. }\end{array}$ & $\begin{array}{l}+600 \\
-600\end{array}$ & $\begin{array}{l}+320 \\
-290\end{array}$ & $\begin{array}{l}+690 \\
-6500\end{array}$ \\
\hline $\mathrm{H}$ & -17.0 & $\begin{array}{r}-35.4 \\
\end{array}$ & 51.2 & 80 & $\begin{array}{l}-300 \\
-90\end{array}$ & 390 & 460 & 90 & 8 & -23.4 & $\begin{array}{l}-30.1 \\
-20.7\end{array}$ & 0.0 & 40.5 & $\begin{array}{r}-910 \\
10\end{array}$ & $\begin{array}{r}-560 \\
-160\end{array}$ & $\begin{array}{l}-290 \\
450\end{array}$ & $\begin{array}{l}-560 \\
520\end{array}$ \\
\hline & +0.8 & ${ }_{-3.0}^{+3.2}$ & $\begin{array}{l}{ }_{-4.6}^{+4.4} \\
\end{array}$ & ${ }_{-230}^{+230}$ & $\begin{array}{l}+140 \\
-150\end{array}$ & $\begin{array}{l}+110 \\
-110\end{array}$ & $\begin{array}{l}+140 \\
-80\end{array}$ & $\begin{array}{l}+140 \\
-80\end{array}$ & & $\begin{array}{l}+27.2 \\
-262\end{array}$ & $\begin{array}{l}+24.0 \\
-11.3\end{array}$ & ${ }_{-0.0}^{+0.0}$ & $\begin{array}{l}+20.6 \\
-19.3\end{array}$ & $\begin{array}{l}+250 \\
-180\end{array}$ & $\begin{array}{l}{ }_{-120}^{+160} \\
\end{array}$ & $\begin{array}{l}{ }_{-70}^{+90} \\
\end{array}$ & $\begin{array}{l}+100 \\
-40\end{array}$ \\
\hline B0 & -43.6 & 16.1 & $\begin{array}{r}45.6 \\
\end{array}$ & $\begin{array}{l}-1230 \\
-120\end{array}$ & $\begin{array}{l}-100 \\
470\end{array}$ & $\begin{array}{l}-100 \\
100\end{array}$ & 550 & 180 & 13 & $\begin{array}{l}-26.2 \\
-8.0\end{array}$ & $\begin{array}{l}-1.3 .3 \\
\end{array}$ & $\begin{array}{c}-0.0 \\
0.0\end{array}$ & 96.3 & $\begin{array}{r}-180 \\
-170\end{array}$ & $\begin{array}{l}-120 \\
360\end{array}$ & 220 & $\begin{array}{l}-40 \\
480\end{array}$ \\
\hline $\mathrm{St}$ & $\begin{array}{l}+3.5 \\
-3.5 \\
-3.5\end{array}$ & ${ }_{-1.6}^{+1.6}$ & $\begin{array}{l}+4.5 \\
-4.5\end{array}$ & $\begin{array}{l}+200 \\
+200\end{array}$ & $\begin{array}{l}+230 \\
-230\end{array}$ & $\begin{array}{l}+180 \\
-1800\end{array}$ & $\begin{array}{l}+210 \\
-170\end{array}$ & $\begin{array}{l}+210 \\
-170\end{array}$ & & $\begin{array}{l}+115.6 \\
-43.5\end{array}$ & $\begin{array}{l}+62.3 \\
{ }_{-2058}\end{array}$ & $+{ }_{-0.0}^{+0.0}+$ & $\begin{array}{r}+225.2 \\
-496.6\end{array}$ & $\begin{array}{l}+190 \\
+110\end{array}$ & $\begin{array}{l}+210 \\
-200\end{array}$ & $\begin{array}{l}+130 \\
+130\end{array}$ & $\begin{array}{l}+160 \\
\quad 80\end{array}$ \\
\hline & -84.1 & -21.8 & 33.8 & -190 & -70 & 250 & 390 & 50 & 27 & $\begin{array}{l}-43.3 \\
-55.4\end{array}$ & -10.6 & 0.0 & $\begin{array}{r}-49.6 \\
68.3\end{array}$ & $\begin{array}{l}-110 \\
-250\end{array}$ & $\begin{array}{l}-200 \\
-90\end{array}$ & $\begin{array}{l}-150 \\
270\end{array}$ & 430 \\
\hline $\mathrm{St}$ & $\begin{array}{l}+6.6 \\
-6.9\end{array}$ & $\begin{array}{l}{ }_{-2.0}^{+2.0} \\
\end{array}$ & $\begin{array}{l}+3.1 \\
-3.1\end{array}$ & ${ }_{-120}^{+120}$ & $\begin{array}{l}{ }_{-200}^{200} \\
-200\end{array}$ & $\begin{array}{l}+190 \\
-190\end{array}$ & $\begin{array}{l}+150 \\
-80\end{array}$ & $\begin{array}{l}+150 \\
-80\end{array}$ & & $\begin{array}{l}+72.5 \\
-22.9\end{array}$ & $\begin{array}{l}+22.1 \\
-24.7\end{array}$ & $\begin{array}{l}{ }_{-0.0}^{+0.0} \\
\end{array}$ & $\begin{array}{l}+19.7 \\
-{ }_{-26.1}\end{array}$ & ${ }_{-120}^{+150}$ & $\begin{array}{l}+150 \\
-170\end{array}$ & $\begin{array}{r}+180 \\
-110\end{array}$ & $\begin{array}{l}+120 \\
-50\end{array}$ \\
\hline $\mathrm{B}$ & -30.7 & $\begin{array}{l}-2.0 \\
7.9\end{array}$ & 16.1 & $\begin{array}{l}-2120 \\
-200\end{array}$ & $\begin{array}{l}-200 \\
110\end{array}$ & $\begin{array}{l}-190 \\
180\end{array}$ & 290 & $\begin{array}{r}-80 \\
-140\end{array}$ & 100 & $\begin{array}{r}-22.9 \\
-10.3\end{array}$ & $\begin{array}{l}-24.7 \\
-1.8\end{array}$ & $\begin{array}{r}-0.0 \\
0.0\end{array}$ & $\begin{array}{l}-26.1 \\
10.7\end{array}$ & $\begin{array}{r}-120 \\
-360\end{array}$ & $\begin{array}{l}-170 \\
120\end{array}$ & $\begin{array}{l}-1100 \\
240\end{array}$ & $\begin{array}{l}-50 \\
450\end{array}$ \\
\hline Sta & $\begin{array}{l}+1.8 \\
{ }_{-2.0}^{1.8}\end{array}$ & ${ }_{-0.7}^{+0.7}$ & ${ }_{-1.3}^{+1.5}$ & ${ }_{-20}^{+20}$ & $\begin{array}{l}{ }_{-30}^{30} \\
\end{array}$ & $\begin{array}{l}+30 \\
{ }_{-30}^{30}\end{array}$ & ${ }_{-10}^{+10}$ & ${ }_{-10}^{+10}$ & & $\begin{array}{l}+4.0 \\
-3.6\end{array}$ & $\begin{array}{l}+2.5 \\
-2.3\end{array}$ & ${ }_{-0.0}^{+0.0}$ & $\begin{array}{l}+3.3 \\
-3.5\end{array}$ & $\begin{array}{l}+50 \\
-60\end{array}$ & $\begin{array}{l}+20 \\
-20\end{array}$ & $\begin{array}{l}+20 \\
-10\end{array}$ & $\begin{array}{l}{ }_{-40}^{+50} \\
0\end{array}$ \\
\hline B & -32.5 & $\begin{array}{l}-0.7 \\
-2.7\end{array}$ & 22.0 & -280 & 210 & 130 & 370 & $\begin{array}{l}-10 \\
-50\end{array}$ & 90 & 8.5 & -22.4 & $\begin{array}{c}-0.0 \\
0.0\end{array}$ & 24.6 & -350 & 70 & 220 & 430 \\
\hline St & $\begin{array}{l}{ }_{-2.0}^{+1.8} \\
-x_{1}\end{array}$ & ${ }_{-0.3}^{+0.2}$ & $\begin{array}{l}+1.8 \\
-1.7\end{array}$ & $\begin{array}{l}{ }_{-40}^{40} \\
-40\end{array}$ & $\begin{array}{l}{ }^{+50} \\
-50\end{array}$ & $\begin{array}{l}{ }_{-40}^{40} \\
\text {. }\end{array}$ & ${ }_{-40}^{+40}$ & $\begin{array}{l}{ }_{-40}^{40} \\
\end{array}$ & & $\begin{array}{l}+11.3 \\
-8.5\end{array}$ & $\begin{array}{r}+5.9 \\
-7.7\end{array}$ & $\begin{array}{l}+0.0 \\
-0.0\end{array}$ & $\begin{array}{l}+10.9 \\
-6.9\end{array}$ & $\begin{array}{l}+10 \\
{ }_{-10}^{10}\end{array}$ & $\begin{array}{l}+60 \\
-60\end{array}$ & $\begin{array}{l}+30 \\
+30\end{array}$ & $\begin{array}{l}+10 \\
-20\end{array}$ \\
\hline B. & 40.7 & 16.6 & 51.5 & 160 & -240 & 330 & 480 & 120 & 20 & $\begin{array}{l}-18.3 \\
12.8\end{array}$ & 46.2 & $\begin{array}{r}-0.0 \\
0.0\end{array}$ & $\overline{58.9}$ & 220 & $\begin{array}{l}-60 \\
-170\end{array}$ & 380 & 500 \\
\hline & & & $\begin{array}{l}+6.6 \\
-5.6\end{array}$ & $\begin{array}{l}+160 \\
-160\end{array}$ & ${ }_{-220}^{+210}$ & $\begin{array}{l}+160 \\
-150\end{array}$ & $\begin{array}{l}+190 \\
-140\end{array}$ & $\begin{array}{l}+190 \\
-140\end{array}$ & & $\begin{array}{l}+25 . \\
-42\end{array}$ & $\begin{array}{l}+37.0 \\
-290\end{array}$ & $\begin{array}{l}+0.0 \\
-0.0\end{array}$ & $\begin{array}{r}+35.5 \\
-254\end{array}$ & $\begin{array}{l}+100 \\
-160\end{array}$ & $\begin{array}{l}+220 \\
-240\end{array}$ & $\begin{array}{r}+130 \\
-110\end{array}$ & $\begin{array}{r}+170 \\
-70\end{array}$ \\
\hline B434 & -16.1 & $\begin{array}{l}-1.8 \\
\end{array}$ & 33.6 & $\begin{array}{l}-160 \\
130\end{array}$ & $\begin{array}{l}-220 \\
-280\end{array}$ & $\begin{array}{l}-100 \\
210\end{array}$ & $\begin{array}{l}-140 \\
380\end{array}$ & $\begin{array}{l}-140 \\
-30\end{array}$ & 71 & $\begin{array}{r}-425.9 \\
-25.9\end{array}$ & $\begin{array}{l}-2.0 \\
15.2\end{array}$ & $\begin{array}{r}-0.0 \\
0.0\end{array}$ & 31.5 & $\begin{array}{r}160 \\
0 .\end{array}$ & $\begin{array}{l}-240 \\
-280\end{array}$ & $\begin{array}{l}-110 \\
310\end{array}$ & 420 \\
\hline & & $\begin{array}{l}+1.7 \\
-2.1\end{array}$ & $\begin{array}{l}+3.1 \\
-2.4\end{array}$ & $\begin{array}{l}+80 \\
-80\end{array}$ & $\begin{array}{l}+60 \\
-60\end{array}$ & $\begin{array}{l}+40 \\
-40\end{array}$ & ${ }_{-40}^{+50}$ & $\begin{array}{l}+60 \\
-40\end{array}$ & & $\begin{array}{r}+9.6 \\
-107\end{array}$ & $\begin{array}{l}-0.1 \\
-9\end{array}$ & $+{ }_{-0.0}^{+0.0}$ & $\begin{array}{l}3.0 \\
9.8\end{array}$ & $\begin{array}{l}+90 \\
+90\end{array}$ & $\begin{array}{l}+30 \\
-40\end{array}$ & $\begin{array}{l}+30 \\
-40\end{array}$ & $\begin{array}{l}+20 \\
-10\end{array}$ \\
\hline B45 & $\begin{array}{l}-0.7 \\
-26.7\end{array}$ & -52.5 & 61.5 & $\begin{array}{l}-80 \\
170\end{array}$ & $\begin{array}{l}-60 \\
-20\end{array}$ & $\begin{array}{l}-40 \\
430\end{array}$ & 570 & 230 & 8 & $\begin{array}{l}-10.7 \\
-45.5\end{array}$ & $\begin{array}{r}-49.2 \\
-45.1\end{array}$ & $\begin{array}{r}-0.0 \\
0.0\end{array}$ & $\overline{80.4}$ & $\begin{array}{l}-900 \\
120\end{array}$ & $\begin{array}{l}-40 \\
-70\end{array}$ & $\begin{array}{r}-40 \\
460\end{array}$ & 570 \\
\hline St & +2.0 & $\begin{array}{l}+5.7 \\
-5.4\end{array}$ & $\begin{array}{l}+7.5 \\
-6.7\end{array}$ & $\begin{array}{l}+360 \\
{ }_{-350}\end{array}$ & $\begin{array}{l}+220 \\
-220\end{array}$ & $\begin{array}{l}+210 \\
-200\end{array}$ & $\begin{array}{l}70 \\
90\end{array}$ & $\begin{array}{l}+280 \\
-190\end{array}$ & & $\begin{array}{r}{ }_{-46.8}^{+49.8} \\
\end{array}$ & $\begin{array}{l}+49.2 \\
-26.5\end{array}$ & ${ }_{-0.0}^{+0.0}$ & $\begin{array}{r}+34.1 \\
{ }_{-296}\end{array}$ & $\begin{array}{l}+370 \\
{ }_{-300}^{3}\end{array}$ & $\begin{array}{l}+240 \\
-210\end{array}$ & $\begin{array}{r}+190 \\
+150\end{array}$ & $\begin{array}{l}-260 \\
140\end{array}$ \\
\hline B481 & $\begin{array}{l}-2.3 \\
-6.1\end{array}$ & $\begin{array}{r}6.4 .4 \\
28.7\end{array}$ & $\begin{array}{l}-6.4 \\
-36.4\end{array}$ & $\begin{array}{l}-250 \\
-220\end{array}$ & -30 & -400 & $\begin{array}{l}-190 \\
460\end{array}$ & $\begin{array}{r}-60 \\
60\end{array}$ & 21 & $\begin{array}{l}-46.8 \\
12.7\end{array}$ & 27.9 & $\begin{array}{c}-0.0 \\
0.0\end{array}$ & 31.1 & $\begin{array}{l}-3100 \\
-210\end{array}$ & 60 & $\begin{array}{l}-450 \\
-440\end{array}$ & $\begin{array}{l}-140 \\
500\end{array}$ \\
\hline Sta & & $\begin{array}{l}+3.0 \\
+3.1\end{array}$ & $\begin{array}{r}+3.9 \\
-3.3\end{array}$ & $\begin{array}{l}+70 \\
+80\end{array}$ & $\begin{array}{l}+60 \\
+60\end{array}$ & $\begin{array}{l}+50 \\
{ }_{-5}^{5}\end{array}$ & +80 & $\begin{array}{l}+90 \\
+-80\end{array}$ & & $\begin{array}{l}+6.1 \\
+55\end{array}$ & $\begin{array}{l}+7.7 \\
+-76\end{array}$ & $\begin{array}{l}+0.0 \\
-0.0\end{array}$ & $\begin{array}{l}+8.5 \\
+-8.4\end{array}$ & $\begin{array}{l}+70 \\
+70\end{array}$ & $\begin{array}{l}+80 \\
{ }_{-80}\end{array}$ & $+{ }_{-40}^{+40}$ & $\begin{array}{l}+60 \\
{ }_{-40}\end{array}$ \\
\hline 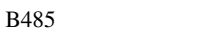 & $\begin{array}{l}-26.3 \\
-26.3\end{array}$ & $\begin{array}{l}-3.1 \\
-6.0\end{array}$ & 27.4 & $\begin{array}{l}-80 \\
-330\end{array}$ & $\begin{array}{l}-60 \\
140\end{array}$ & $\begin{array}{l}-570 \\
270\end{array}$ & 450 & $\begin{array}{r}-80 \\
30\end{array}$ & 2 & $\begin{array}{l}-5.3 \\
4.3\end{array}$ & $\begin{array}{l}-1.6 \\
-14.8\end{array}$ & $\begin{array}{r}-0.0 \\
0.0\end{array}$ & $\begin{array}{r}-8.4 \\
15.5\end{array}$ & -380 & $\begin{array}{r}-80 \\
20\end{array}$ & 370 & 530 \\
\hline Stat & & ${ }_{-0.6}^{+0.5}$ & $\begin{array}{l}{ }_{-2.1}^{2} .4 \\
\end{array}$ & $\begin{array}{l}{ }_{-30}^{30} \\
-30\end{array}$ & ${ }_{-20}^{20}$ & ${ }_{-20}^{20}$ & ${ }_{-20}^{+20}$ & $\begin{array}{l}+20 \\
-20\end{array}$ & & $\begin{array}{l}+3.5 \\
-2.9\end{array}$ & $\begin{array}{l}+1.7 \\
-2.0\end{array}$ & ${ }_{-0.0}^{+0.0}$ & ${ }_{-2.1}^{+2.8}$ & $\begin{array}{l}+10 \\
{ }_{-10}^{10}\end{array}$ & $\begin{array}{l}+30 \\
+30\end{array}$ & ${ }_{-20}^{+10}$ & $\begin{array}{l}{ }_{-10}^{+10} \\
\text {. }\end{array}$ \\
\hline & -22.0 & 28.2 & -26.8 & -120 & 230 & -180 & 320 & -90 & 100 & -2.5 & -3.0 & 0.0 & 5.5 & -290 & 300 & -370 & 560 \\
\hline $\mathrm{St}$ & $\begin{array}{l}+1.6 \\
-1.9\end{array}$ & $\begin{array}{l}{ }_{-3.3}^{+3.8} \\
\end{array}$ & $\begin{array}{l}+3.1 \\
-3.7\end{array}$ & $\begin{array}{l}{ }_{-50}^{50} \\
-50\end{array}$ & $\begin{array}{l}+30 \\
-30\end{array}$ & $\begin{array}{l}+20 \\
-30\end{array}$ & ${ }_{-20}^{+20}$ & $\begin{array}{l}+20 \\
-20\end{array}$ & & $\begin{array}{l}{ }_{-4.8}^{3.9} \\
-4\end{array}$ & $\begin{array}{l}+3.1 \\
-3.0\end{array}$ & $\begin{array}{l}+0.0 \\
-0.0\end{array}$ & $\begin{array}{l}+3.9 \\
+2.9 \\
-2.9\end{array}$ & $\begin{array}{l}{ }_{-50}^{+80} \\
\text {. }\end{array}$ & $\begin{array}{l}+60 \\
{ }_{-50}^{60}\end{array}$ & $\begin{array}{l}+60 \\
{ }_{-100}^{60}\end{array}$ & $\begin{array}{l}+70 \\
-60\end{array}$ \\
\hline & -21.6 & $\begin{array}{l}-3.3 \\
\end{array}$ & -14.0 & $\begin{array}{l}-30 \\
-70\end{array}$ & 250 & -170 & 20 & -130 & 100 & $\begin{array}{l}-12.8 \\
-12.8\end{array}$ & $\begin{array}{l}-3.0 \\
-1.5\end{array}$ & $\begin{array}{c}-0.0 \\
0.0\end{array}$ & 13.3 & -210 & 290 & $\begin{array}{l}-100 \\
-230\end{array}$ & $\begin{array}{r}-60 \\
430\end{array}$ \\
\hline & ${ }_{-2}^{+1}$ & $\begin{array}{r}{ }_{-2.0}^{+2.9} \\
-\end{array}$ & $\begin{array}{l}+1.5 \\
-2.1\end{array}$ & $\begin{array}{l}{ }_{-50}^{50} \\
-50\end{array}$ & $\begin{array}{l}{ }_{-30}^{30} \\
-30\end{array}$ & $\begin{array}{l}+50 \\
-50\end{array}$ & + & $\begin{array}{l}{ }_{-20}^{30} \\
\end{array}$ & & $\begin{array}{l}{ }_{-4.8}^{5.8} \\
-x^{2}\end{array}$ & $\begin{array}{l}+4.8 \\
-4.7\end{array}$ & $\begin{array}{l}{ }_{-0.0}^{+0.0} \\
\end{array}$ & $\begin{array}{l}{ }_{-4.2}^{4.6} \\
\text { (2) }\end{array}$ & $\begin{array}{l}+80 \\
{ }_{-100}^{+80}\end{array}$ & $\begin{array}{l}+20 \\
-30\end{array}$ & $\begin{array}{l}+20 \\
-30\end{array}$ & $\begin{array}{l}+50 \\
+-30\end{array}$ \\
\hline & -1.9 & 14.1 & 48.9 & $\begin{array}{l}-360 \\
-360\end{array}$ & -350 & $\begin{array}{l}-300 \\
460\end{array}$ & & 290 & 0 & 33.3 & 46.7 & $\begin{array}{r}-0.0 \\
0.0\end{array}$ & 57.5 & -330 & $\begin{array}{l}-300 \\
-290\end{array}$ & $\begin{array}{l}-510 \\
510\end{array}$ & 670 \\
\hline & & ${ }_{-1.1}^{+1.1}$ & & -50 & & $\begin{array}{l}{ }_{-20}^{30} \\
-20\end{array}$ & $\begin{array}{l}+70 \\
-60\end{array}$ & $\begin{array}{r}+70 \\
-70\end{array}$ & & $\begin{array}{l}+6.1 \\
-566\end{array}$ & $\begin{array}{l}+8.2 \\
-76\end{array}$ & $\begin{array}{l}+0.0 \\
-0.0\end{array}$ & $\begin{array}{l}+9.7 \\
+89\end{array}$ & $\begin{array}{l}+50 \\
+50\end{array}$ & ${ }_{-70}^{+60}$ & ${ }_{-20}^{+20}$ & $\begin{array}{l}+60 \\
-60\end{array}$ \\
\hline & $\begin{array}{l}-0.5 \\
-6.0\end{array}$ & $\begin{array}{r}-1.14 \\
5.2\end{array}$ & $\begin{array}{l}-3.6 \\
17.8\end{array}$ & $\begin{array}{l}-50 \\
-110\end{array}$ & $\begin{array}{l}-60 \\
70\end{array}$ & 300 & $\begin{array}{l}-60 \\
330\end{array}$ & $\begin{array}{l}-70 \\
-160\end{array}$ & 100 & $\begin{array}{c}-5.6 \\
0.1\end{array}$ & $\begin{array}{l}-7.6 \\
0.6\end{array}$ & $\begin{array}{r}-0.0 \\
0.0\end{array}$ & $\begin{array}{r}-8.9 \\
1.0\end{array}$ & $\begin{array}{l}-50 \\
-170\end{array}$ & 210 & $\begin{array}{l}-20 \\
590\end{array}$ & $\begin{array}{l}-600 \\
660\end{array}$ \\
\hline Sta & + & ${ }_{-0.4}^{+0.5}$ & .6 & ${ }_{-20}^{+20}$ & $\begin{array}{l}{ }_{-30}^{30} \\
\end{array}$ & +10 & ${ }_{-1}^{+1}$ & $\begin{array}{l}+20 \\
-20\end{array}$ & & & +1.1 & $\begin{array}{l}+0.0 \\
-0.0\end{array}$ & $\begin{array}{l}{ }_{-06}^{1.0} \\
\text {. }\end{array}$ & $\begin{array}{l}+60 \\
-120\end{array}$ & ${ }_{-80}^{40}$ & $\begin{array}{l}{ }_{-40}^{60} \\
-40\end{array}$ & $\begin{array}{l}+70 \\
-50\end{array}$ \\
\hline B598 & 1 & -0.5 & 20.4 & 40 & 50 & 300 & 310 & -170 & 100 & $\begin{array}{l}-0.8 \\
-0.7\end{array}$ & $\begin{array}{l}-2.8 \\
-2.1\end{array}$ & $\begin{array}{r}-0.0 \\
0.0\end{array}$ & $\begin{array}{l}-0.6 \\
3.4\end{array}$ & $\begin{array}{r}-120 \\
30\end{array}$ & $\begin{array}{r}-80 \\
-30\end{array}$ & 550 & 550 \\
\hline & & ${ }_{-0.1}^{+0.1}$ & ${ }_{-1.3}^{+1.4}$ & +6 & $\begin{array}{l}+60 \\
-60\end{array}$ & $\begin{array}{l}+30 \\
+30\end{array}$ & $\begin{array}{l}+30 \\
+20\end{array}$ & ${ }_{-20}^{+30}$ & & $\begin{array}{l}+2.4 \\
{ }_{-26}\end{array}$ & $\begin{array}{l}+2.3 \\
{ }_{-26}\end{array}$ & $\begin{array}{l}+0.0 \\
-0.0\end{array}$ & $\begin{array}{l}+2.5 \\
-19\end{array}$ & $\begin{array}{l}+50 \\
+50\end{array}$ & $\begin{array}{l}{ }_{-50}^{50} \\
\end{array}$ & $\begin{array}{l}+60 \\
+60\end{array}$ & $\begin{array}{l}+70 \\
-60\end{array}$ \\
\hline B. & -5.5 & -0.1 & 5. & 110 & 190 & 270 & 350 & -220 & 100 & -6.6 & -3.4 & 0.0 & 7.5 & 0 & 150 & 340 & 380 \\
\hline & $\begin{array}{l}+0.5 \\
-0.4\end{array}$ & ${ }_{-0.1}^{+0.1}$ & $\frac{99}{8}$ & +2 & ${ }_{-20}^{20}$ & $\begin{array}{l}{ }_{-10}^{10} \\
-10\end{array}$ & $\begin{array}{l}+20 \\
-20\end{array}$ & $\begin{array}{l}+20 \\
-10\end{array}$ & & $\begin{array}{l}{ }_{-0 .}^{0.6} \\
\text {. }\end{array}$ & $+{ }_{-0.4}^{0.4}$ & ${ }_{-0.0}^{+0.0}$ & ${ }_{-0.5}^{+0.4}$ & ${ }_{-20}^{+20}$ & $\begin{array}{l}+20 \\
-30\end{array}$ & $\begin{array}{l}+20 \\
-20\end{array}$ & $\begin{array}{l}+20 \\
-20\end{array}$ \\
\hline B & 1 & 0.4 & 20.8 & 34 & 90 & 150 & 380 & -100 & 100 & -23 & -6.3 & 0.0 & 24.7 & 21 & 60 & 290 & 370 \\
\hline & & ${ }_{-0.1}^{+0.1}$ & +1.6 & +3 & +30 $+{ }_{-30}^{+30}$ & ${ }_{-20}^{+20}$ & ${ }_{-22}^{+24}$ & $\begin{array}{l}{ }_{-20}^{30} \\
-20\end{array}$ & & $\begin{array}{l}+3.7 \\
-4.6 \\
-4.6\end{array}$ & $\begin{array}{l}+1.7 \\
-1.7\end{array}$ & ${ }_{-0.0}^{+0.0}$ & $\begin{array}{l}+4.5 \\
-3.6\end{array}$ & $\begin{array}{l}+30 \\
-30 \\
-30\end{array}$ & ${ }_{-20}^{+20}$ & $\begin{array}{l}+20 \\
-20\end{array}$ & $\begin{array}{l}+10 \\
-10\end{array}$ \\
\hline B & -4 & $\begin{array}{r}-0.1 \\
4.0\end{array}$ & 11 & 26 & 0 & 360 & 4 & $\begin{array}{l}-20 \\
-60\end{array}$ & 100 & $\begin{array}{l}-4 \\
-10 .\end{array}$ & $\begin{array}{l}-1.1 \\
-0.3\end{array}$ & $\begin{array}{r}-0.0 \\
0.0\end{array}$ & $\begin{array}{l}-3.6 \\
10.9\end{array}$ & $\begin{array}{l}-30 \\
160\end{array}$ & $\begin{array}{l}-20 \\
170\end{array}$ & 430 & $\begin{array}{r}-10 \\
490\end{array}$ \\
\hline St & -0 & ${ }_{-0.3}^{+0.3}$ & ${ }_{-0.8}^{+0.8}$ & $\begin{array}{l}+20 \\
-20\end{array}$ & +20 & $\begin{array}{l}{ }_{-10}^{+10} \\
\end{array}$ & + & ${ }_{-10}^{+10}$ & & ${ }_{-0.5}^{+0.5}$ & ${ }_{-0.5}^{+0.5}$ & ${ }_{-0.0}^{+0.0}$ & ${ }_{-0.5}^{+0.5}$ & +20 & $\begin{array}{l}+20 \\
-20\end{array}$ & $\begin{array}{l}{ }_{-10}^{+10} \\
\text {. }\end{array}$ & $\begin{array}{l}{ }_{-10}^{+10} \\
\text {. }\end{array}$ \\
\hline & -22.0 & $\begin{array}{l}-0.3 \\
\end{array}$ & 38.2 & -250 & -230 & $\begin{array}{l}-100 \\
180\end{array}$ & 4 & $\begin{array}{l}-10 \\
20\end{array}$ & 38 & - & & $\begin{array}{c}-0.0 \\
0.0\end{array}$ & 249 & -210 & $\begin{array}{l}-290 \\
\end{array}$ & $\begin{array}{l}-10 \\
350\end{array}$ & 490 \\
\hline Stat & ${ }_{-1.2}^{+1.1}$ & $\begin{array}{l}+2.5 \\
-28\end{array}$ & $\begin{array}{l}+3.2 \\
-2.9\end{array}$ & $\begin{array}{l}30 \\
30 \\
30\end{array}$ & $\begin{array}{l}+100 \\
-100\end{array}$ & $\begin{array}{l}+1 \\
+1\end{array}$ & + & $\begin{array}{l}+90 \\
-50\end{array}$ & & $\begin{array}{l}+_{-1}^{3} \\
-1\end{array}$ & $\begin{array}{l}+34.8 \\
-18.5\end{array}$ & $\begin{array}{l}+0.0 \\
-0.0\end{array}$ & $\begin{array}{l}+43.7 \\
-1146\end{array}$ & $\begin{array}{l}+60 \\
{ }_{-9}^{60}\end{array}$ & $\begin{array}{l}+50 \\
{ }_{-40}\end{array}$ & $\begin{array}{l}+70 \\
+130\end{array}$ & $\begin{array}{l}+60 \\
+{ }_{-40}\end{array}$ \\
\hline B108: & -8.5 & -28.7 & 31.1 & -380 & -260 & 190 & 50 & 90 & 2 & 35.3 & 9.2 & $\begin{array}{r}-0.0 \\
0.0\end{array}$ & $\begin{array}{l}-14.6 \\
36.8\end{array}$ & -280 & -320 & 290 & 520 \\
\hline $\mathrm{St}$ & 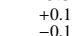 & $\begin{array}{l}+2.3 \\
+2.5\end{array}$ & $\begin{array}{l}+2.7 \\
-25\end{array}$ & $\begin{array}{l}+60 \\
+60\end{array}$ & $\begin{array}{r}+30 \\
+40\end{array}$ & $\begin{array}{l}+30 \\
+30\end{array}$ & $\begin{array}{l}+50 \\
+50\end{array}$ & $\begin{array}{l}+60 \\
+50\end{array}$ & & +1 & $\begin{array}{l}9.2 .2 \\
-6.9\end{array}$ & $\begin{array}{l}+0.0 \\
-0.0\end{array}$ & +164 & $\begin{array}{l}+60 \\
{ }_{-7}^{6}\end{array}$ & $\begin{array}{l}+20 \\
+20\end{array}$ & $\begin{array}{l}+40 \\
-40\end{array}$ & $\begin{array}{l}+30 \\
+30\end{array}$ \\
\hline B1 & -2.8 & 21.9 & 12.0 & 160 & 200 & 170 & 310 & -150 & 100 & -10.9 & 6.0 & 0.0 & 12.8 & 80 & 330 & 230 & 410 \\
\hline Stat. & ${ }_{-0.6}^{+0.7}$ & ${ }_{-2.3}^{+2.6}$ & ${ }_{-1.3}^{+1.4}$ & $\begin{array}{l}{ }_{-30}^{40} \\
\end{array}$ & $\begin{array}{l}+20 \\
-20\end{array}$ & $\begin{array}{l}+30 \\
-30\end{array}$ & ${ }_{-20}^{+20}$ & $\begin{array}{l}+30 \\
-30\end{array}$ & & $\begin{array}{l}{ }_{-2.2}^{+1.8} \\
\end{array}$ & $\begin{array}{l}3.5 \\
+3.1\end{array}$ & $\begin{array}{l}{ }_{-0.0}^{+0.0} \\
\end{array}$ & $\begin{array}{l}{ }_{-2.5}^{3} .0 \\
\end{array}$ & $\begin{array}{l}{ }_{-50}^{50} \\
-50\end{array}$ & $\begin{array}{l}+30 \\
{ }_{-40}^{3}\end{array}$ & $\begin{array}{l}+20 \\
-20\end{array}$ & $\begin{array}{l}+20 \\
-20\end{array}$ \\
\hline
\end{tabular}

Notes. Same as Table A.1. 


\section{Appendix B: Photometry and SED fitting}

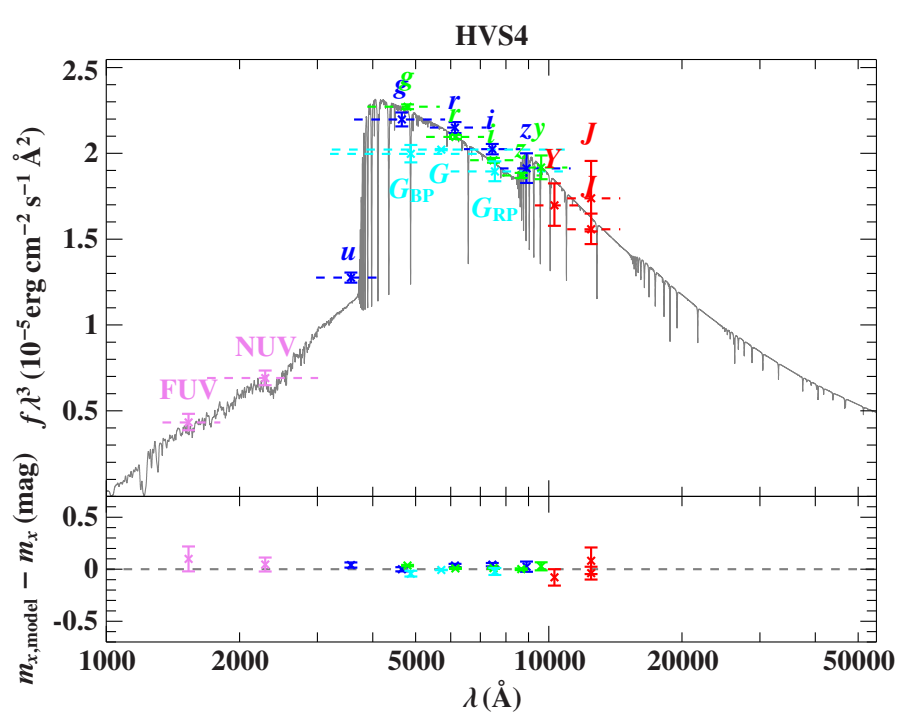

Fig. B.1. Same as Fig. 6. SDSS: blue; Pan-STARRS: green; UKIDSS: red; Gaia: cyan; GALEX: violet.

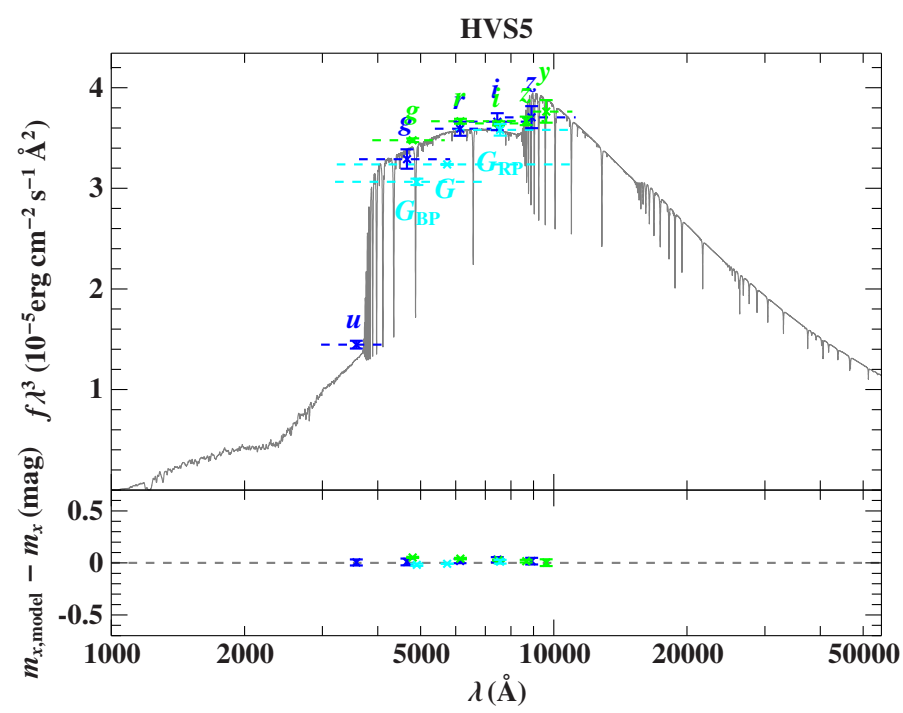

Fig. B.2. Same as Fig. 6. SDSS: blue; Pan-STARRS: green; Gaia: cyan.

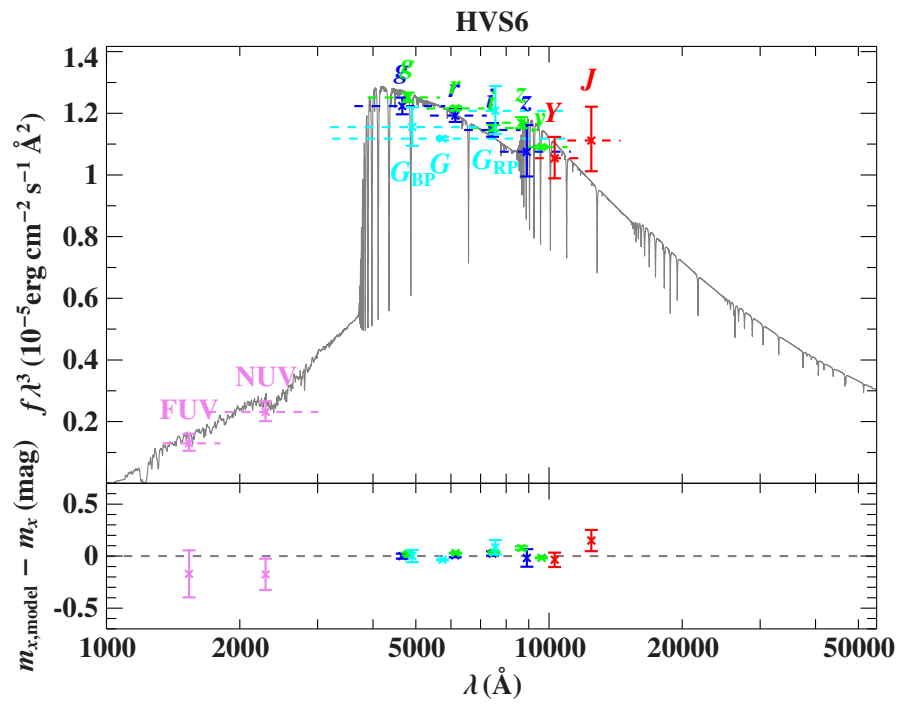

Fig. B.3. Same as Fig. 6. SDSS: blue; Pan-STARRS: green; UKIDSS: red; Gaia: cyan; GALEX: violet.

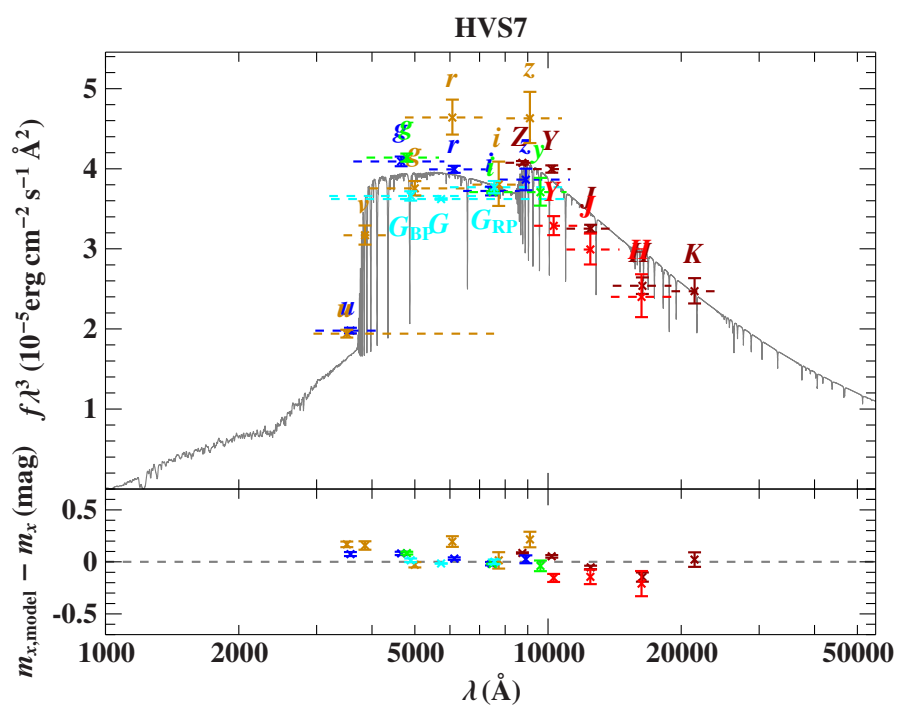

Fig. B.4. Same as Fig. 6. SDSS: blue; Pan-STARRS: green; UKIDSS: red; Gaia: cyan; VISTA: dark red; SkyMapper: orange.

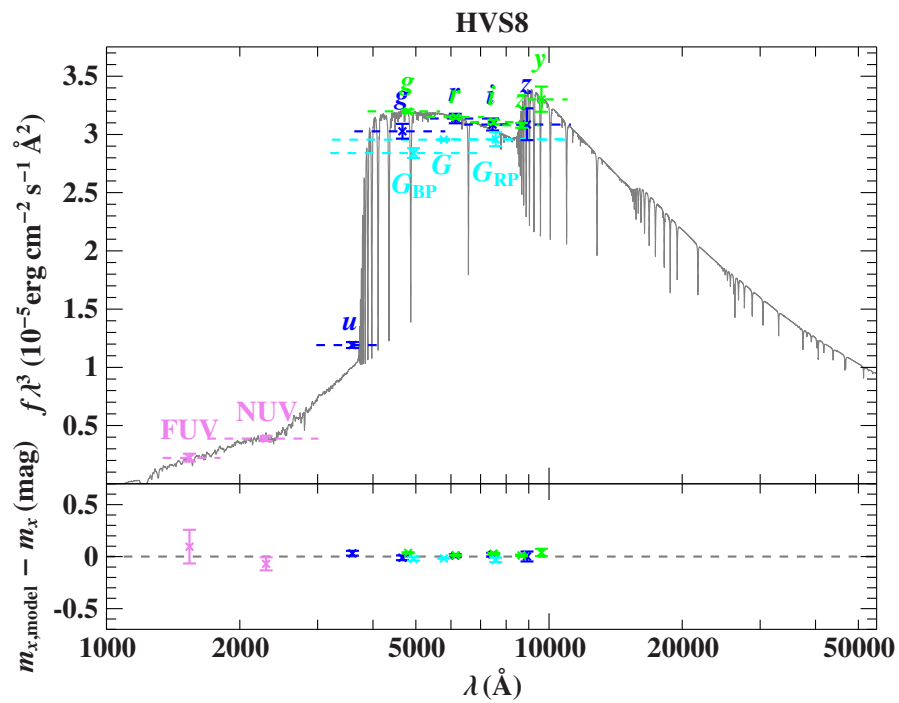

Fig. B.5. Same as Fig. 6. SDSS: blue; Pan-STARRS: green; Gaia: cyan; GALEX: violet. 


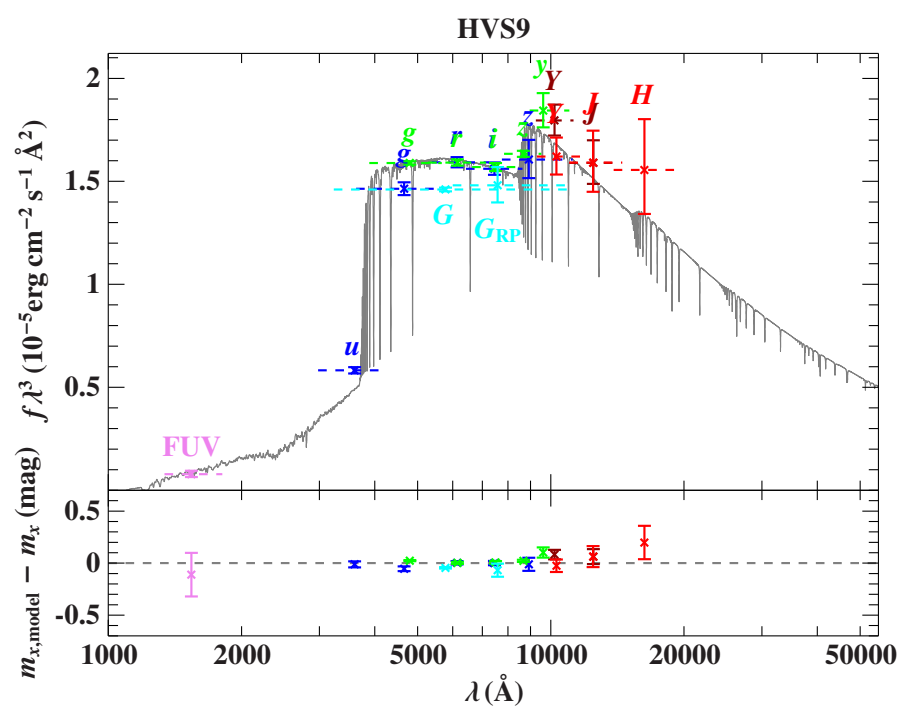

Fig. B.6. Same as Fig. 6. SDSS: blue; Pan-STARRS: green; UKIDSS: red; Gaia: cyan; GALEX: violet; VISTA: dark red.

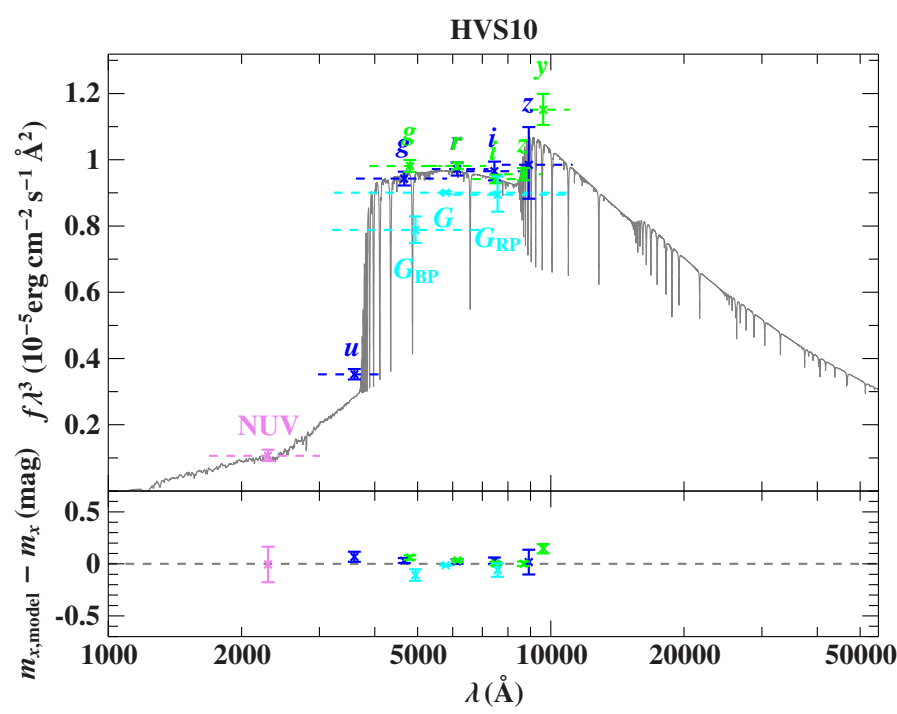

Fig. B.7. Same as Fig. 6. SDSS: blue; Pan-STARRS: green; Gaia: cyan; GALEX: violet.

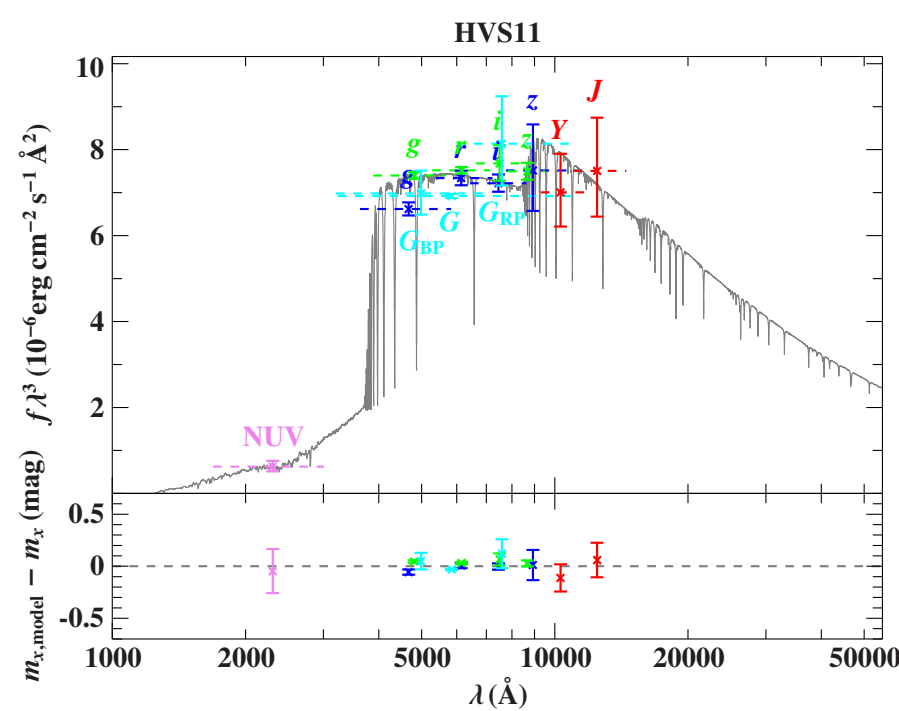

Fig. B.8. Same as Fig. 6. SDSS: blue; Pan-STARRS: green; UKIDSS: red; Gaia: cyan; GALEX: violet.

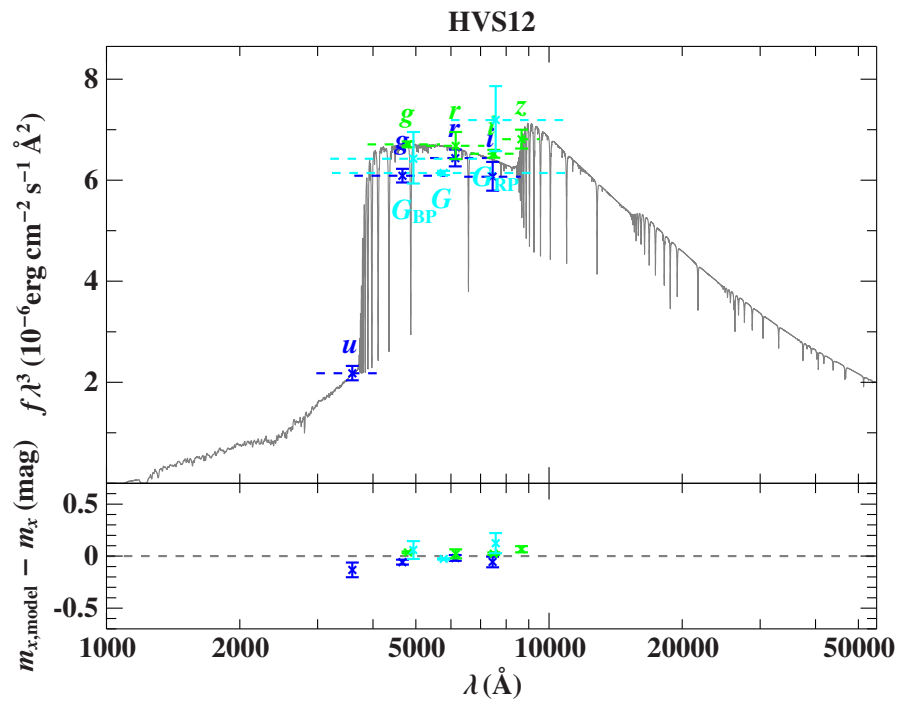

Fig. B.9. Same as Fig. 6. SDSS: blue; Pan-STARRS: green; Gaia: cyan.

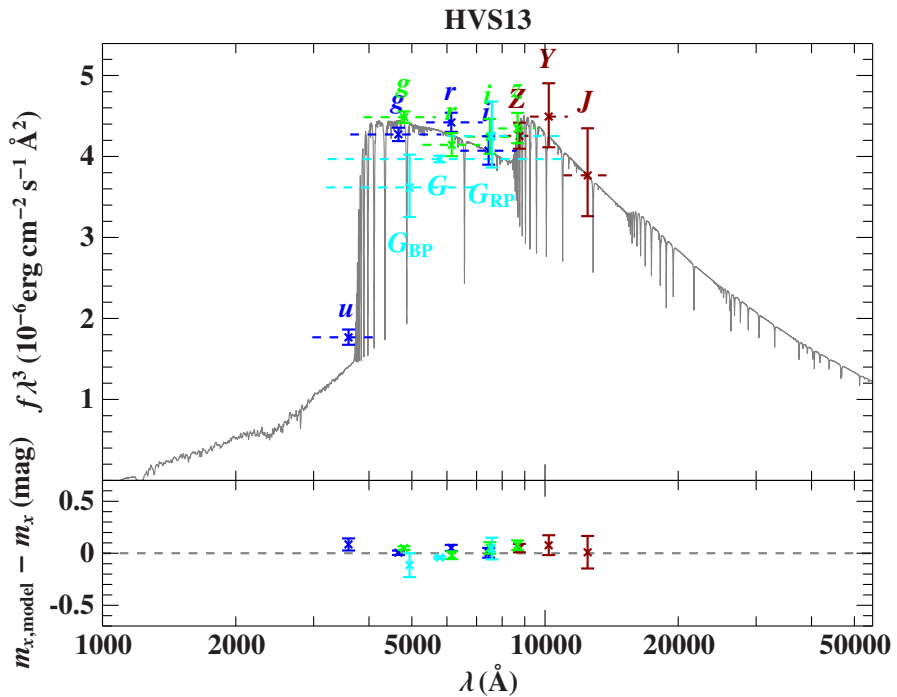

Fig. B.10. Same as Fig. 6. SDSS: blue; Pan-STARRS: green; Gaia: cyan; VISTA: dark red.

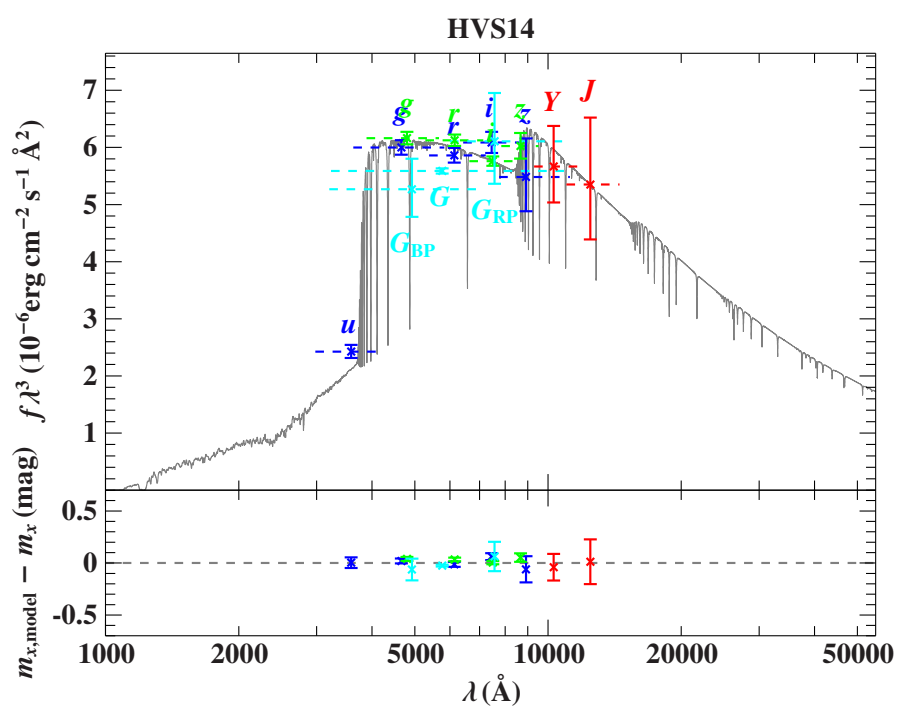

Fig. B.11. Same as Fig. 6. SDSS: blue; Pan-STARRS: green; UKIDSS: red; Gaia: cyan. 


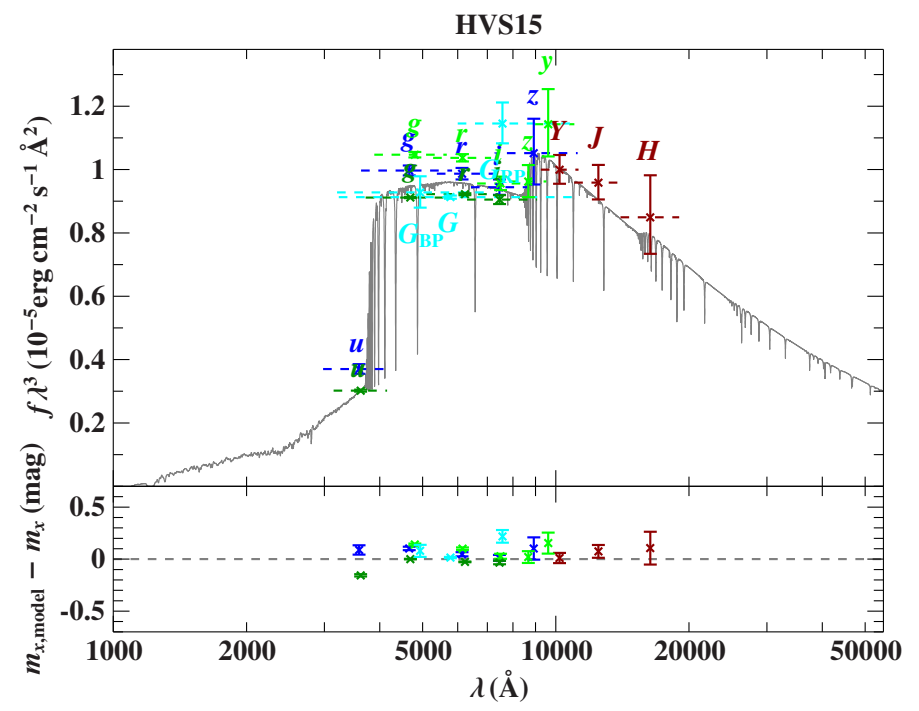

Fig. B.12. Same as Fig. 6. SDSS: blue; Pan-STARRS: green; Gaia: cyan; VISTA: dark red; VST-KiDs: dark green.

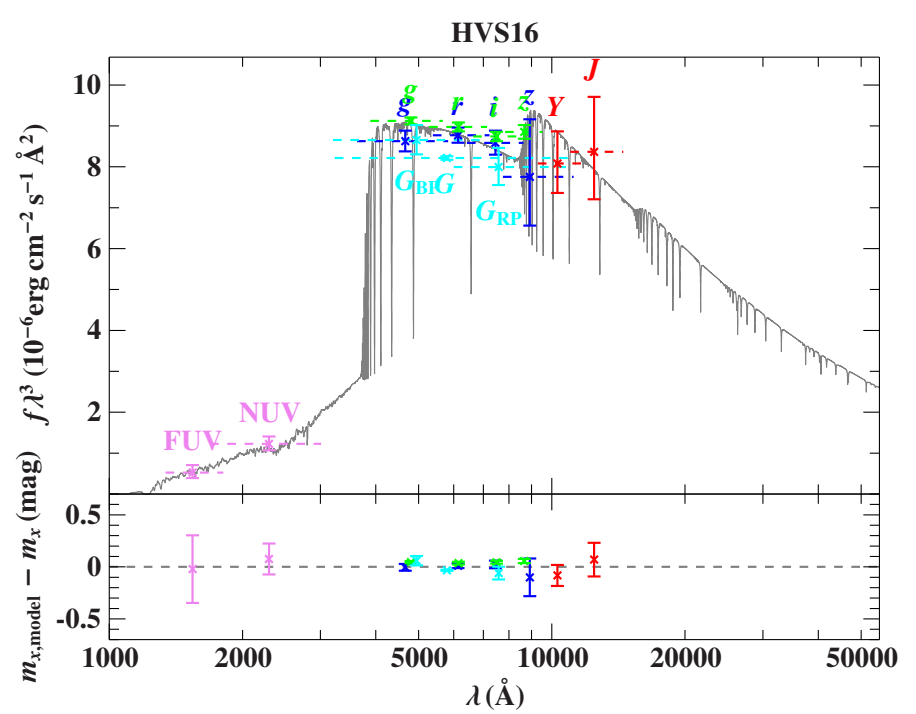

Fig. B.13. Same as Fig. 6. SDSS: blue; Pan-STARRS: green; UKIDSS: red; Gaia: cyan; GALEX: violet.

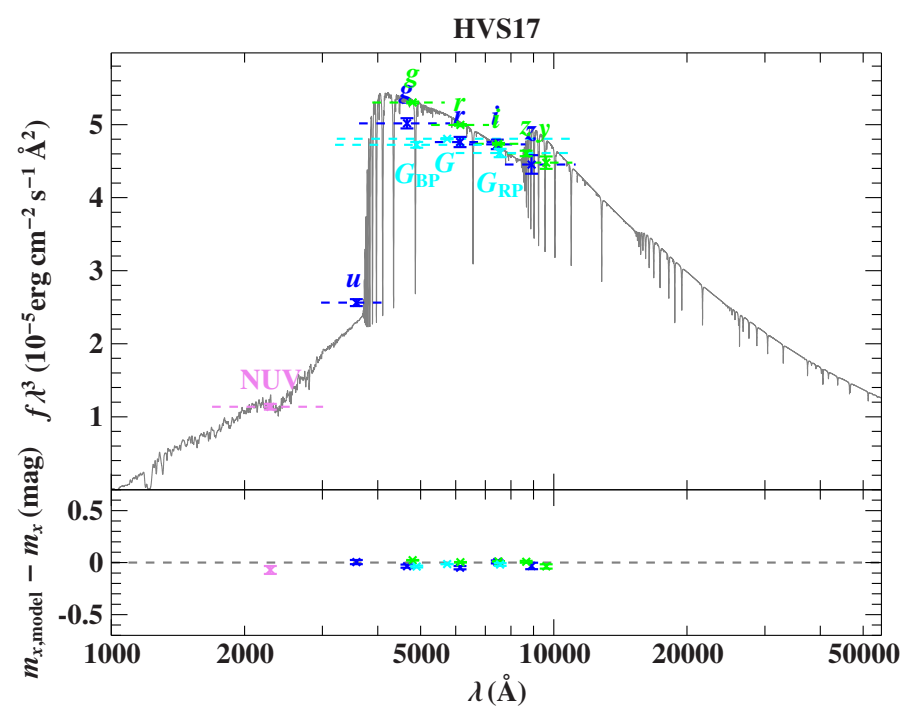

Fig. B.14. Same as Fig. 6. SDSS: blue; Pan-STARRS: green; Gaia: cyan; GALEX: violet.

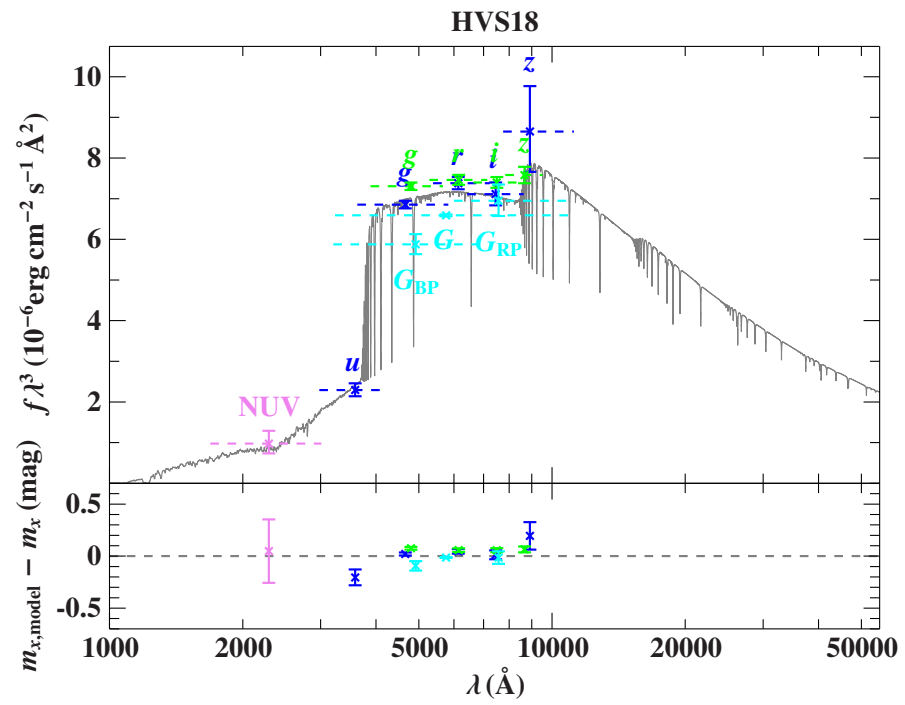

Fig. B.15. Same as Fig. 6. SDSS: blue; Pan-STARRS: green; Gaia: cyan; GALEX: violet.

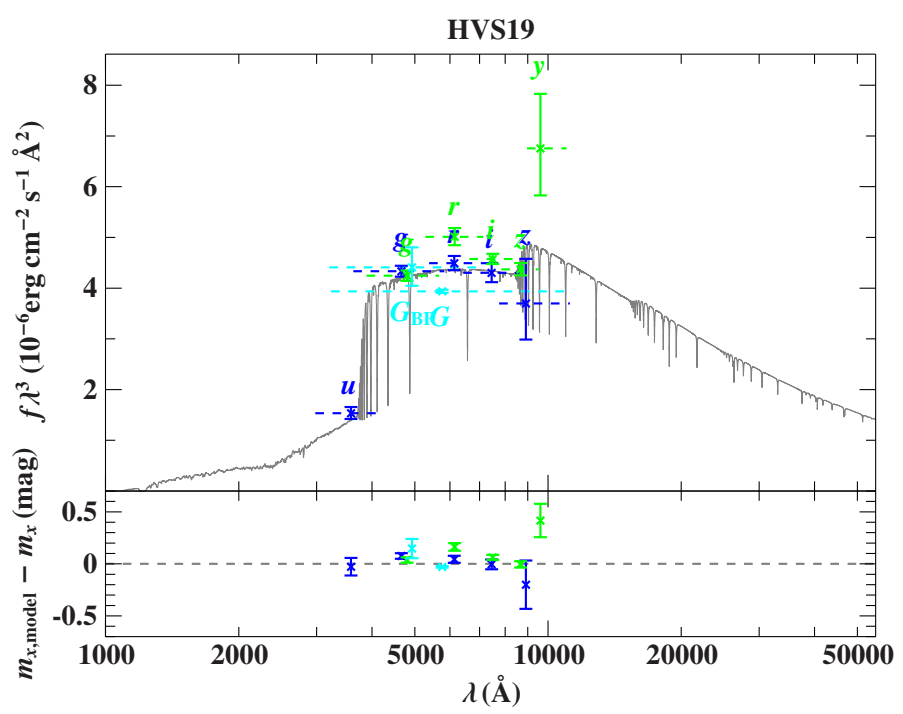

Fig. B.16. Same as Fig. 6. SDSS: blue; Pan-STARRS: green; Gaia: cyan.

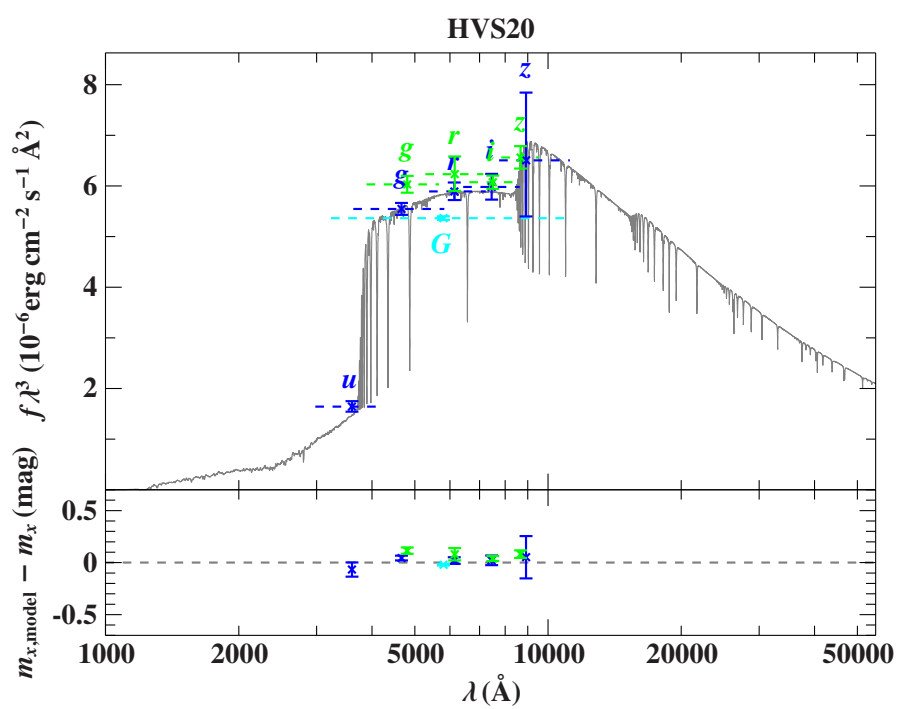

Fig. B.17. Same as Fig. 6. SDSS: blue; Pan-STARRS: green; Gaia: cyan. 


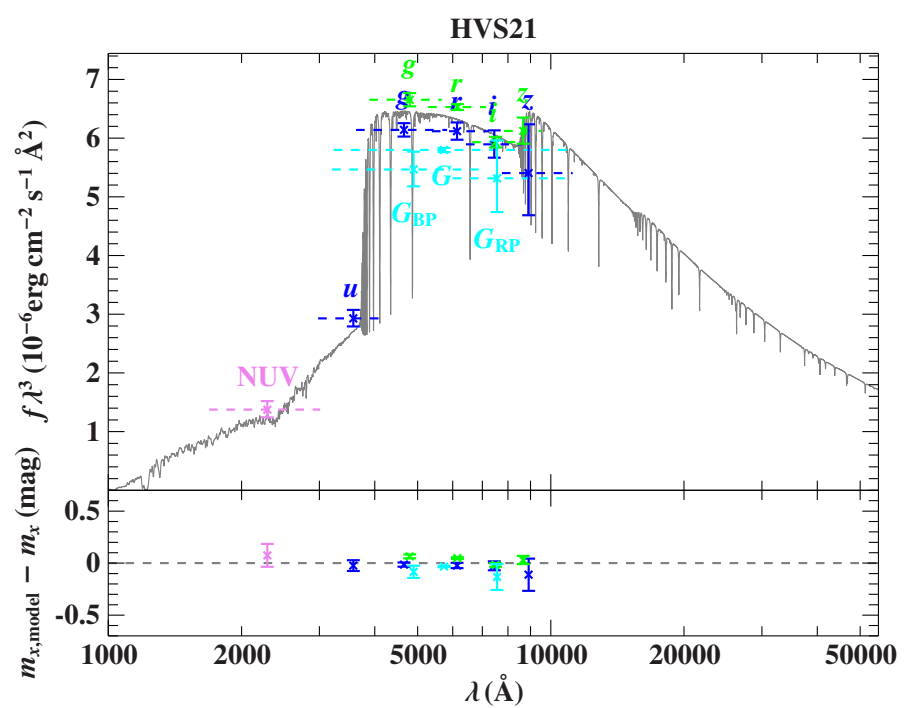

Fig. B.18. Same as Fig. 6. SDSS: blue; Pan-STARRS: green; Gaia: cyan; GALEX: violet.

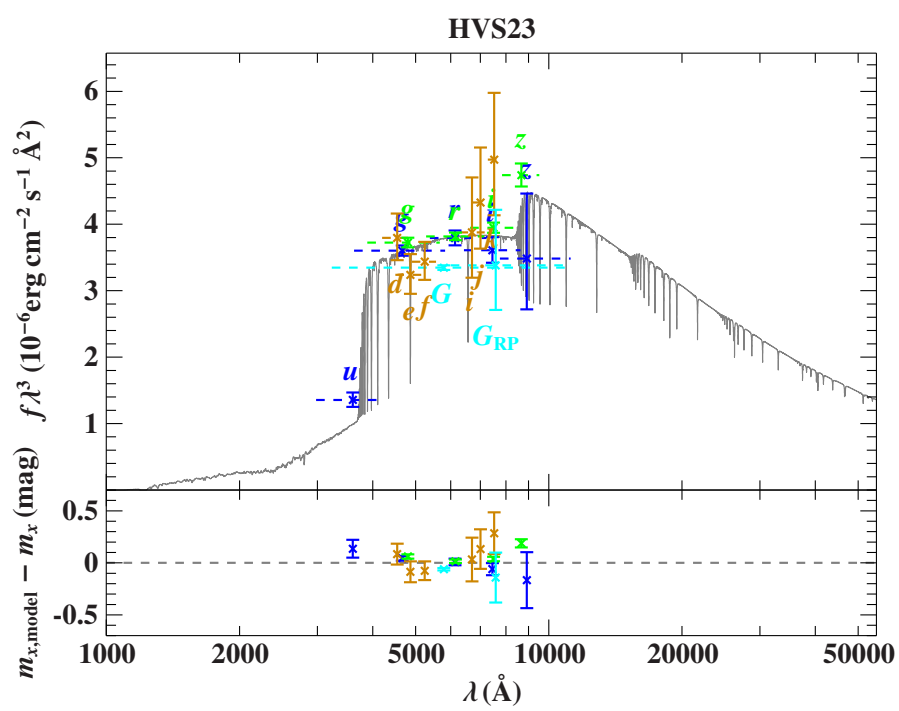

Fig. B.19. Same as Fig. 6. SDSS: blue; Pan-STARRS: green; Gaia: cyan; BATC: orange.

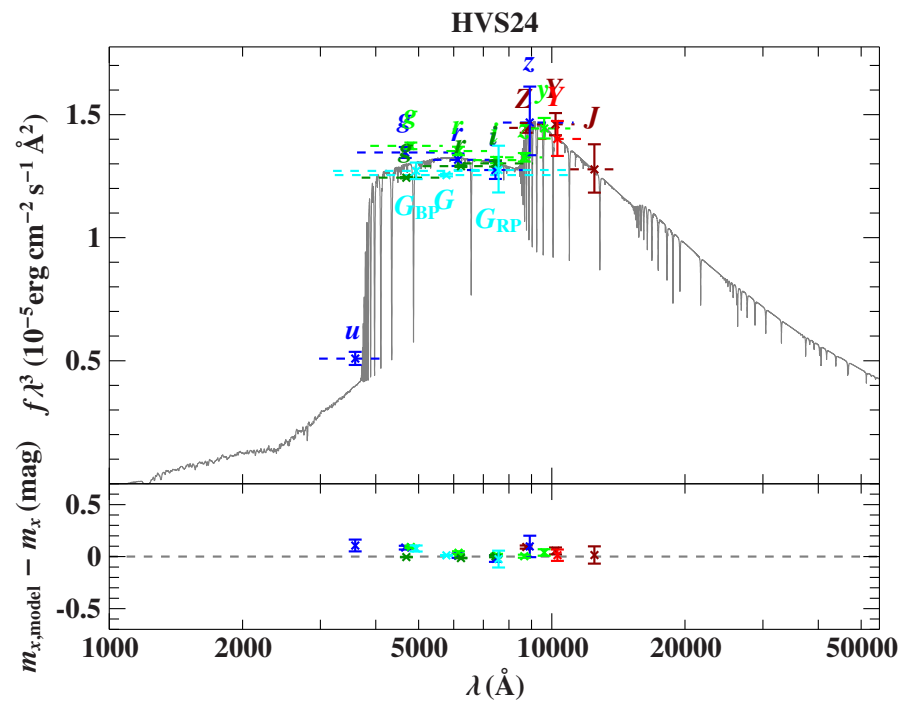

Fig. B.20. Same as Fig. 6. SDSS: blue; Pan-STARRS: green; UKIDSS: red; Gaia: cyan; VISTA: dark red; VST-KiDs: dark green.

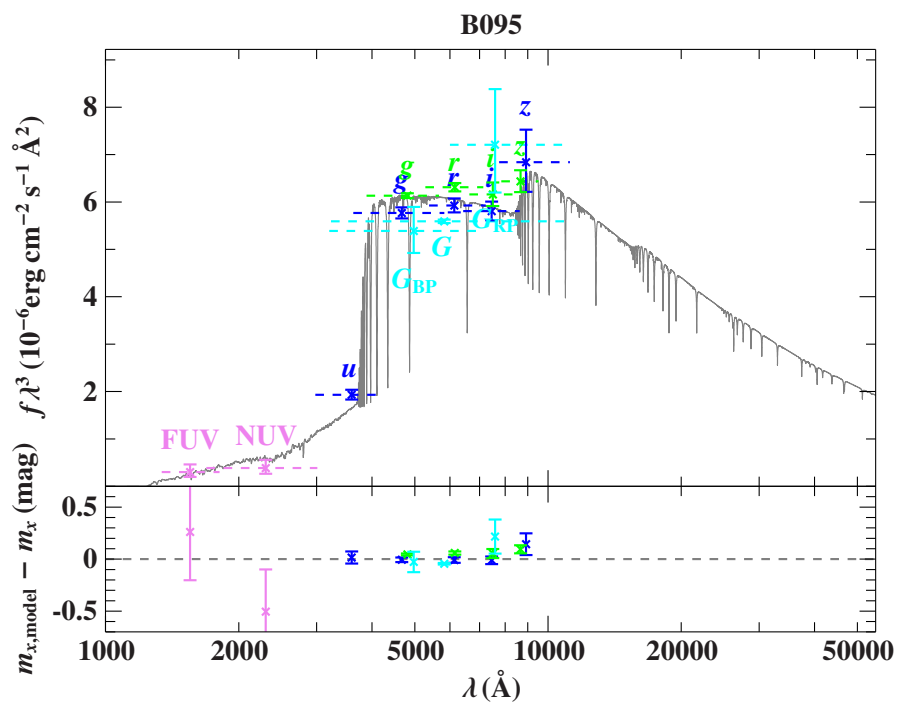

Fig. B.21. Same as Fig. 6. SDSS: blue; Pan-STARRS: green; Gaia: cyan; GALEX: violet.

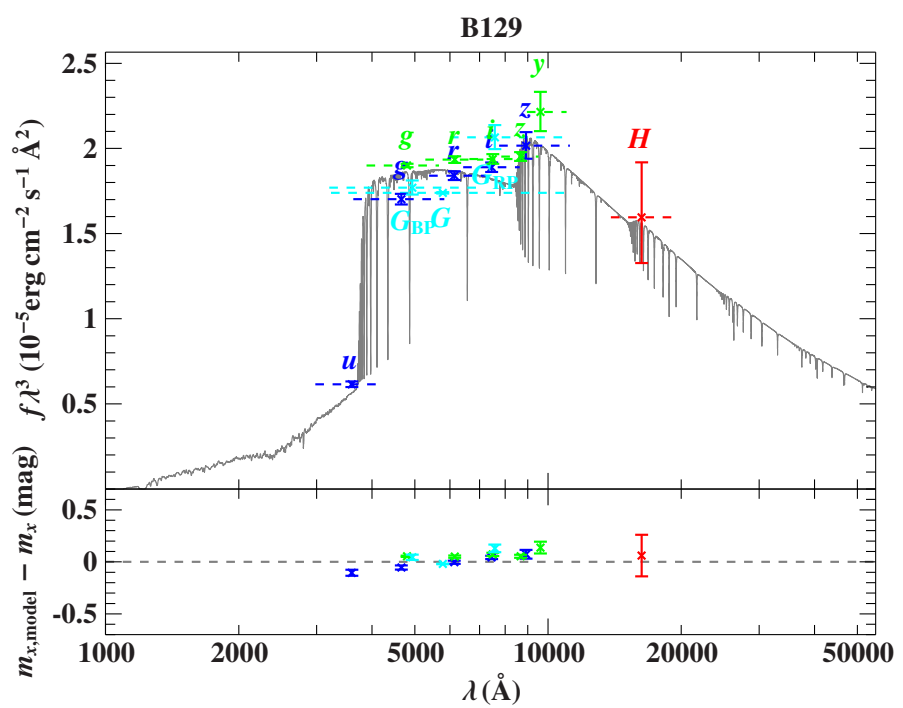

Fig. B.22. Same as Fig. 6. SDSS: blue; Pan-STARRS: green; UKIDSS: red; Gaia: cyan.

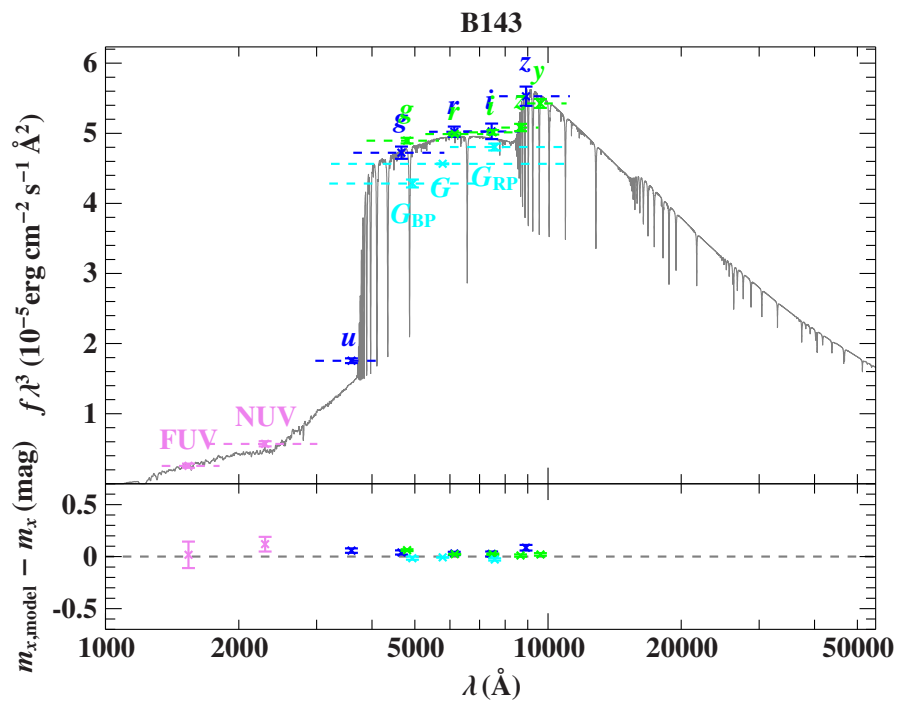

Fig. B.23. Same as Fig. 6. SDSS: blue; Pan-STARRS: green; Gaia: cyan; GALEX: violet. 


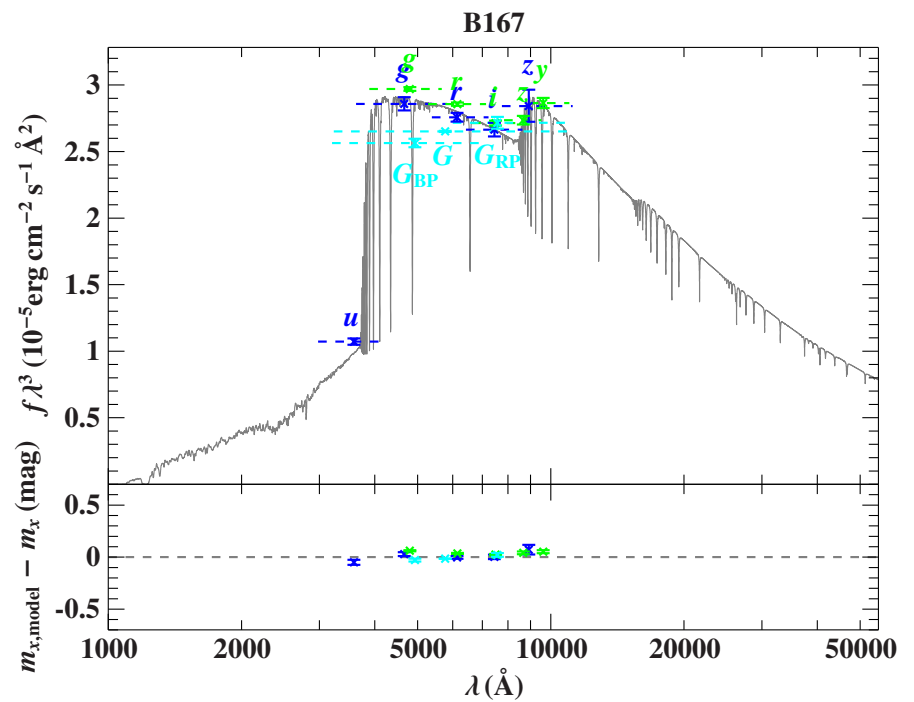

Fig. B.24. Same as Fig. 6. SDSS: blue; Pan-STARRS: green; Gaia: cyan.

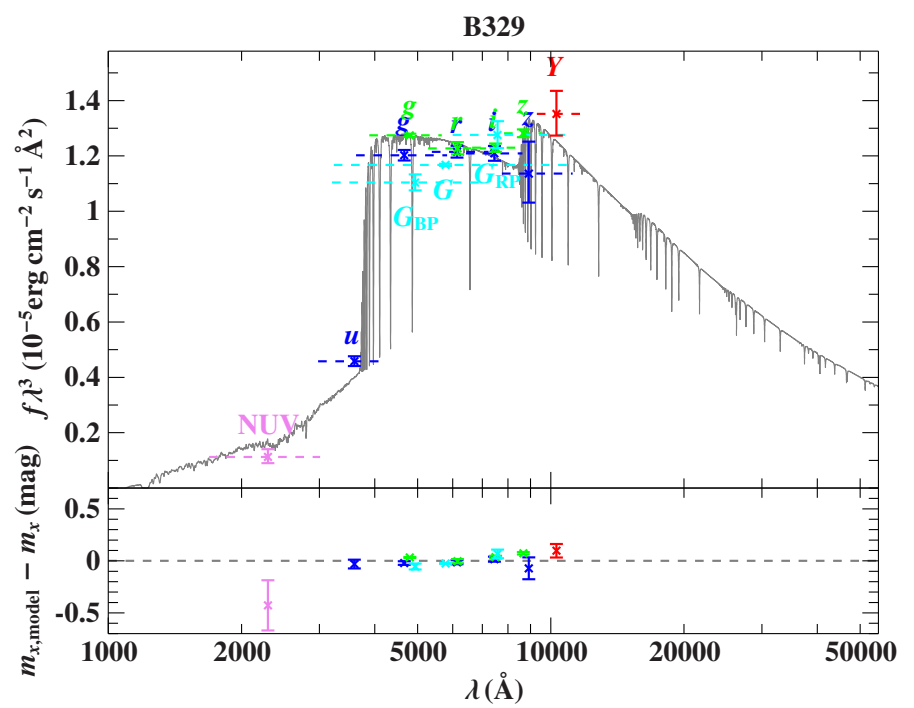

Fig. B.25. Same as Fig. 6. SDSS: blue; Pan-STARRS: green; UKIDSS: red; Gaia: cyan; GALEX: violet.

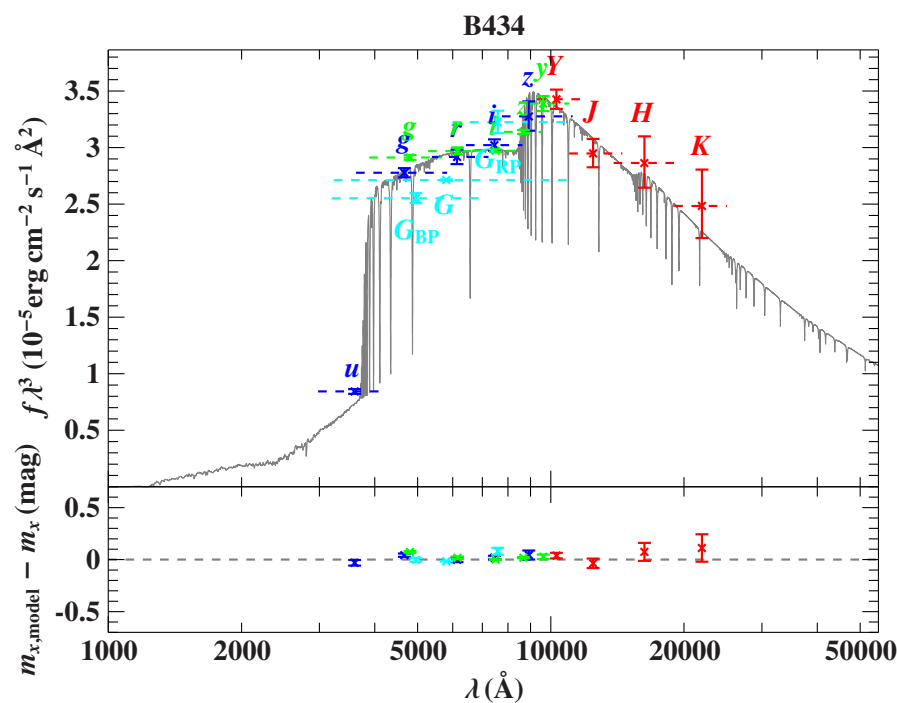

Fig. B.26. Same as Fig. 6. SDSS: blue; Pan-STARRS: green; UKIDSS: red; Gaia: cyan.

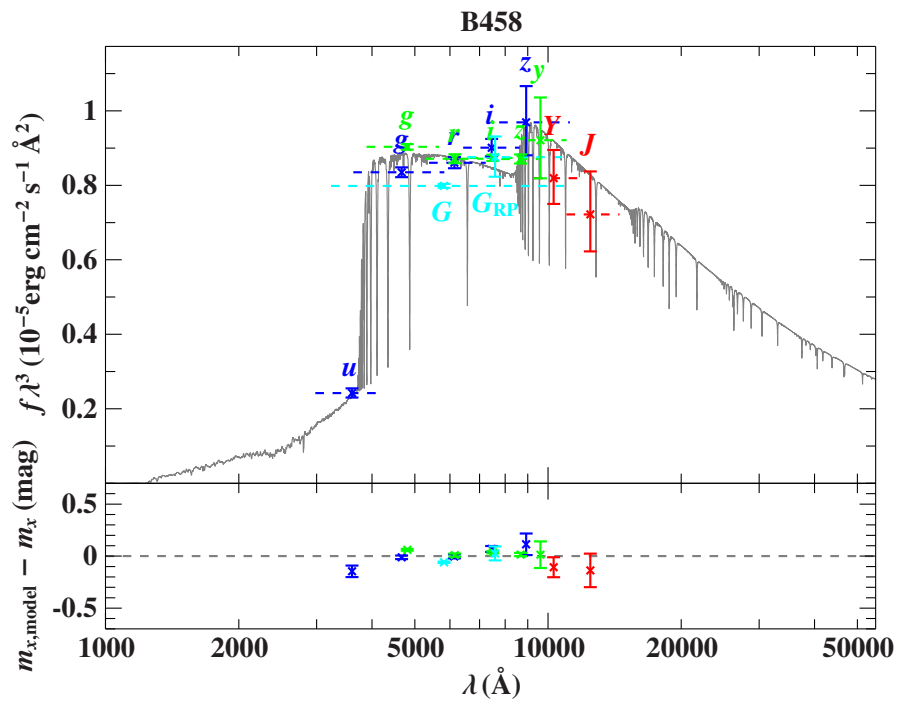

Fig. B.27. Same as Fig. 6. SDSS: blue; Pan-STARRS: green; UKIDSS: red; Gaia: cyan.

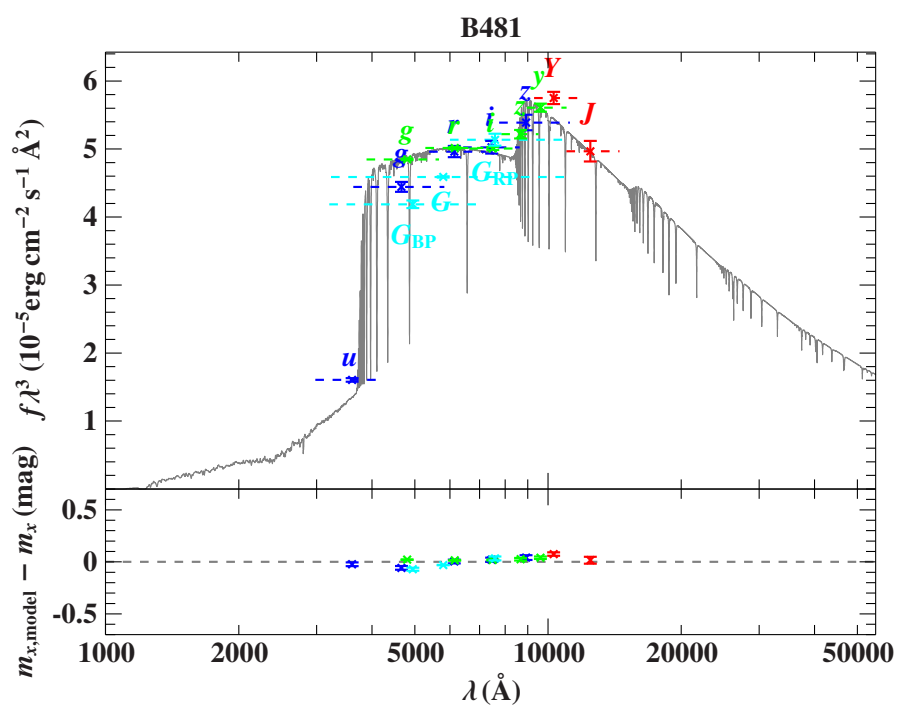

Fig. B.28. Same as Fig. 6. SDSS: blue; Pan-STARRS: green; UKIDSS: red; Gaia: cyan.

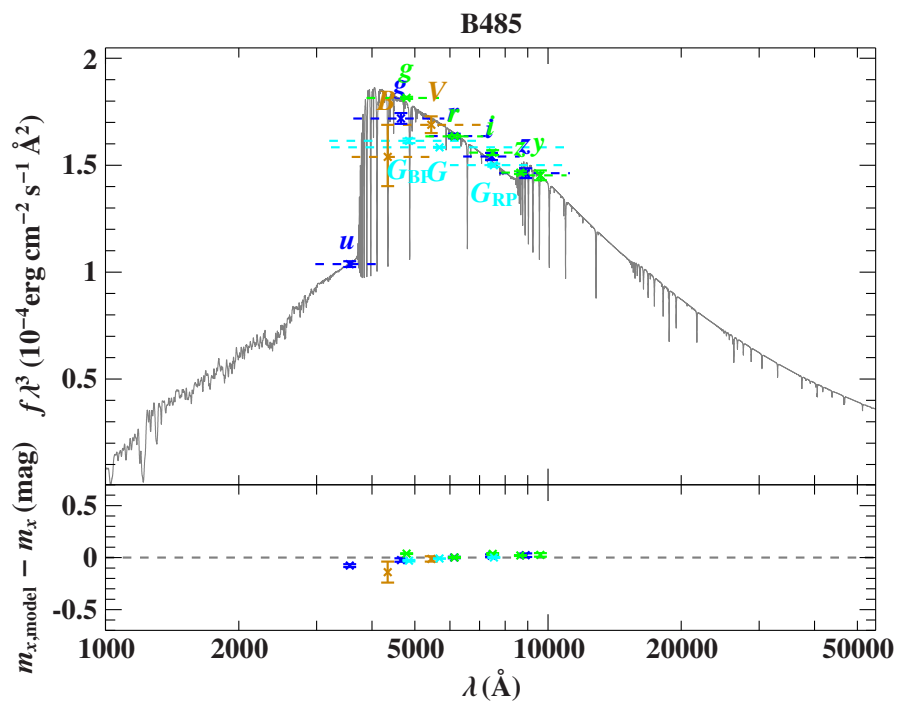

Fig. B.29. Same as Fig. 6. SDSS: blue; Pan-STARRS: green; Gaia: cyan; Johnson: orange. 


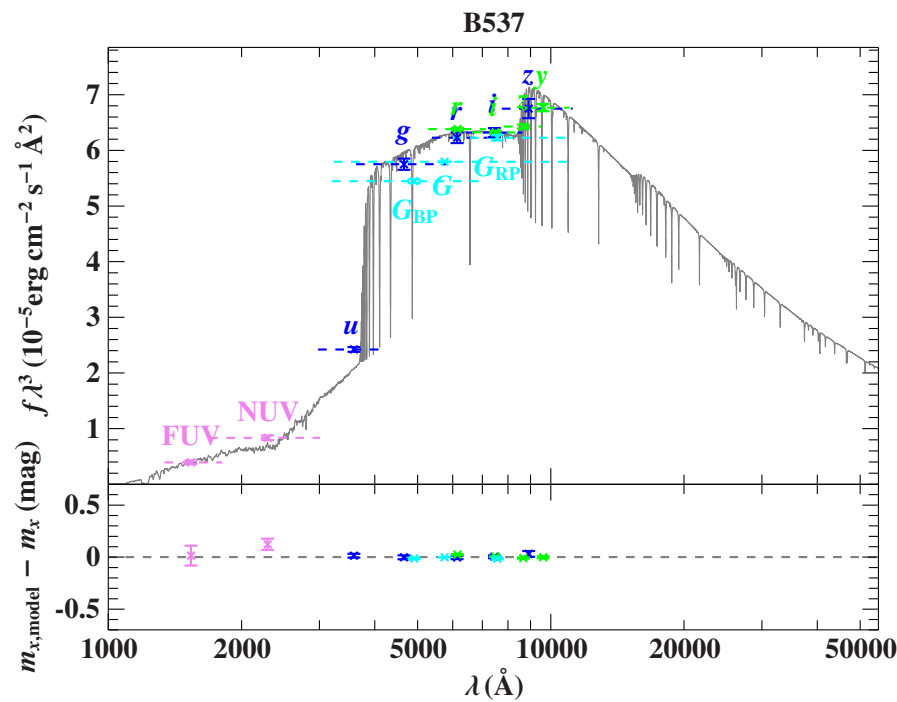

Fig. B.30. Same as Fig. 6. SDSS: blue; Pan-STARRS: green; Gaia: cyan; GALEX: violet.

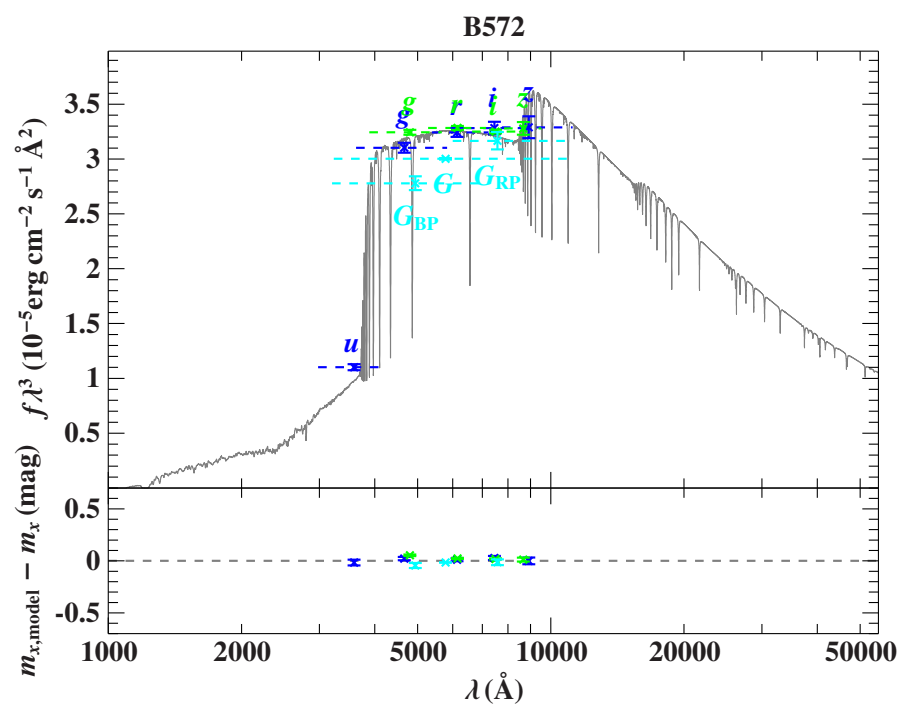

Fig. B.31. Same as Fig. 6. SDSS: blue; Pan-STARRS: green; Gaia: cyan.

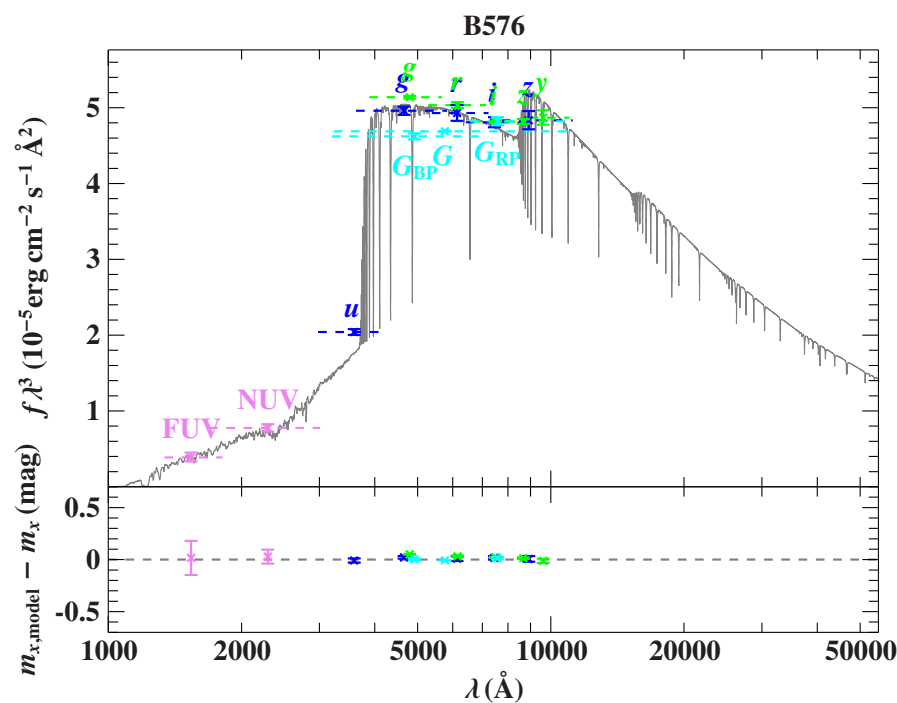

Fig. B.32. Same as Fig. 6. SDSS: blue; Pan-STARRS: green; Gaia: cyan; GALEX: violet.

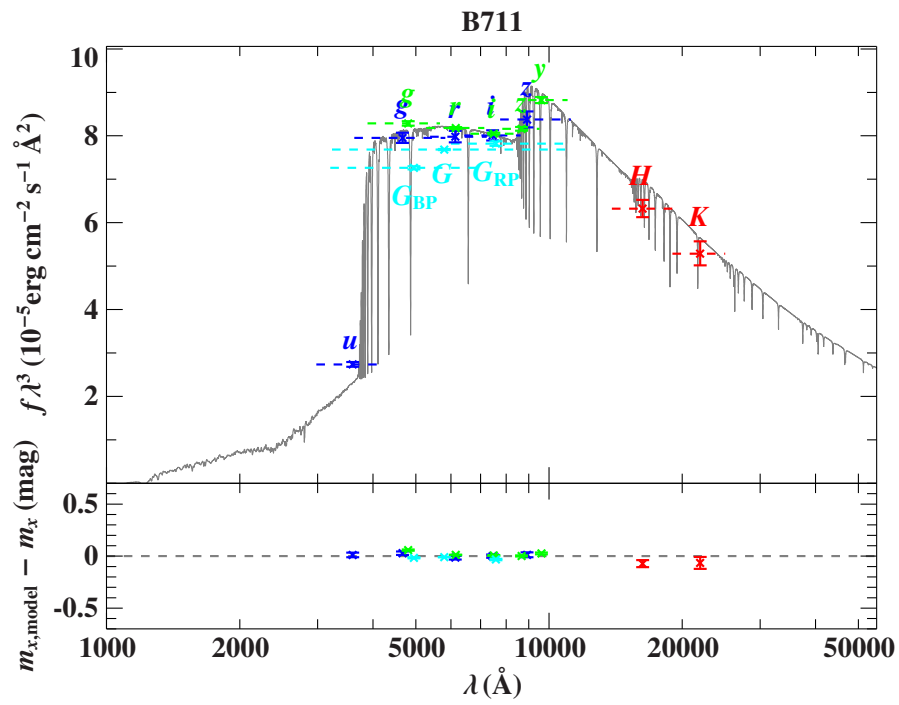

Fig. B.33. Same as Fig. 6. SDSS: blue; Pan-STARRS: green; UKIDSS: red; Gaia: cyan.

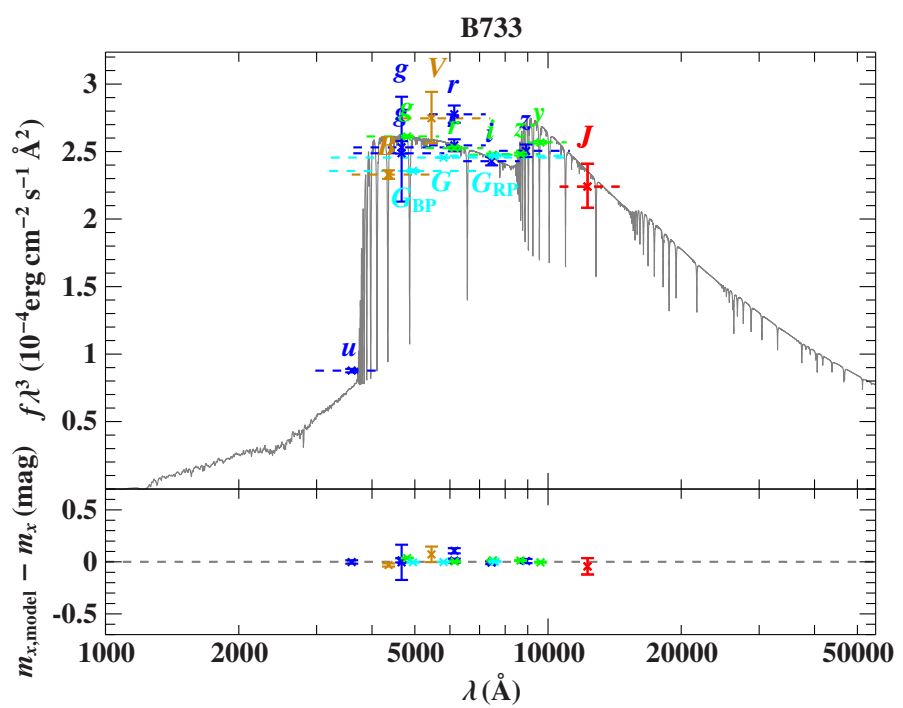

Fig. B.34. Same as Fig. 6. SDSS: blue; Pan-STARRS: green; 2MASS: red; Gaia: cyan; Johnson: orange.

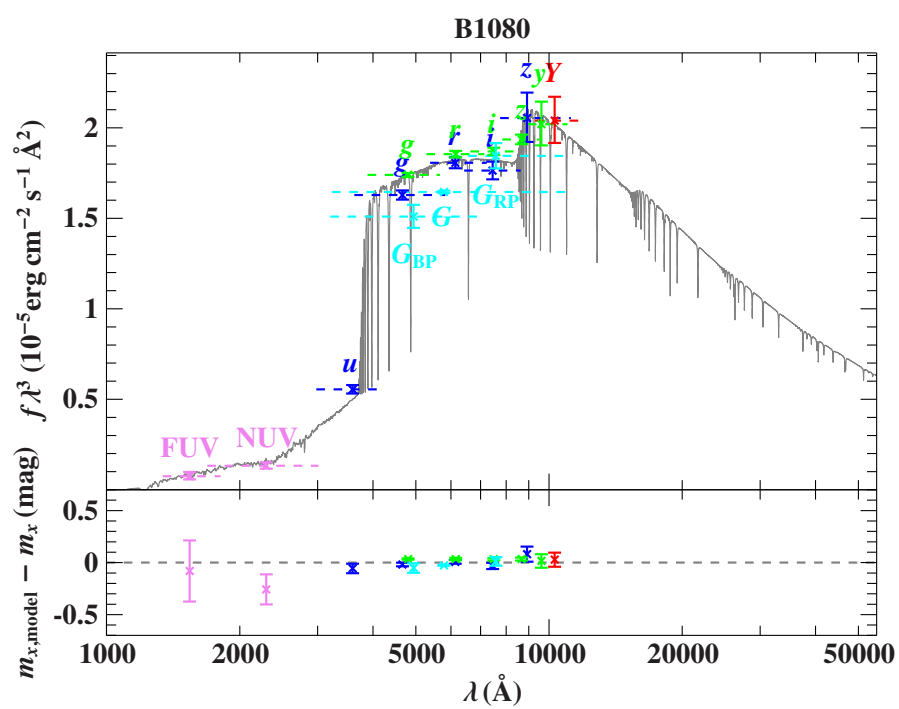

Fig. B.35. Same as Fig. 6. SDSS: blue; Pan-STARRS: green; UKIDSS: red; Gaia: cyan; GALEX: violet. 


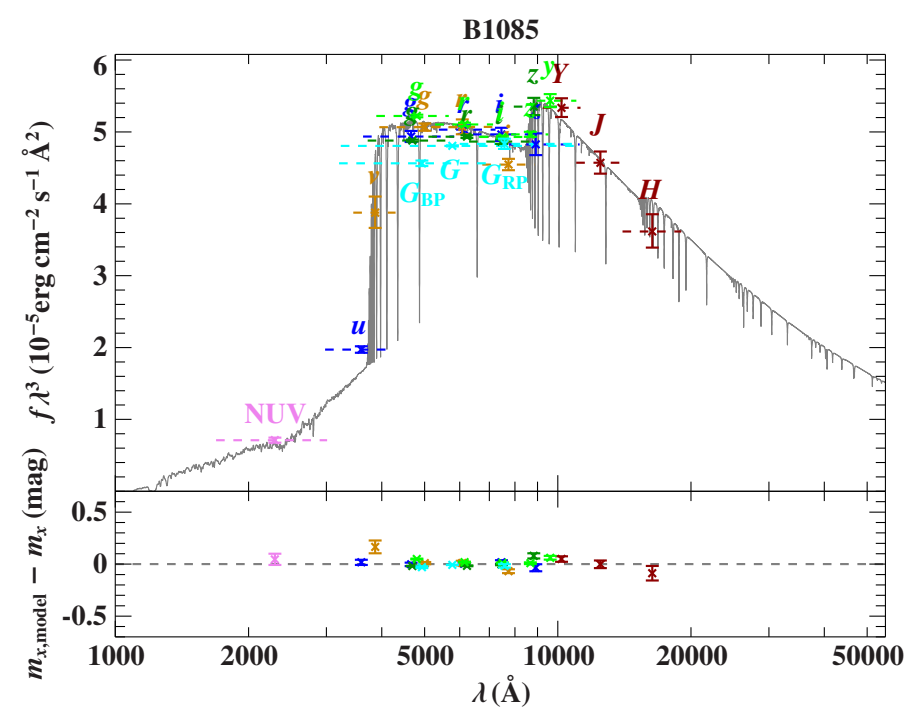

Fig. B.36. Same as Fig. 6. SDSS: blue; Pan-STARRS: green; Gaia: cyan; GALEX: violet; VISTA: dark red; SkyMapper: orange; VSTKiDs: dark green.

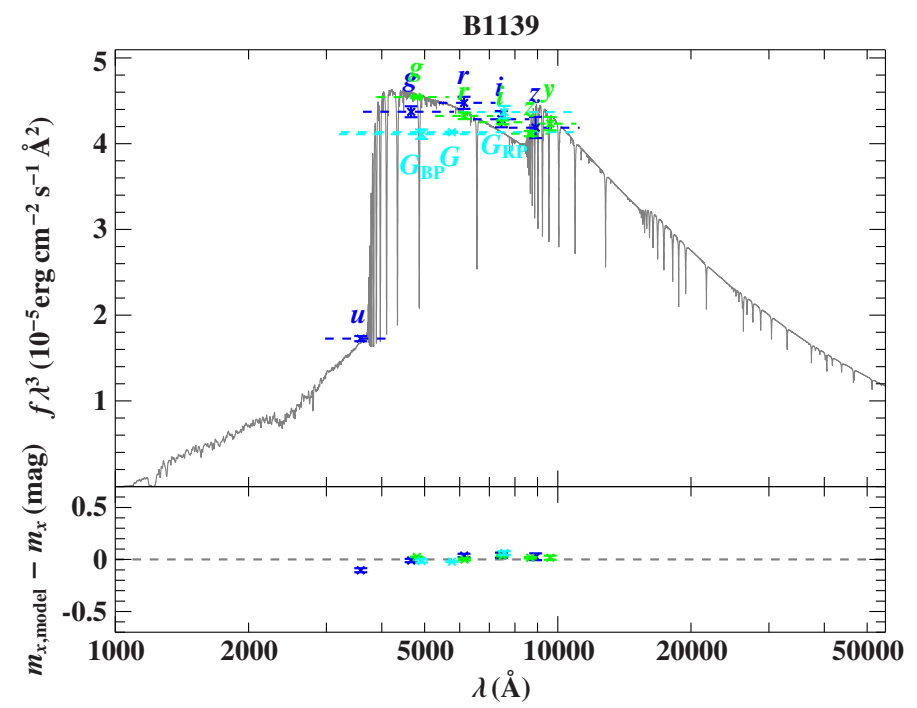

Fig. B.37. Same as Fig. 6. SDSS: blue; Pan-STARRS: green; Gaia: cyan. 